Illinois State University

ISU ReD: Research and eData

Theses and Dissertations

2-19-2014

\title{
A Longitudinal Case Study of the Impact of Democracy on Food Security in Ghana and Implications for Theory Development
}

Katelyn Marie Colaric

Illinois State University, kmcolar@gmail.com

Follow this and additional works at: https://ir.library.illinoisstate.edu/etd

Part of the African Languages and Societies Commons, African Studies Commons, Political Science Commons, and the Public Health Education and Promotion Commons

\section{Recommended Citation}

Colaric, Katelyn Marie, "A Longitudinal Case Study of the Impact of Democracy on Food Security in Ghana and Implications for Theory Development" (2014). Theses and Dissertations. 150.

https://ir.library.illinoisstate.edu/etd/150

This Thesis is brought to you for free and open access by ISU ReD: Research and eData. It has been accepted for inclusion in Theses and Dissertations by an authorized administrator of ISU ReD: Research and eData. For more information, please contact ISUReD@ilstu.edu. 


\title{
A LONGITUDINAL CASE STUDY OF THE IMPACT OF DEMOCRACY ON FOOD SECURITY IN GHANA AND IMPLICATIONS FOR THEORY DEVELOPMENT
}

\author{
Katelyn M. Colaric
}

154 Pages

May 2014

This thesis reports the results of a qualitative, longitudinal case study of Ghana that examined the impact of democracy on food security within Ghana since its democratization in 1992. First, the study reviews existing literature about food security, a newly-emerging concern in political science, as well as the literature on democracy and human rights. To fill the gaps in existing literature regarding the impact of democracy on food security, [and the author finds it overzealous to prove that democracy always benefits food security levels across varying states, cultures, and years] the thesis examines food security developments in Ghana, a developing democracy in southern Africa.

The study analyzes the shift in the food security status that Ghana experienced from pre-democratization (pre-1992) to post-democratization (post-1992) in order to determine whether and how democracy had a positive impact. The author studies legislation, policy implementations, literature, and data of pre- and post-democratization years. Based on these data, it appears that in the specific case of Ghana, democracy has positively impacted food security levels because of democracy's two main mechanisms: political stability and government effectiveness, and government accountability and 
proficiency. Since 1992, Ghana has made great strides in both democratic mechanisms and has, in turn, transformed itself from being a state that primarily focuses on improving the economy at the expense of the majority and for the benefit of the political and social elite, to a nation that prioritizes a free and nonviolent environment, having a moral and citizen-centered government grounded in equality, and the political participation of individuals and citizen organizations that work together to improve general wellbeing and food security. For Ghana, it appears that democratizing and remaining committed to democracy fostered great strides toward food security. The potential for applying these findings to other studies emerges out of the study's larger implications. Ultimately, these mechanisms can be tested in other cases to see if similar findings emerge. This then can contribute to theory development with regards to the relationship between democracy and food security. 


\section{A LONGITUDINAL CASE STUDY OF THE IMPACT OF DEMOCRACY ON FOOD SECURITY IN GHANA AND IMPLICATIONS FOR THEORY DEVELOPMENT}

KATELYN M. COLARIC

A Thesis Submitted in Partial Fulfillment of the Requirements for the Degree of

MASTER OF SCIENCE

Department of Politics and Government

ILLINOIS STATE UNIVERSITY 
(C) 2014 Katelyn M. Colaric 


\section{A LONGITUDINAL CASE STUDY OF THE IMPACT OF DEMOCRACY ON FOOD SECURITY IN GHANA AND IMPLICATIONS FOR THEORY DEVELOPMENT}

KATELYN M. COLARIC

COMMITTEE MEMBERS:

Noha Shawki

Yusuf Sarfati

Lori Riverstone-Newell 


\section{ACKNOWLEDGMENTS}

First and Foremost, I would like to thank Dr. Noha Shawki for all of her advice and guidance throughout this process and for making this one of the greatest learning experiences of my time in higher education. Dr. Shawki, I had many moments of doubt as to if I could write this thesis. Having you there to help me through it meant so much to me! You are an amazing mentor and professor and I am grateful for everything you have taught me throughout my undergraduate and graduate studies at Illinois State University (ISU). Dr. Riverstone-Newell and Dr. Yusuf Sarfati, I would also like to thank you for assisting me throughout this long process. I appreciate the time that you have devoted to being a member of my committee and for every insightful suggestion that you have given me. I would also like to thank the many professors within the Department of Politics and Government that have in their own ways shaped my academic and personal development throughout my last six years at ISU.

I would like to give special thanks to my husband Tim, parents Pat and Mary, Great-Aunt Beatsie, and other family and friends. Your continued support and encouragement have given me the strength and perseverance to accomplish my academic ambitions.

This thesis is dedicated to Mom, Dad, and Tim.

K.M.C. 


\section{CONTENTS}

Page

ACKNOWLEDGMENTS

CONTENTS

ii

TABLES

PART ONE: FOUNDATIONAL CONCEPTS - DEMOCRACY

AND FOOD SECURITY

\section{CHAPTER}

I. INTRODUCTION: THE PROBLEM AND ITS BACKGROUND

Statement of the Problem

Statement of Purpose

Significance

Study Overview

Conclusion

II. LITERATURE REVIEW 9

$\begin{array}{ll}\text { Theories and Terms } & 9\end{array}$

$\begin{array}{lr}\text { Democracy } & 9\end{array}$

The Right to Food, Food Security and Food Insecurity 13

$\begin{array}{ll}\text { Review of the Theoretical Literature } & 17\end{array}$

Democracy, Capability, and Human Rights 18

The Significance of Regime Type and Development

Status

How the Mechanisms of Democracy can Improve

Food Security Levels

Political Stability and Government Effectiveness 
Political Participation and Government

Accountability and Proficiency

Research Question and Hypothesis

III. RESEARCH DESIGN

Using a Longitudinal Case Study as Opposed to a Large-N Study

Why Ghana?

Case Study Overview 41

Overcoming Research Obstacles

PART TWO: GHANA - CASE STUDY, FINDINGS, AND ANALYSIS

\section{CHAPTER}

IV. CASE STUDY: TOWARDS DEMOCRACY - GHANA'S PREDEMOCRATIZATION FOOD SECURITY STRUGGLES

A Brief History

The First Thirty-Five Years

1992 to Present: Becoming a True, Functioning

Democracy

Learning from the Past to Shape the Present and Future

1980s Economic Improvements Provided Few Benefits for Average Citizens

Transforming the Economy

THE IMF and Structural Adjustment Programs

How the ERP could and should have Improved Food Security

Social Costs and Consequences

V. FINDINGS AND ANALYSIS: THE 1990s AND BEYOND GHANA'S UNPRECEDENTED IMPROVEMENTS 
Differences in the Ideologies of Political Parties and Presidents

The Political Party System and the Political Environment

Government Effectiveness: Preventing Corruption and

Abiding by the Rule of Law

Using Government to Better the Lives of the Populace

Political Stability, Government Effectiveness and Food Security

Cultivating Improved Production Among Farmers

Infrastructure Advancements: Roadways, Water Supply, and Sewage Disposal

Political Participation and Government Accountability and Proficiency

Voting Rights and Political Participation

Freedom of Speech and the Media

The Influence of Civil Society

110

Proficiency and Development

Political Participation, Government Accountability and

Proficiency, and Food Security

The Powerful Presence of Food Security-Based Civil Society Groups

Merging Accountability with Proficiency:

Innovative Strategies, Research and Development

Data Indicators of Significant Food Security Improvements

Continuing Food Security Commitments and International Recognition

VI. SUMMARY, CONCLUSIONS, AND RECOMMENDATIONS

Summary of the Research Problem, Methods, and Findings 


\section{TABLES}

Table Page

1. Freedom in Ghana $\quad 80$

2. Political Stability and Absence of Violence 83

3. Access to Improved Drinking Water 99

4. Domestic Food Price Level 123

5. Global Hunger Index Scores 124

6. Percentage of Population Underweight 125

$\begin{array}{ll}\text { 7. Prevalence of Undernourishment } & 125\end{array}$

8. Daily Energy Supply 126 


\title{
PART ONE: FOUNDATIONAL CONCEPTS - DEMOCRACY AND FOOD SECURITY
}

\author{
CHAPTER I
}

INTRODUCTION: THE PROBLEM AND ITS BACKGROUND

\begin{abstract}
Statement of the Problem
One of the remarkable facts in the terrible history of famine is that no substantial famine has ever occurred in a country with a democratic form of government and relatively free press...famines never afflicted any country that is independent, that goes to elections regularly, that has opposition parties to voice criticisms, that permits newspapers to report freely and to question the wisdom of government policies without extensive censorship - Amartya Sen, The Washington Times, Oct 20 1998; p. A12.
\end{abstract}

Following the end of the Cold War in 1991, and the dissolution of Communist Soviet Union, democracy emerged within many states as an icon of legitimacy, representative government, freedom, such that: "By the mid-1990s, the percentage of states in the world that were democracies had increased from 27 percent in 1974 to over 60 percent. Democracy had become the dominant form of government in the world" (Diamond 2005, 13). Scholars such as Amartya Sen—renowned economist, philosopher, and Nobel Memorial Prize winner-studied this trend, as well as what many states deemed to be the benefits of democracy in the everyday lives of citizens. Sen introduced his pioneering argument in the early 1970s (stated in the quotation above) that remains a 
controversial debate in the discipline of political science: That is, that democracy's principle of "government by and for the people," when properly and fully adhered to, prevents famine in all democracies. Furthermore, the emerging interest in food justice and food sovereignty studies in the field of political science has added dimension to this debate by raising the question of if and how democracy positively impacts human rights and, more specifically, food security. The complexity of this issue has left the field of political science with little substantial progress or new findings since Sen's work in the late twentieth century. Yet, many democracy and food security scholars still deem Sen's findings relevant to this study (see Beetham 1997;1999; Langlois 2003; Nezhad et al. 2011; Spicker 2008). However, his work has a number of critics who suggest that his work is more romanticized than realistic, that it has inescapable gaps, and that it may no longer have a sound place in the debate about democracy's impact on famine. (see de Waal 1990; Edkins 2001; Keen 1994).

Sen's work, while deemed revolutionary within twentieth century political scholarship, has left the twenty-first century discipline with unanswered questions and unresolved debate. For example, does the proclaimed power of democracy apply to lesser forms of food insecurity than famine? Can food security exist in non-democracies or is democracy always obligatory? Undoubtedly, Sen has provided democracy advocates and scholars with a strong initial stepping stone for the study of the potential positive effects of democracy within given states, but such a bold argument that democracy never allows for or tolerates famine is a finding that needs to be retested to prove its continuous applicability in the modern world. Some scholars (such as those discussed in the review of literature, Part I, Chapter 2) have tackled the objective of qualitatively and empirically 
proving that Sen's findings still apply to all states, and to the more general issue of food security, not simply famine. These studies have largely been conducted by gathering data from hundreds of countries across the globe and, while their findings do support Sen's original argument that democracy is a powerful famine (and more generally, food insecurity) prevention tool, this is largely the extent of their findings and their contributions to existing scholarship. Finding it overzealous to prove that democracy always benefits food security levels across varying states, cultures, years, etc., this study serves to determine whether or not democracy's mechanisms are conducive to food security in the specific case of Ghana, a developing democracy in southern Africa.

\section{Statement of Purpose}

The purpose of this study is to conduct a longitudinal case study of Ghana with the intention of evaluating Ghana's developing democracy in relation to its strengthening food security system. The intent is to determine whether and how food security improvements in Ghana are a product of democratic politics. While many factors, such as a state's economic stance or receipt of food aid, can contribute to food security improvements within any given state, Ghana's democratization and food security improvements pose a unique possibility that food security may have risen primarily as a result of the state's growing democracy. While this is a possibility, it is an unfounded presumption and therefore poses a unique research opportunity. Accordingly, this thesis serves to determine if these two variables - democracy and food security — are independent of each other but have occurred in harmony, or if democracy has directly caused Ghana's incremental food security advances. 


\section{Significance}

The specific nature of this thesis exceeds the parameters of previous scholarship because it allows for a more detailed and analytical examination of the relationship between democracy and food security within an individual state. The more commonly used research design involves conducting a cross-national study. Cross-national studies and analyses tend to provide the finding that democracy has aided in food security improvements across a multitude of countries, but rarely, if ever, provide answers to the most significant questions of why and how democracy has successfully done so within all of these cases. As a result, the findings of these studies are helpful in providing brief analyses of what is currently occurring in varying democratic states; however, they fail to focus on what these cases have in common, and, most importantly, what democratic mechanisms are common to all the cases. Arguably, they fail to show the "bigger picture," or what their findings mean. This leaves the discipline with very little progress in understanding how to apply existing theory about the benefits of democracy to the real world. The following analysis serves to fill this research gap by collecting specific findings of one successful case - Ghana — and by studying the many ways in which Ghana has proven to be successful in reducing food insecurity since fully democratizing in 1992. Focusing on one case allows for a more detailed analysis of how-via what mechanisms — democracy may foster food security.

Ghana was chosen for this case study because its recent food security levels and democratic prospects have been distinguished in the international community and in scholarly works as exemplary. Furthermore, recent publications, news sources, and even the President of the United States, Barack Obama, have referred to Ghana as one of the 
most accomplished countries in Africa in terms of maintaining a true democracy and growing food security prospects (“Obama: Ghana's Economy and Democracy is a Success Story”). Specifically, “Ghana reduced undernourishment more rapidly than any other country in the world between 1980 and 1996" ("Food Insecurity" 1999) and is often predicted to be the first country that will meet the Millennium Development Goal of cutting the country's hunger in half by 2015 (IFPRI 2011). It further serves as an adequate, modern case study because it demonstrates how a state can transform from an authoritarian regime with significant levels of food stress into a well-functioning democracy with greatly increased food security levels. While existing data and literature suggest that such progress is a success story, they do not give insight into why and how Ghana has accomplished these improvements, what implications emerge, and how such implications can provide important advancements in theory-building within political science.

Conducting this study has three potential benefits: First, and most importantly, to provide insight into why and how Ghana has continued to reduce food insecurity through recent decades, thus affording Ghanaian scholars and officials a more comprehensive assessment of what democratic mechanisms, implementations and practices have been successful and how further improvements to these mechanisms may advance the state's food security levels in the future; second, to provide an initial glimpse into how other African countries may follow the same or a similar path in order to reduce food insecurity within their states; and, third, to provide scholars a better understanding of why Ghana is often deemed a democracy and food security success case, and why Ghana serves as a stepping stone for further food security theory-building within the discipline. As Franco, Álvarez-Dardet, and Ruiz suggest, conducting such a longitudinal 
case study may provide the discipline with more thorough and much needed understanding regarding the instances in which democracy may be a successful means of achieving higher food security levels (2004).

Undoubtedly, democracy may not always foster an environment conducive to upholding human rights and food security, as evidenced in the human rights struggles of India. As Anupam Hazra explains, between 1990 and 1992, 26 percent of India's population was undernourished. Between 2003 and 2005, this increased to 28 percent (2009). According to the International Food Policy Research Institute (IFPRI), India's Global Hunger Index (GHI) score has not seen any improvement in nearly 20 years. Even though India democratized in 1950, as of 2012, its GHI score lingers at 22.9, which is an “alarming” hunger level (International Food Policy Research Institute 2012).

\section{Study Overview}

To accomplish its objective, this thesis contains three parts, consisting of a total of six chapters. Part one — entitled "Foundational Concepts - Democracy and Food Security"- begins with this introductory chapter followed by a literature review and statement of the research question and hypothesis in chapter two. It concludes with an explanation of the study's research design in chapter three. Part two- "Ghana - Case Study, Findings, and Analysis"- presents the longitudinal case study of Ghana's democratization and food security developments over time. Chapter four offers a brief discussion of the nation's transformation since achieving independence, covering the many forms of government that Ghana has had throughout its history, leading up to and including its final democratization in 1992. Chapter four then eases into an analysis of how and why Ghana's previous authoritarian years led to high levels of food insecurity. 
Chapter five presents the case study's main findings and analysis of how democratization and the mechanisms of democracy discussed within existing theoretical literature havewhen put into practice- have helped make food security advancements a reality for Ghana. Part three (chapter six) concludes this study with a summary of the research problem, methods and findings, conclusions and implications, and recommendations for future research.

\section{Conclusion}

Briefly, this case study concludes first and foremost that, in the specific case of Ghana, democratic mechanisms have significantly and positively impacted food security levels by producing an environment in which food security efforts by the government and grassroots activity can develop and prosper. Because Ghana has made copious strides in both political stability and government effectiveness, and political participation and government accountability and proficiency, it has transformed itself from being a state that primarily focuses on improving the economy at the expense of the majority, and for the benefit of the political and social elite, to a nation that prioritizes the following: the political rights and freedoms of citizens; having a moral and citizen-centered government that equally and fairly distributes social services; governance via the collaboration of government and non-governmental organizations (NGOs) working to improve the food and agriculture sector; and, as a result of all of these, the right to food and achieving food security. The findings of this study suggest that, for Ghana, democratizing and remaining committed to democratic mechanisms fostered food security. While this study does not claim that all democracies are food secure, or that democratizing always facilitates or 
accelerates food security improvements, it does show that this was the case for Ghana. It suggests that more research is needed to determine if similar cases arrive at the same conclusion. 


\section{CHAPTER II}

\section{LITERATURE REVIEW}

The study of democracy's effect on food security is heavily influenced by both old and new concepts. Specifically, this work examines the well-researched area of human rights as well as the particular issue of food security, a newly-emerging concern in political science. The most relevant theories and terms are defined below. Each of these theories and terms can have multiple definitions because of variation in sources, scholars, and years within which the terms have appeared in literature; however, the sections below provide contemporary, universal, and accepted definitions according to the most well-respected scholarly works pertaining to democracy, human rights, and food security. Following the discussion of relevant theories and terms, the section entitled "Review of the Theoretical Literature" examines existing literature pertaining to the connection among democracy, human rights, and food security collectively, and explains how the primary mechanisms of democracy impact food security. The chapter concludes with a presentation of the research question and hypothesis.

\section{Theories and Terms}

\section{Democracy}

This study recognizes that the definition of democracy is neither static nor inflexible. Defining democracy is complex because, as scholar Robert Dahl discusses in 
Democracy and its Critics, political scientists do not collectively subscribe to one specific definition of democracy (1989). However, in order to study the democratic progression of Ghana and democracy's potentially positive influence on food security levels, a general definition is necessary. A distinction must be made between when Ghana first declared itself a democracy (1957 to 1980s) and when Ghana proved to be a working democracy (1992 to present). Therefore, to differentiate between the two and to explain democracy and describe democratic regimes, this study provides an overview of the most universally studied components of democracy: its political and governmental components. As discussed below, these components generate a citizen-centered society in which food security can flourish. For this reason, a variety of sources and definitions have been analyzed to provide an inclusive understanding of these components of democracy and, therefore, democracy overall.

Regarding the "political structure" of democracy, scholar David Beethamrenowned for his works on democracy and its impact on human rights—argues that the political structure of democracy is grounded in the rights of citizens and principles of popular control and popular equality.

Democracy I take to be a mode of decision-making about collectively binding rules and policies over which the people exercise control, and the most democratic arrangement to be that in which all members of the collectivity enjoy effective equal rights to take part in such decisionmaking directly - one, that is to say, which realizes to the greatest conceivable degree the principles of popular control and equality in its exercise. (Beetham 1999, 33)

In transcripts from his 2004 lecture entitled "What is Democracy?" Larry Diamond expands upon this description of democracy and explains that popular control is upheld in democracy because the citizens are self-governing and are perpetually the most powerful political actors in society because they have the authority to elect temporary leaders. 
Furthermore, democracy only exists if popular control is dispersed equally to all citizens. Put into practice, we see the political structure of democracy as competition via free and fair elections among politically equal citizens. Political participation is therefore exemplified by "public participation, observance, deliberation, and political equality...freedom of speech, association and opinion” (Nezhad et al. 2011).

The "governmental structure" of democracy is rooted in the separation of powers and the rule of law. In democracies, no branch of power can transcend the others because the principle of checks and balances prevents this from happening. The equality of all branches of government within democracy directly prevents the rise of authoritarian leadership. Furthermore, the rule of law ensures that citizens can only be "ruled by laws, not by individuals" (Diamond 2004). Thus, the people are represented and protected by these laws so as to prevent political suppression by overly powerful individuals. According to Democracy Web, an online resource created by Freedom House and the Albert Shanker Institute and funded by the National Endowment for the Humanities, any breach of the constitution and of the people's right to govern is an obstruction of democracy and calls for the dismissal of the individual(s) who violated citizens' constitutional rights (2012).

Although the conceptual understanding of democracy described above provides insight into what many scholars consider to be the most significant components of democracy and, in turn, provides an understanding of what democracy is, the following study also requires a measurable understanding of democracy. To assess how Ghana's levels of democracy have changed over time, some form of measurement is necessary. Arguably, the best way to measure Ghana's democratic progression is to analyze where it 
sits on a democratic scale and how Ghana's position on that scale changes each year. To that end, this research used Freedom House scores.

Considered to be one of the world's most renowned non-governmental political research institutes focusing on democracy, Freedom House is recognized for its democracy advocacy, significant research accomplishments, and overall integrity. Jessica Tuchman Mathews, president of the Carnegie Endowment for International Peace stated: "The explosion of democracy is a central development of our era. Freedom House provides an invaluable resource in this authoritative survey of the on-the-ground realities of the state of freedom around the world" (Freedom House 2013, 37). In an effort to expand recognition of the significance of democracy, and to analyze its presence in the global community over time, Freedom House has analyzed and evaluated countries according to "freedom levels" since 1950, and now provides freedom scores for over 195 countries.

For this reason, this study utilizes Freedom House's freedom ratings scale to track the progression of Ghana's democratic strength over time. Freedom House measures democracy on a scale of one to seven, with one being most free and seven being least free. Further, the Freedom House scale is broken down into categories of "free" (scores of 1.0 to 2.5), "partly free" (scores of 3.0 to 5.0), and "not free" (scores of 5.5 to 7.0 ). Scores - and therefore categories — of each country are determined by analyzing how each country scores in answering a "checklist" of political rights and civil liberties questions.

The political rights questions are grouped into three subcategories: Electoral Process (3 questions), Political Pluralism and Participation (4), and Functioning of Government (3). The civil liberties questions are grouped into four subcategories: Freedom of Expression and Belief 
(4 questions), Associational and Organizational Rights (3), Rule of Law (4), and Personal Autonomy and Individual Rights (4). Scores are awarded to each of these questions on a scale of 0 to 4 , where a score of 0 represents the smallest degree and 4 the greatest degree of rights or liberties present. The political rights section also contains two additional discretionary questions: question A (For traditional monarchies that have no parties or electoral process, does the system provide for genuine, meaningful consultation with the people, encourage public discussion of policy choices, and allow the right to petition the ruler?) and question B (Is the government or occupying power deliberately changing the ethnic composition of a country or territory so as to destroy a culture or tip the political balance in favor of another group?). (Freedom House 2012)

Although Freedom House provides scores based on levels of freedom, their core argument about the significance of these scores is that freedom is most accomplishable within liberal and electoral democracies, democracies that score highly on the above political rights and civil liberties questions. Furthermore, they argue that countries that are free are full-fledged democracies. Because of this link between freedom and democracy, the freedom scores can be used for this study to demonstrate how Ghana has become more democratic in recent decades. Accordingly, Ghana's freedom scores are analyzed for the years spanning from 1980 through 2012.

\section{The Right to Food, Food Security and Food Insecurity}

Food security is a subcategory of human rights. Thus, in studying food security, it is crucial to understand what human rights are and what they entail. Concern for human rights and recognition of the importance to protect people's human rights emerged in 1948 with the adoption of the Universal Declaration of Human Rights. The Declaration states that all people regardless of race, gender, economic status, and location have the natural, God-given right to freedom, equality, and other such rights (The Universal Declaration of Human Rights 1948). Specific rights are outlined in the articles of the Declaration. Most significant to this study is Article 25, which highlights the right to 
food — and therefore food security — as a human right that should be attainable for all people. Article 25 is as follows:

Article 25.

(1) Everyone has the right to a standard of living adequate for the health and well-being of himself and of his family, including food [my emphasis], clothing, housing and medical care and necessary social services, and the right to ecurity in the event of unemployment, sickness, disability, widowhood, old age or other lack of livelihood in circumstances beyond his control. (The Universal Declaration of Human Rights 1948)

Similarly, the International Covenant on Economic, Social and Cultural Rights (ICESCR), adopted by the United Nations General Assembly in 1966, states that all of mankind should have equal rights to economic, social, and cultural rights. The ICESCR is broken into five parts consisting of 31 articles. The Covenant and its articles emphasize the importance of equal human rights for all people and states that "human rights" includes self-determination, work and just working conditions, adequate living conditions, physical and mental health, and education. Most applicable to this study is Article 11 of Part III. Article 11 proclaims that all people should have the right to an adequate standard of living (discussed in more depth in "Food Security" below). To date, 160 countries and territories have signed and ratified the Covenant. Ghana is one of these countries (International Covenant on Economic, Social and Cultural Rights 1966). Spanning both the Universal Declaration of Human Rights and the ICESCR, the right to adequate food is emphasized as being a requirement to achieving adequate health. Because nutrition and health are human rights, the theoretical framework and study of human rights in general is applicable to food security research.

According to Article 11 of the ICESCR, it is every state's duty to provide "adequate food" to all people in order to ensure that they can eventually be free from hunger, and so that the country as a whole can achieve successful food security levels. 
Every person has the right to food and this right should not be threatened, restricted or prohibited by any person or government. Article 11 establishes that all people have the "right to adequate food... [and] the fundamental right of everyone to be free from hunger" (ICESCR 1966). Furthermore, it presents the following as a few of the many possible efforts that should be taken up in the name of the right to food and food security: "improve methods of production, conservation and distribution of food by making full use of technical and scientific knowledge, by disseminating knowledge of the principles of nutrition and by developing or reforming agrarian systems in such a way as to achieve the most efficient development and utilization of natural resources" (ICESCR 1966).

Looking specifically at "food security," this study defines the term according to the World Health Organization's definition and characterization. Food security exists

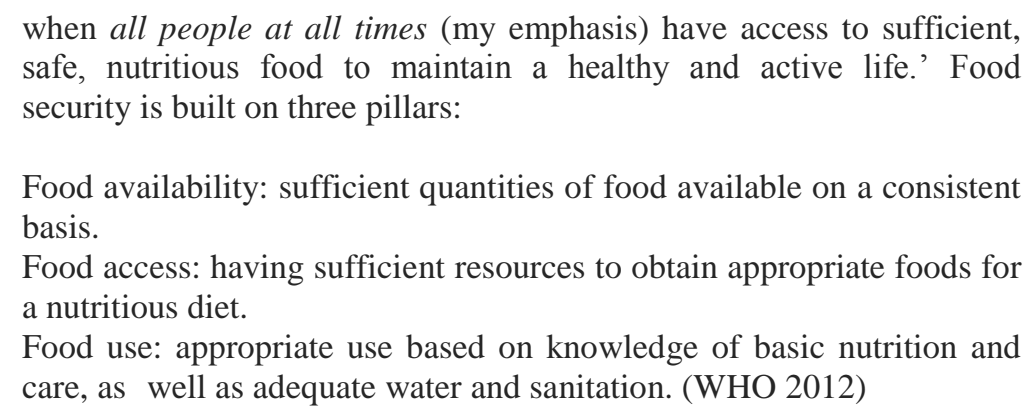

Scholars, such as Amartya Sen, who study the issue of food security often focus

first on understanding food insecurity struggles in order to better understand how to improve food security levels within a given state. For instance, Sen focuses most of his work, elaborated on below, on the study of why democracy affects famine levels within a given state. However, the existence of lesser forms of food insecurity within countries and regions begs the question if democracy impacts other forms of food insecurity. Likely, researching the relationship between democracy and food security more generally may be beneficial to states of varying food security levels. For this 
reason, this study takes into consideration the possibility that a relationship exists between democracy and other levels of food stress that are not as severe as famine. Accordingly then, defining "food insecurity," and describing the varying intensities of food insecurity, is as important to this study as defining food security.

Within existing scholarship, "food insecurity" is often used as an umbrella term for undernourishment, severe undernourishment, famine threat, and famine. It serves this purpose because most definitions of food insecurity are vague so as to apply to a multitude of varying degrees of food stress. Sue Ann Anderson of The American Institute of Nutrition provides perhaps the best explanation of food insecurity with her allencompassing definition that is applicable across different cultures, countries, and times: "Food insecurity exists whenever the availability of nutritionally adequate and safe foods in socially acceptable ways is limited or uncertain"(Anderson 1990, 1560). The keywords within this definition — "availability," "adequate," "safe," "socially acceptable ways," "limited," and "uncertain" — show that the classification of food insecurity is purposely vague and rightly applies to states experiencing malnutrition just as it does to states experiencing famine, a much more serious form of food stress. As Anderson explains in “Core Indicators of Nutritional State for Difficult-to-Sample Populations," "food insecurity" is a new and evolving term used by many scholars to describe a range of different types of food stress. Countries do not have to experience such an extreme type of food stress as famine to be considered a country experiencing food insecurity. Rather, food insecurity applies to situations with any form of inability to acquire safe and acceptable food. Therefore, studying "food security" and "food insecurity" allows for a more inclusive analysis of how and why democracy impacts many forms of food stress, resulting in a better understanding of the impact of democracy on food security levels more generally. 


\section{Review of the Theoretical Literature}

Again, because food security is a very specific and narrow human rights issue, this thesis' corresponding literature is heavily rooted in existing expansive studies of human rights and health. Because human rights, health, and food security are similar and often interrelated, the human rights and health literature can be applied to the more specific focus of food security. Simply, this study takes a wide theoretical approach and applies it to the more specific sub-category of food security. In addition to the analyses of human rights and health literature, this study discusses literature pertaining specifically to food security.

Since the Cold War, and the steady increase of democratization worldwide, the discipline of political science has seen a growth in scholarship that promotes democracy as being the most successful, citizen-centered and human rights supportive form of government (Sen 1999a). Furthermore, the discipline has witnessed a merge of the study of democracy and the study of human rights and the debate as to whether or not democracy and human rights are independent of each other, or if they are more similar and interrelated than previously understood (Beetham 1999; Beetham 1997). This debate continues to be a growing interest among democracy supporters and scholars. Scholars such as David Beetham, Amartya Sen, Anthony Langlois, Julie Norman, and Paul Spicker argue that human rights are best implemented, most respected, and most often retained within democracies, and that other forms of government have generally not made equivalent achievements in human rights. An emphasis on actual rights and the capabilities of people to secure their rights equally and for an infinite period of time is at the core of this argument (Sen 1999a). 


\title{
Democracy, Capability, and Human Rights
}

Beginning with the term capability, renowned scholar Amartya Sen argues that the most important aspect of acquiring human rights is not the actual rights themselves, but that all people have the capability of fairly, freely, and fearlessly accessing their rights. Without this, the rights themselves are irrelevant:

\begin{abstract}
the idea of capability is linked with substantive freedom, it gives a central role to a person's actual ability to do the different things that she values doing. The capability approach focuses on human lives, and not just on the resources people have...by proposing a fundamental shift in the attention from the means of living to the actual opportunities a person has, the capability approach aims at a fairly radical change in the standard evaluative approaches...in political philosophy. (Sen 2009, 253)
\end{abstract}

Sen proposes a new approach to the study of human rights that had escaped the discipline thus far: in order to spread human rights, we need to be first concerned with ensuring that all people have the consistent and uninterrupted capability of accessing these human rights. While the 1948 Universal Declaration of Human Rights and similar doctrines such as the ICESCR agree that all humans have a God-given right to freedom, equality, and other such rights, ensuring "the right to human rights" is the first step in making these proclaimed rights a reality (Nussbaum 2007).

Furthering Sen's findings, Siddiqur Rahman Osmani highlights that ensuring capability and, in turn, human rights is primarily the responsibility of the state and is dependent on the state's commitment to respect, protect, and fulfil human rights. Using the right to food as an example, he expounds that

the duty to respect entails that the state must not do anything to deprive people of their access to food...the duty to protect goes one step further by requiring the state not only to refrain from violating people's right to food, but also to prevent third parties from violating it...the duty to fulfil goes even further in extending the state's obligation. It is then the obligation of the state to create the conditions - through economic and other policies - that would enable the people to acquire the food they need. (Osmani 210) 
Capability then is essential to obtaining human rights and, therefore, citizen well-being because it provides all citizens with the freedom and opportunity to achieve these outcomes (Strauss and Horsten 2013).

Herein, we can see the significance of democracy in achieving capability and human rights. Capability itself is rooted within democracy because of democracy's political structure and governmental structure. Through these structures, citizens have the capability to acquire and maintain human rights via freedoms and opportunities such as free and fair elections, lobbying, voting, representative government, checks and balances, the rule of law, a free and equal opportunity environment to fearlessly assemble and express interests, opinions, and values, etc. (United Nations 2013a).

Skeptics of this idea, known as separationist theorists, argue that there is no inherent relationship between democracy and the respect of human rights. Instead, scholars such as Andrew Nathan (1997) and Jack Donnelly (1999) believe that nondemocracies can and do uphold human rights. Furthermore, they see the unification of these two notions in existing scholarship to be a Western-centric notion and tactic to push democratization and western ideals on other regions and countries. They urge human rights scholars to separate these two notions. However, separationist theorists fail to recognize the underlying connection between capability and human rights and that capability is subject to one's ability to control one's own destiny via politics and governmental institutions (Ebadi 2013; United Nations 2013a). In non-democracies, political control and access to human rights are completely dependent on the control of an authoritarian leader (Poe and Tate 1994). Such a system of government eliminates capability and therefore limits human rights. 
Not only do non-democratic states limit rights but they also only provide "human standards or norms," not human rights themselves. In non-democracies, the lack of citizen rule, self-determination, and endless capability can at most only provide "human norms." Because authoritarian rulers can choose to limit human rights at any time, the upholding of human rights in these countries is always subject to change and limitations: "A so-called human right within an otherwise authoritarian governmental system, is not a right as such. It is a condescension, a privilege, a long leash...still conceived as the property of the ruler, not of the people... being allowed or permitted to engage in a certain activity is a far cry from being entitled to it by way of right" (Langlois 2003, 1014-1015). Human rights norms in states that are run by even the most well-intentioned undemocratic rulers stand the chance of eventually experiencing severe and catastrophic change. Human rights cannot be forever implemented in a state within which there is a possibility or probability that at some point a malevolent ruler may take control and disregard the needs of the general population. Therefore, in non-democracies, human rights are subject to the intentions of the ruler (Hafner-Burton and Tsutsui 2007). Democracy's rule by the people is arguably the best counter to this insecurity because democracy—government by the people, for the people—means that the people can produce a constant, a demand, within their state that ensures that human rights are consistently priority. Therefore, we see human rights as actual rights in democratic states wherein capability and human rights in general are constant and self-determined (Langlois 2003; Norman 2005). 


\section{The Significance of Regime Type and Development Status}

Corresponding literature specifically pertaining to the right to food security explains why food insecurity is a recurring problem in undemocratic countries. It is argued that countries struggling with issues of famine and other food related insecurities could reduce the concentration of this presence within their state, or even potentially eliminate food insecurity as a whole, by way of democratization (Smith 1998; Paarlberg 2002; Lappé 2008). In analyzing why democratic countries generally have less food insecurity than undemocratic countries, a common argument about the implications of regime type emerges: democratic regimes are more threatened by famine and in turn, fight to suppress its impact on society. In "Why Half the Planet is Hungry," scholar Amartya Sen argues that "in democratic countries, even very poor ones, the survival of the ruling government would be threatened by famine, since elections are not easy to win after famines; nor is it easy to withstand criticism of opposition parties and newspapers" (Sen 2002). Not only is it difficult for politicians and leaders to withstand criticism, but it is nearly impossible for them to escape the repercussions of criticism. Often, politicians that do not support the health needs and demands of the electorate, and do not address the electorate's main concerns within their campaigns, are not elected. Likewise, the electorate will reject and, in turn, not re-elect the existing government officials and administrations as a whole who do not work to protect the electorate from famine (Spicker 2008; Huntington 1996).

Although the reality of food insecurity is of concern within all states and across all levels of stress, Sen argues that it is of gravest concern and most evident in nondemocratic underdeveloped countries specifically. As explained in Development as 
Freedom, every human's right to food is defined by his or her freedom to grow or buy an adequate amount of food (Sen 1999b: 161). Citizens of non-democracies can easily be denied their right to food even if food is plentiful. These citizens often experience malnutrition and starvation because they are not given access to the food around them (Food and Agriculture Organization 2012). Most often, many underdeveloped countries rely on small-scale agriculture for the country's most profitable source of income influencing the country's gross domestic product; however, in most of these states, agriculture is a form of profit, not a source of nutrition for citizens. This occurs because "the alienation of the rulers from those ruled...the social or political distance between the governors and the governed can play a crucial role in the nonprevention of the famine" (Sen 1999b: 170). Working to reduce and eliminate famine is an expensive and laborious task. For this reason, Sen and his supporters argue that democratization is necessary for the development of such underdeveloped countries.

However, scholars such as Marshall Wallace oppose Sen's beliefs and argue that fighting famine is not unique to democracy and that the stability of authoritarian regimes can be equally threatened if they do not implement policies and actions that best suit society's needs, in this case, if they do not work to suppress famine in society. Wallace argues that authoritarian regimes are just as inclined to fight famine because if they do not, the threat of rebellion or revolutionary activities may arise (Wallace 2011). For this reason, he argues that authoritarian governments need legitimacy in order to survive and are likely to implement policies and mechanisms to fight famine: "Ultimately, a loss of legitimacy tends to lead to the overthrow of the governing authority...it must be perceived by the people that they [authoritarian governing bodies and officials] are in fact 
working to alleviate the population's hunger..." (Wallace 2011, 1-2).

In his many studies on democracy and famine — especially in "Democratic Political Process and the Fight Against Famine"-Alex de Waal acts as the beacon of light in this debate. He effectively explains that the debate over which form of government fosters famine prevention and food security is not as simple as most existing scholarship implies. Rather, he explains that,

The democracy-dictatorship distinction is of course not clear cut. There can be states with democratic processes and institutions that are not seeking support of certain constituencies, and therefore are indifferent to their welfare (or lack of it), while some authoritarian states can derive legitimacy from their reduction of poverty and prevention of famine. $(2000,13)$

De Waal's findings show that famine prevention and eradication is not intrinsic to any government. He argues that government must allow primary and secondary activism to occur in order to prevent or eliminate famine. Primary activism he takes to be the ability and right of citizens to assemble and rally for their collective interests. Secondary activism is the political involvement of outside organizations and institutions in realizing human rights (de Waal 2000). He finds that democracy is more favorable when compared to authoritarian governments in fighting famine and lesser forms of food insecurity because its democratic mechanisms consent to and encourage primary and secondary activism, enabling grass-roots and top down efforts to form and most importantly, persevere. He provides examples of authoritarian regimes - China, Sudan, Kenya, and Ethiopia — that successfully instituted short-term famine elimination efforts but failed to sustain them long-term, all resulting in resurfacing famine. The section below provides a more detailed discussion of how democracy's core mechanisms work to prevent and eradicate famine and lesser forms of food insecurity. 
While many political scientists credit factors such as economy, literacy, and nutritional status for high food security levels and overall health within a given state and argue that democracy alone may not have as equally strong of an impact, existing statistical findings show otherwise. The influence of regime type should not be discounted because its impact proves to continuously increase over time. Differently, factors such as economy, literacy, and nutritional status tend to slowly lose influential power over time and these factors' benefits diminish accordingly. For instance, Franco, Álvarez-Dardet, and Ruiz's regression analysis of food security levels across the world in 1998 - a study of 170 countries constituting 75 percent of the world's countries-shows that democracy can have an independent, positive relationship with health. Economic factors, which are often argued to be conducive to higher levels of food security do not prove to have this same impact: "When all of these variables were taken into account, the economic ones lost their weight, thereby increasing the importance of the effect of democracy" (Franco, Álvarez-Dardet, and Ruiz 2004, 1442).

Furthermore, opposing arguments that belittle the significance of democracy often mistake democracy's "lagged effect" for a complete lack of impact. They do not account for the fact that, although instituting democracy can have upwards of a three-year "lagged effect," after this lag, states often experience that democracy has a positive and continuously improving impact on general health, food security, and life expectancy (Przeworski, Cheibub, and Limongi 2000; Zweifel and Navia. 2000; Lake and Baum 2001). Likely, democracy's lagged effect occurs because democracy takes time to develop within any state. While it may not emerge as essential to achieving food security initially, its prioritization of human rights and equality shows that, in fact, democracy can 
impact a state's food security levels and that it has the potential to be one of the most significant factors in improving citizen health and life expectancy in underdeveloped countries (Lin et al. 2012).

The ways in which democracy tends to set the foundation for improving food security is especially apparent when comparing statistics pertaining to food security in democratic states to that of authoritarian states. In all, democracies are more successful in reducing malnutrition and other forms of food stress - when compared to authoritarian regimes - because democracy's free and fair environment, accountability to the people, and representation of the middle and lower classes nurture an environment focused on making improvements to general health. Countries that are free tend to have the highest levels of health overall (London and Williams 1990; Moon and Dixon 1985; Wickrama and Mulford 1996). The same generalization cannot be said of authoritarian regimes because they do not offer a free and fair environment, government is not held accountable to the people, and the lower and middle classes are often left unrepresented within the political system (Besley and Kudamatsu 2006).

\section{How the Mechanisms of Democracy can Improve Food Security Levels}

Although the abovementioned food security scholars and corresponding literature provide theoretical and empirical arguments as to why democracy fosters food security, elaboration on how democracy does so is necessary. Answering the question of "how democracy is conducive to food security" is rooted in understanding what mechanisms of governance are most conducive to food security. Within the field of political science, this is an obvious weakness of existing literature. Many studies provide findings that support 
the argument that democracy has a positive impact on health and more specifically food security; however, these studies do not explain what mechanisms of democracy produce this positive impact. Research conducted by both Jalil Safaei and Franco, Álvarez-Dardet, and Ruiz identify this shortcoming. It is not sufficient enough to state that democracy improves food security but, instead, scholars need to expand upon existing research and show how this is the case (Safaei 2006; Franco, Álvarez-Dardet, and Ruiz 2004). The main mechanisms that link democracy and food security are political stability and government effectiveness, and political participation and government accountability and proficiency.

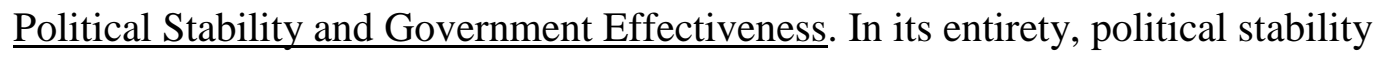
consists of and refers to ensuring that citizens live in an environment that is free of violence and allows citizens to assemble, vote, and take part in other forms of political participation discussed in Political Participation and Government Accountability and Proficiency below (see page 31). Democracy's utilization of political stability features occurs in the form of a chain reaction wherein each feature is a prerequisite on the pathway to a more stable food security system (Goldsmith 1986; Goodell and Powelson 1982; Khohli 1986; Sorensen 1991).

Democracy ensures that citizens live in an environment of political stability, free from violence. Democracy can help prevent what political theorists term "military famine," the existence of famine as a direct result of internal, physical repression and violence. Craig Jenkins and Stephen J. Scanlan's findings show that internal violence has a direct impact on increasing hunger rates and that democratization counters this hunger 
because it promises an environment that is focused on prioritizing the physical needs of the people so that citizens have the physical capability to be politically involved in society (2001). Democracy cannot function if the people who are supposed to impact government the most (via voting, political assembly, and the like) are subject to violence, and as result, are afraid to be politically active and to make demands of government. Equally, democracy cannot function if these same people are treated so poorly that they are physically incapable of political participation (Dobel 1978; Keane 2004).

Institutionalization and Political Stability. Attention must also be drawn to the significance of institutionalization in maintaining political stability, as Samuel P. Huntington terms “order.” In Political Order in Changing Societies, Huntington presents a groundbreaking argument about political institutionalization and its impact on political order that is still viewed as being an relevant contribution to the subfield of comparative politics and the study of world order (Fukuyama 2011). First, he defines institutionalization as "the process by which organizations and procedures acquire value and stability" (Huntington 1968, 12). He then explains that institutionalization is a requirement of achieving political stability (order) and preventing the emergence of political violence, regardless of government type. With this work being published during the "second reverse wave of democratization" (see Huntington's The Third Wave: Democratization in the Late Twentieth Century), Huntington was not alone in believing that democracy (regime type) is not the most important factor in the quest for political order, especially among Third World countries. For Huntington, "the most important political distinction among countries concerns not their form of government but their 
degree of government" (Huntington1968, 1). While democracy is the best case scenario, for most Third World countries of this time (1960s), efforts to modernize (like industrial countries) often facilitated rapid social changes but did not develop political institutions that could support the growth of these social developments. Without strong political institutions, these efforts can lead to political disorder and violence (Kurth 2009). Some scholars believe that Third World countries fall victim to this and are in turn less institutionalized (Kuenzi and Lambright 2001). For this reason, it is often argued that institutionalization in the Third World is not as easily attainable as it has been for industrialized countries and often comes with uncertainties (Lupu and Riedl 2012). Huntington attributes that for these countries, institutionalization may be more achievable if they do not push modernization and democratization as the only way to achieve institutionalization and in turn political stability (order) (1968).

However, some scholars still emphasize that while we cannot expect all Third World countries to modernize and democratize in order to institutionalize in the same way that industrialized countries have, we also cannot presume that they are all incapable of doing so. Scholars such as Adeje (2013), Mainwaring (1998), and Weissenbach (2010) have studied the relationship between democracy and institutionalization of political parties and have found that there is a connection between democracy and institutionalization because the components of institutionalization are also significant to and are requirements of a stable democracy:

Institutionalization of a party system is vital for the success of a democratic system...they [political parties] are the main tool by which democracy is introduced and maintained in modern politics... Without strong political parties, politics is reduced to unlimited opportunism and the blatant self-serving interest of politicians who may derail the nation-building process and the democratic entrenchment...(Abeje 2013) 
Therefore, these scholars note that institutionalization is crucial in maintaining political order and stability within democracies, particularly within the Third World. Ghana's political stability transformation and institutionalization is representative of this argument and more importantly, is an instance in which institutionalization occurred out of democratization and fostered political stability. This is addressed on page 80 of the case study.

Political Stability and Food Security. In applying existing findings on political stability, the absence of violence, and political institutionalization to the study of food security concerns, scholars have largely found that there is a relationship between political stability and food security:

Food security and political stability are often inextricably linked in many countries. Historically, significant malnutrition and famine have been caused by the disruption of food supplies through wars and civil strife...yet, the concepts of food security and political stability are often mutually dependent and reinforcing. Food security, for example, can influence the political stability of countries. Simultaneously, political instability (such as wars or other forms of civil strife) can influence food security. (Smith 1998)

The differences in political stability and food security successes between nondemocracies and democracies can be seen in the following manners. First, within nondemocracies, violence produces an environment of conflict that makes food security relatively impossible: "Conflict clearly causes food insecurity...conflict can destroy up to 90 percent of GDP...conflict can undermine decades' worth of development. Conflicts further compound the problems of infant mortality by encouraging governments to divert funds from social priorities to military spending" (Pinstrup-Anderson and Watson II 2001, 261). In many non-democratic states wherein internal violence exists, such violence most often prevents the success of food security efforts because it hinders 
society's ability to focus attention on food security efforts. In violent states experiencing either internal violence or civil conflict, land is not easily accessible for the purposes of farming, agriculture yields are not as abundant, and crops are not equally accessible to all citizens because agricultural work conducted by citizens is interrupted by the hardships of living in a violent environment (Verwimp 2012; De Soysa et al). Such hardships may include but are not limited to emotional trauma, physical illnesses and abuses, and the need to concentrate on one's own survival (Safaei 2006). Providing statistical support of why violence constrains agricultural production and distribution in Africa specifically, Robert L. Paarlberg finds that

\begin{abstract}
violent conflict reduces agricultural productivity and compromised secure access to food...countries experiencing conflict in Africa...tend to experience a significant drop in food production. They produce on average 12.4 percent less food per capita in war years than in peacetime. A comparison of actual historical food production in Africa after 1980 to a "peace adjusted trend" shows that peace would have added 2-5 percent to the continent's total food production per year. $(2002,32)$
\end{abstract}

These findings show that food accessibility in violent, largely authoritarian states is a multifaceted concern. Preluding Sen's finding that famine is often a result of a lack of capability to access nutritious food is the reality that capability is not possible without the existence of adequate yields to begin with. The more limited the yields, the more restrictive government may be on the distribution of these yields to citizens. A violent atmosphere that restricts fruitful yields can have a devastating impact on food security among citizens (Messer, Cohen, and D’Costa 1998).

Differently, the democratic focus on ensuring that citizens live within a nonviolent society provides the potential for higher yields and the equal distribution of safe foods because the strength of the democratic state relies on a healthy, fearless, and 
active electorate. For these reasons, democracy is best sustained when safety, health and food security are a priority (Safaei 2006). To ensure the survival of democracy, it is the general obligation of a democratic state to suppress violence in an effort to ensure political stability. The degree to which democratic states take this obligation seriously can be seen in the fact that these states tend to implement more social security and social equity policies and programs focused on improving citizen health rates than do nondemocracies. As Safaei elaborates:

...out of concern for the poor and less privileged groups or mainly in
response to the strong demands by organized labor, many countries
have designed various social security/insurance plans to ensure some
degree of social equity...countries with higher degrees of democracy
and social conscience, as reflected in their...less stratified social
structure, tend to provide more generous social security programs.
$(2006,772)$

A democratic state wherein citizens are safe and have the physical strength to be politically involved impacts political participation levels, which has a positive effect on food security as discussed in the next section.

In terms of government effectiveness, democracy prioritizes and works to implement the following efforts that improve good governance and can increase food security levels: control of corruption, the rule of law, and the division of power. The existence of internal corruption within a state can perpetuate the suppression and oppression of the lower classes and, correspondingly, those living in poverty and with significant food insecurity (Kaufmann 1997; Svensson 2005). Directly pertaining to the general population's food security levels, corruption is one of the greatest causes of recurring low health rates within society. This is a common finding within authoritarian regimes wherein all power is held within the hands of a small percentage of the population, the social and political elite (Ruger 2005). As Pinstrup-Anderson and Watson 
explain, this is the case because, within corrupt authoritarian states, the government and its leaders have a monopoly of power and often choose to distribute their attention to those individuals that are able and willing to bribe them. This leaves the majority of citizens with little impact on government and without the health and food security assistance that they need from the national government because assistance does not trickle down to the lower classes. The ensuing consequences are as follows:

\begin{abstract}
More corrupt countries tend to have lower GDP/capita, lower human capital...they are generally less open to imports...reduce pro-poor growth and agricultural investments. The poorest people, minorities, and women are often excluded from government services, and NGOs that strive to reach the poor are often unable to reach the ultra poor who suffer from social exclusion. (Pinstrup-Anderson and Watson II 2001, 257-60)
\end{abstract}

All of these factors have a distressing influence on food security and limit the extent to which the government works and succeeds in producing acceptable food security levels.

Democracy and its internalization of the rule of law and separation of powers work to weaken government corruption and to prioritize human health. First, the democratic rule of law requires that all citizens are equally subject to rules and laws and are not merely subject to the demands of one overly powerful individual (United Nations Office on Drugs and Crime 2012). What differentiates democracy's rule of law from the common practices of authoritarian regimes is that all government officials and leaders are equally subject to the laws that they implement in society and the laws that predate their time in office. This creates an environment that revolves around the golden rule of using government to better the lives of not only themselves, but of all others (O'Brien, Greene, and McQuoid-Mason 1994). This can directly improve food security within the state because officials who want to ensure their own health and wellbeing will focus attention on implementing policies that spotlight health and food security improvements. These policies, in turn, will trickle down to all classes of society. Holding the government 
accountable to the rule of law and separating power among the executive, legislative, and judicial branches, prevents one branch of government from becoming too powerful and from prioritizing their own needs over the needs of the general public (Abbassi 2013).

In addition to being legally bound to abide by the rule of law, democracies are often recognized as being ethically committed to equally distributing social services within society, including the distribution of healthy, safe foods and other healthy living services. Scholars Wise and Sainsbury explain that democracy's obligation to the separation of powers, the rule of law, and the equal distribution of services in general, collectively create a more food secure environment than many non-democratic regimes: "more potential actions are generated for consideration, there is better monitoring and control of government and government bureaucracies, decisions are more likely to reflect the wishes of the majority, and hence government decisions are more likely to be health promoting" (Wise and Sainsbury 2007, 181).

Political Participation and Government Accountability and Proficiency. Lastly, democracy's potential to produce adequate food security levels is largely due to its inherent "political participation and government accountability and proficiency" mechanism. In the context of democracy, this mechanism refers to the extent to which citizens can take part in and make a change to their country's political arena and how government acts as the voice of these citizens when making policy. Citizens can use political participation to demand pro-poor and hunger reduction policies and other food security efforts. For instance, in underdeveloped democracies with high poverty levels (as is the case in Ghana's history), political participation works to ensure that political figures and candidates prioritize "pro-poor growth" and health. Pro-poor growth refers to 
"growth that is good for the poor" (DFID 2004). While the general definition of "propoor growth" is vague, it leaves room to assess how health and food security directly fit within pro-poor efforts. If a large population of a democratic state is living in povertywhich is common within underdeveloped countries - that population has the ability to directly improve their food security status via political demands, mass assembly, and press outlets. This overarching process is termed "food democracy." In this sense, poor citizens are not "mere recipients or passive targets of government" and are instead "agents with knowledge, assets, and goals" (Pinstrup-Anderson and Watson II 2001, 252). The extent of food security concerns among the electorate becomes more evident and so does the powerful impact that the political participation of society has on addressing these concerns and changing the food system for the better. There is political pressure to ensure 'greater access and collective benefit from
the food system' so that it provides 'the means to eat adequately,
affordably, safely, humanely, and in ways one considers civil and
culturally appropriate'....at the core of food democracy is the idea that
people can and should be actively participating in shaping the food
system, rather than remaining passive spectators on the sidelines.
(Hassanein 2003, 79) This furthers the extent to which democracy's political structure can increase a democratic state's focus on food security improvements.

This can be seen in the ways in which government interacts with and recognizes the power of civil society in the decision making process, works to ensure equal opportunity and inclusive growth, and implements developmental policies and programs for the betterment of society (United Nations 2013b). Within any state, civil society groups have the potential to either be powerful, well-respected organizations of governance or weak as a consequence of being suppressed by government. What is most readily apparent is that civil society is oftentimes most influential within states that 
prioritize the needs, desires, and demands of their citizens, most often seen as being democracies (Fox 2000; Diamond 1994). African studies scholar Michael Bratton implies that in most authoritarian regimes civil society efforts are heavily restricted by the government's unsupportive, even threatening structure: "[Civil society] cannot flourish amid political disorder, lawlessness, and inadequate physical infrastructure, or intermittent essential services. Civic organizations depend upon the state for creation of certain basic conditions of existence" (Bratton 1989, 428). Differently, civil society's place within democracy is strong and interactive because, within a democratic environment, supportive government provides opportunities and abilities that are not as readily available to civil society activists in authoritarian regimes. Democracy offers an environment in which civil society efforts can thrive, in which they are safe from violence, corruption, and oppression. Democracy offers

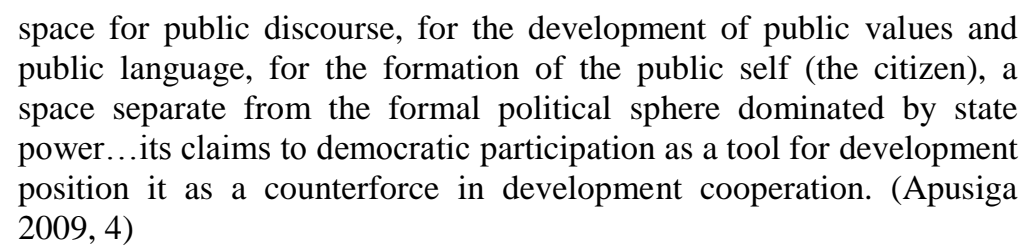

This might directly impact a society's level of food security because democracy allows civil society groups that focus on issues of individual and collective safety to create grassroots efforts. Civil society organizations predominantly campaign for better treatment of the general public, and more explicitly the less fortunate. Therefore, democratic civil society organizations serve collectively to empower citizens to pursue their own development needs and goals (Hadenius and Uggla 1996). Democracy provides a direct route to helping these citizens with their food security needs by not only allowing the existence of food and health related civil society groups, but also by being accountable to and by interacting with these civil society activists to ensure equal 
opportunity and inclusive growth. Accordingly, an open and interactive democratic government is favorable to stronger and more inclusive food security civil society groups (Levkoe 2006). These civil society organizations produce food security and health benefits and make demands of government that are advantageous for those who may have otherwise been marginalized by the state:

The potential gains from community-driven development are large. It has the explicit object of reversing power relations in a manner that creates agency and voice for poor people, allowing them to have more control over development assistance. This is expected to make the allocation of development funds to be more responsive to their needs, improve the delivery of public goods and services, and strengthen the capabilities of the citizenry to undertake self-initiated development activities. (Apusiga 2009, 6)

Similarly, democracy is regularly credited for the establishment of modern agriculture and health-based government departments and organizations, the enactment of citizen-centered food and health policies, growth in rural infrastructure, improvements in food and nutrition education, and other efforts that improve "safe water supplies, sanitation, and sewage disposal systems...disease prevention and reduced mortality" (Safaei 2006, 772), all of which are prerequisites of food security. Together, these attributes are largely responsible for improved food security and general health rates. The energy that democratic governments exert in order to make these improvements in society are largely unparalleled by authoritarian regimes. These efforts are time consuming, expensive, and inherently beneficial to the general public, all of which are viewed as counterproductive to the self-serving nature of authoritarian government. However, focusing on these developmental policies and programs is not only a requirement of but is also favorable to democratic government because it has positive implications for the wellbeing of the electorate and, therefore, the strength of democracy itself (Pinstrup-Anderson and Watson II 2001). Each of democracy's mechanisms-as 
discussed in this section - have a direct, positive bearing on a state's food security status. Furthermore, because of these mechanisms, it is probable that on average, democratic states have an advantage over authoritarian regimes regarding food security.

\section{Research Question and Hypothesis}

Rooted in the above literature and research findings, the purpose of this thesis is to test whether or not findings about the benefits of democratic mechanisms hold true when applied to a longitudinal case study of Ghana and to determine if democracy is foremost responsible for Ghana's food security improvements in recent decades. If so, why and how has this occurred and what evidence exists to show that Ghana's democratic progress has been the key to the state's growing food security levels? Chapter three explains why Ghana has been chosen for this study.

Expanding upon existing literature, this researcher hypothesizes that Ghana's democratization and subsequent democratic progress since 1980 has been primarily responsible for Ghana's improved food security levels. Likely, democratization did not have an immediate impact. More realistically, it is probable that political stability and government effectiveness, as well as political participation and government accountability and proficiency have nurtured the preconditions for gradually strengthening food security patterns. Analyzing existing data about Ghana's democratic development and data regarding Ghana's food security and health improvements will show that democracy has a positive effect on food security among the country's general population. An "if-then" statement can likely be inferred in this specific case. If strength

of democracy increases, then so does food security. The author also hypothesizes that the most important democratic variables impacting this causal relationship are the absence of violence, free and fair elections, freedom of the press, control of corruption, the rule of 
law, civil society involvement, equal opportunity and inclusive growth, and a governmental emphasis on growth and development policies and programs.

Developments within food security are expected to be directly associated with the strength of these democratic factors. 


\section{CHAPTER III \\ RESEARCH DESIGN}

The previous chapter provides theory and insight into how democracy can foster food security and more precisely that the connection between food security and democracy should not be deemed a coincidence. Rather, there is preliminary support of the argument that a relationship exists between these variables. However, the researcher needs to greatly expand on the above theory in order to provide evidence that a country's democratic status can directly influence its food security status and that this theory applies to and is evidenced in reality. For this reason, chapter four below presents a case study of Ghana that shows that, in this specific case, democracy fosters food security more so than authoritarianism. Proving that Ghana has done more to uphold the right to food since becoming a democracy than it did when it was a non-democracy, chapters four and five present a longitudinal case study that depicts the development of food security efforts and successes over time.

\section{Using a Longitudinal Case Study as Opposed to a Large-N Study}

In researching how Ghana's democracy has fostered improved food security levels, the researcher selected a longitudinal case study as the study's research method. A small-N case study approach was selected instead of a large-N study for many reasons. 
First, as explained by scholars M. Heath and Caroline Tynan and also Garrett Glasgow, large- $\mathrm{N}$ studies are beneficial for research in which the purpose is to find patterns across a multitude of cases $(2010 ; 2013)$. Scholars such as Andrew Martin point out that large-N studies provide more measurable validity than small-N studies and that small-N studies do not allow the researcher to make causal inferences. Undoubtedly, small-N studies do not easily provide quantifiable findings; however, in many cases, large- $\mathrm{N}$ studies are indicative of an "outsider" perspective (Health and Tynan 2010) in which it is very difficult to understand why the independent variable influences the dependent variable. For the purpose of showing how and why democracy has positively impacted food security levels in Ghana, a small-N study in the form of a longitudinal case study results in more detailed findings that provide an "insider" perspective of this issue.

A longitudinal approach for this case study and analyzing one country over time best limits the number of variables that could potentially alter findings. For instance, as Tom W. Smith explains in "Developing Comparable Questions in Cross-National Survey," "...the very differences in language, culture, and social structure that make cross-national research so analytically valuable are the same that seriously hinder the achievement of measurement equivalency" $(2003,69)$. This explains one of the ways in which conducting a case study comparing and contrasting two or more states (either in a most similar or most different case design) could lead to weaknesses that may skew the reliability of the findings. Contrarily, looking at Ghana's democratic progress over time entails comparing and contrasting its food security levels throughout history as it has advanced democratically, preventing this from occurring. Similarly, conducting a longitudinal case study allows the researcher to analyze and potentially rule out any other 
factors that may account for food security improvements. For instance, in the case study below, economic development is studied very carefully to determine if improvements in the economy led to food security improvements instead of democratization.

\section{Why Ghana?}

Ghana is the subject of this case study because of its unprecedented advancements in both democratic development and food security in the last two decades. The nation's turnaround in its governing structure and food security improvements begs the question of if these variables occurred simultaneously by coincidence or if democracy has been the cause of improved food security levels. Simply put, is democracy the independent variable to the dependent variable of food security and, if so, why do we see this relationship? While this case study may not prove that democracy always fosters higher levels of food security, testing the relationship between these two variables may provide insight into the instances in which democracy facilitates higher levels of food security than that of non-democracies. As a result of this conclusion then, this case study may encourage scholars to revisit Amartya Sen's findings about the positive impact of democracy on famine and to test if this applies to lesser forms of hunger in other nations today. Ghana then acts as a preliminary example and jumping off point for future research in this regard.

\section{Case Study Overview}

This case study analyzes the shift in food security status that Ghana experienced from pre-democratization (pre-1992) to post-democratization (post-1992) in order to 
determine how democracy positively impacted the shift. Have the democratic mechanisms discussed in chapter two created preconditions and the environment necessary to improve Ghana's food security status as the theory claims they do? First, chapter four gives a brief history of Ghana's governing systems and its many transitions and struggles for democracy from independence through today. Following this analysis, the scope of this study is narrowed to analyzing roughly a decade of pre-democratic government's food security levels and efforts (1980-1992) and contrasting it to food security levels and efforts that emerged out of democracy (1992-2012). Doing so shows that Ghana's non-democratic governments from 1980 until 1992 encouraged low food security levels while Ghana's democratization and the sustainment and strengthening of this democracy has led to significant improvements in food security.

This section shows how Ghana's non-democratic government of the 1980s implemented minimal food security policies and that, during this timeframe, food security and the well-being of the populace were not priority. Instead, this was a government that focused on the needs and desires of the few elite and on bettering the economy to improve the nation's standing in the global marketplace. The literature shows that such a lack of government support had a severe impact on food insecurity levels and produced increased hunger and malnutrition. Sources include legislation, policy implementations such as the Economic Recovery Program (ERP), literature and data showing the livelihood and hunger struggles of farmers, data representing "brain-drain," unemployment rates, and data showing the distortion of the pricing system and corresponding inflation.

The study presents existing data to provide quantitative support of these qualitative findings and to show that the lack of food and health policies and non- 
democracy more generally had severe ramifications. Data includes the Domestic Food Price Level Index, Global Hunger Index (GHI), malnutrition and underweight percentages, and the Dietary Energy Supply (DES). The FAO's Domestic Food Price Level Index is an index generated by dividing the Food Purchasing Power Parity (FPPP) by the General PPP so as to determine an index of the price of consumer food in a given country.

Similarly, GHI scores are calculated by adding up the proportion of the population that is undernourished (in percent), the prevalence of underweight in children younger than five (in percent), and the proportion of children dying before the age of five (in percent) and dividing these findings by three. Index scores range from 100 (most extreme hunger) — in which all of the population would be malnourished, all children under the age of five would be underweight, and all children would die before reaching the age of five - to 0 (no hunger), in which no one would be undernourished, no children under five years old would be underweight, and no children would die before the age of five. As the IFPRI explains, neither of these extreme scores are possible; however, they represent both ends of the index's vast spectrum. The spectrum is broken down as follows: scores of 4.9 and below represent low hunger levels, scores of 5.0 to 9.9 are instances of "moderate hunger," 10.0-19.9 are "serious hunger," 20.0-29.9 are “alarming," and 30.0 or greater are "extremely alarming” (IFPRI 2012).

The "percent of undernourished" factor for all four GHI years was calculated by averaging the percent over a three-year period (1990-1992, 1995-1997, 2000-2002, and 2006-2008 respectively). The "prevalence of underweight in children younger than five years" was calculated by collecting data from the year that is closest to the given year or by averaging two years of data if there are two years closest to the year in question. For 
example, for the year 1990, an average was taken from the years 1988 to 1992. The exception to this method is the measurement for 2012. In this case, an average was taken from the years 2005 to 2010 because at the time, this was the most current data available. Lastly, the "under-five mortality" factor for each year was taken from existing data on the mortality rates for under-five mortality rates for that given year. As before, the exception to this is the data presented for 2012 . Here, the reference year is 2010 because again, this was the latest data made available at the time.

Lastly, DES refers to how much energy, in calories, is in the food that is available for consumption. Meeting the DES requirement means that on average, individuals are taking in enough calories, and therefore energy, per day to be considered healthy. The per capita DES requirement is 2,118 calories and when reached by the populace, leads to a more food secure state. (Food and Agriculture Organization n.d.).

Following the analysis of this data, the researcher used the same approach to analyze how democracy has impacted food security levels from 1992 to 2012. This section shows that in democratizing and progressively working to strengthen the existing democracy, Ghana's government has introduced many food security policies that are aimed at directly improving the health and wellbeing of citizens. To remain consistent with the research design of the pre-democracy analysis, this section introduces the same qualitative sources-legislation, policy implementations, institutional developments and progress, and feedback from citizens. This section analyzes the following: surveys, Freedom House scores, news releases, Government of Ghana (GOG) documents, policies and legislation, and CSO programs. These sources show that, in the years after the 1992 elections, there was a progressive reduction in malnutrition and hunger. Next, referring to 
the following data shows that quantitative reports support the qualitative findings: the Domestic Food Price Level Index, GHI, malnutrition and underweight percentages, and DES. Lastly, this study concludes with a comprehensive analysis that discusses these findings explain about Ghana's democratization and its link to food security advances.

\section{Overcoming Research Obstacles}

As with any other study, studying the impact of democracy on food security levels comes with obstacles and potential research weaknesses. First, researchers have largely avoided this issue. Furthermore, food security is a newly emerging issue area within the discipline of political science, making it difficult to find corresponding research as to if democracy has an impact on food security. Also, the definition and characteristics of what constitutes "food security" are still largely up for debate. It is this researcher's belief that the definition of food security by the FAO, provided in the literature review, gives the best insight into the multifaceted components of food security; however, not all scholars and organizations accept this definition as such. Therefore, the term "food security" is largely subjective, creating research difficulties because of the lack of consistency. Second, applying this issue to the specific case of Ghana means that the minimal existing literature becomes even sparser. In overcoming these research weaknesses, there is potential for this study to make a contribution to existing literature. It opens the door to future studies regarding this topic, with the possibility for future researchers to study if these findings are paralleled in any other states.

However, researching a topic that is new to the discipline of political science also comes with many other disadvantages and obstacles. It requires thorough research and 
work with limited resources, which may cause other scholars such as separatists to question if there is enough evidence to support the finding that democracy does influence food security levels. This concern is furthered by the fact that, of existing studies, very few are quantitative and there is a large divide between the number of qualitative studies compared to quantitative ones, which may lead to further concerns regarding if it is possible to measure food security levels at all. To overcome these weaknesses, this study integrates arguably the best existing literature on the subject. For instance, it uses quantitative sources from Freedom House, the Food and Agriculture Organization (FAO), and the International Food Policy Research Institute (IFPRI), all of which are renowned for their contributions to the study of food security issues and for their presence and aid in food insecure nations. 
PART TWO: GHANA - CASE STUDY, FINDINGS, AND ANALYSIS

\author{
CHAPTER IV
}

\title{
CASE STUDY: TOWARDS DEMOCRACY - GHANA'S PRE-DEMOCRATIZATION FOOD SECURITY STRUGGLES
}

\begin{abstract}
A Brief History
"If we get self-government,...we'll transform the Gold Coast into a paradise in 10 years."- Dr. Kwame Nkrumah, in Commanding Heights
\end{abstract}

Ghana, originally named the British Crown Colony of the Gold Coast by its British colonizers, was the first African colony to achieve independence from Great Britain on March 6, 1957 (BBC News 2008). A colony of Great Britain since 1874, Ghana's history is heavily embedded not only in its struggle for independence from Great Britain but also its own subsequent fight to establish democracy, which it did not fully achieve until 1992 (Aidoo 2006). As shown in the introductory quotation to Chapter IV above, Ghanaians were heavily optimistic that achieving independence from Great Britain would result in an almost immediate improvement in governance, economic status, general health, and livelihood more generally. However, this belief was unfounded and as history has proven, the reality of Ghana's struggle to democratize and to improve its political and economic systems would not be an easy feat. The following two sections provide a brief chronological summary of Ghana's history and highlight its path to 
becoming a true democracy.

\section{The First Thirty-Five Years}

A leading advocate for, and arguably the predominant catalyst of, the fight for Ghana’s independence from Great Britain was Dr. Kwame Nkrumah (1909-1972), a native of Ghana whose interest in the benefits of democracy peeked during his Masters and Doctoral studies at the University of Pennsylvania (Yergin and Stanislaw 1998). Believing that all Africans should have the right to self-government and ever-growing stability and prosperity, Nkrumah was a persistent advocate of the Pan-Africanist Movement of 1900 to 1945 (Kwame Nkrumah Academy 2013; Mboukou 1983). This movement — which stresses the importance of African brotherhood and the joint fight of African states to achieve independence from colonization, to improve the economic status of all countries, and to better the lives of all Africans-fostered Nkrumah's push for Ghanaian independence and his ideology that once independent, "we'll transform the Gold Coast into a paradise in 10 years" (Yergin and Stanislaw 1998). Ghanaian natives started to support and strive for these ideals, began uprising against their British oppressors, and initiated demands for independence. After years of continuous opposition via "positive action," such as non-violent strikes and protests, persistence resulted in the secession of Great Britain's rule and a newly independent Ghana. Immediately following independence, Nkrumah was named Ghana's first Prime Minister of native origin. Three short years later in 1960, Nkrumah initiated the formation of a new constitution, which ushered in Ghana's First Republic, democratic presidential elections, and first president, Nkrumah (Birmingham 1998). 
Unfortunately for the Ghanaian people, this progress was short-lived. Nkrumah's perceivably democratic efforts were soon followed by questionable and highly controversial political efforts. Most notably, in 1964, Nkrumah passed a constitutional amendment making the Convention People's Party (CPP) the sole political party in Ghana and making himself president for the remainder of his life, forcing Ghana into a state of dictatorship (Omari 1972). Finding this to be contrary to Ghana's original intentions for independence, the Ghanaian populace began to oppose him and lost confidence in the state's ability to be a true democracy. As a result of society's growing resentment and distrust of Nkrumah, members of the National Liberation Council (NLC) utilized a violent but successful military coup and overthrew Nkrumah and the CPP on February 24, 1966 (Adekson 1976).

The leaders of this coup justified their actions as being necessary for Ghana's potential as a democracy. Arguing that Nkrumah's rule regressed Ghana's progress, the NLC put into practice democratic mechanisms that would develop a more secure and democratic government (Austin 1976). Most importantly, the NLC prioritized creating a new constitution as part of the coming of the Second Republic of Ghana. Furthermore, the NLC acted as a temporary executive governing body consisting of four military officials and four police officers whose overall purpose was to re-solidify Ghana as a democracy and to then ease in a new democratic government via multi-party election. In August of 1969, a presidential election took place and five political parties participated, with the victor being Kofi A. Busia of the Progress Party (PP) who subsequently became the new Prime Minister. Shortly after, Chief Justice Edward Akufo Addo was elected president by the electoral college (Gocking 2005). This marked the beginning of the brief 
Second Republic.

Because this government came as a direct result of the NLC's efforts to establish democracy, the electorate on average believed that this new administration would focus more on the needs of average citizens and less on the desires of society's few elite. However, again, Ghana's citizens were denied a stable democracy, as had been promised to them. The debt that Ghana accumulated at the hands of Nkrumah created an inescapable, debilitating economic struggle that only continued to escalate during Busia's years as Prime Minister. Furthermore, Busia implemented policies that significantly reduced support from the populace:

First, the Progress Party regime had been guilty of extreme economic mismanagement.... Second it had consistently acted against the interests and wishes of one important social formation after another: the civil servants, the farmers, the business community, the unions, the press....Third, it had been acting in defiance of the democratic constitution which it had sworn to uphold. (Goldsworthy 1973, 8)

Combined, these controversies triggered another military coup in 1972, this time by the National Redemption Council (NRC), ending the Second Republic.

Similarly to the military coup of the NLC in 1966, the NRC reasoned that this coup was necessary to reestablish a government of the people and to refocus government on prioritizing the needs of the general public. Initially, the NRC held community support because of its preliminary efforts to undo Busia's unpopular economic policies. However, differently from the NLC, the NRC did not see democracy as a necessity. Instead, in 1975, they retitled themselves as the Supreme Military Council (SMC) and transformed Ghana into a militarily governed state (Lumsden 1980). At this point, it was clear that the SMC, like governments before it, would do little to solve the escalating financial burdens that loomed over the heads of citizens more than ever before. Citizens' struggles as a result of this negligence were most evident in industry, transportation, food 
production, and health declines: "Inflation was estimated to be as high as 300 percent that year. There were shortages of basic commodities, and cocoa production fell to half its 1964 peak" (Library of Congress, 1995). Citizen disapproval mounted and in response, the SMC created anti-opposition policies, which strictly limited the media and other public opinion outlets. Rather than suppressing the people's outrage, this intensified citizen demand for a return to civilian political participation and democracy.

Fearing this opposition, the SMC II—a new take on the original SMC that took hold of the government in July of 1978 — agreed to hold a free and fair election and to recognize the victor as the new government of Ghana. This election occurred June 22, 1979, and Dr. Hilla Limann of the People's National Party (PNP) was elected president, beginning the Third Republic (Goldschmidt 1980). However, this democracy was the most transitory yet. As a new administration with a president that was also new to political office, Limann's administration was subject to the emerging power and opposition of the Armed Forces Revolutionary Council (AFRC), a military-based party led by Flight Lieutenant Jerry John Rawlings who had years of experience in federal politics and government and had been attempting unsuccessful coups against SMC I and SMC II. On December 31, 1981—only two years into the PNP administration-the AFRC executed a successful coup that ended the PNP's rule and the Third Republic (GlobalSecurity.org 2011).

From 1982 through 1987, Rawlings held governing power by way of the Provisional National Defense Council (PNDC), the former AFRC. During his first term, Rawlings implemented some democratic provisions and policies, such as the establishment of "District Assemblies," democratically elected local divisions of 
government that interacted with and impacted federal government policymaking

(International Business Publications, USA 2012). He also created the National

Commission for Democracy (NCD), which aimed to increase the extent to which

government was responsive to the needs and wants of the people. This commission relied heavily on public, political participation and included citizen members (Leite et al. 2000).

Additionally, Rawlings and the PNDC established Ghana's first interaction with the World Bank and the International Monetary Fundy (IMF) to get Ghana the economic assistance that it needed to reduce its high levels of debt:

\begin{abstract}
...the PNDC drew up a program of financial reform that closely followed standard IMF austerity programs but tailored to Ghanaian reality. To the PNDC leadership, it was the only way to get the IMF to provide the loans that the country so desperately needed...by 1985 Ghana had become the model for other African countries that were seeking to follow the IMF and the World Bank's prescriptions for overcoming economic decline...this turnaround was a considerable achievement. (Gocking 2005, 194)
\end{abstract}

Because of this and the many other economic recovery efforts of the PNDC, Ghana saw improvements in its economy. However, the same cannot be said for the state's food security levels. Also, because he was not democratically elected to office, Rawlings' first term did not constitute a democracy. Furthermore, even though Rawlings implemented some democratic efforts, he instituted equally as many undemocratic policies such as banning political parties other than the PNDC, monitoring religious groups, and eliminating independent press sources, all as a way to control PNDC opposition. This ultimately led the general public to increased feelings of unease and distrust. Concerns mounted about whether the PNDC's main priority was protecting the people or protecting its place in government (Adedeji, J.L. 2001). 


\section{2 to Present: Becoming a True, Functioning Democracy}

As it had during its struggle for independence from Great Britain in the 1950s, the Ghanaian populace once again began to make strong, persistent demands for legitimate, democratic government. However, this time persistence paid off and democracy was achieved and sustained. The NCD, with the permission of Rawlings, conducted field research to get an honest, non-coerced answer to what form of government the general public wanted. Citizen responses to nationwide meetings showed that on average the public strongly preferred a multi-party government to any other form of government (IDEG 2007a). In response, the NCD and Rawlings' administration established the Consultative Assembly, which was responsible for proposing changes that should be made to previous constitutions (of 1957, 1969, and 1979). This was the first step in creating an improved, sustainable, and democratic constitution. On April 28, 1992, via a referendum, the general public accepted the Consultative Assembly's proposed constitutional changes and a new constitution was created (GhanaWeb 1994; International Institute for Democracy and Electoral Assistance 2010).

First and foremost, the 1992 Constitution changed Ghana's governing system by formally declaring Ghana a full-fledged democracy:

\footnotetext{
The legal system is based on the constitution, Ghanaian common law, statutory enactments of parliament, and assimilated rules of customary (traditional) law. The 1992 constitution, like previous constitutions, guarantees the institution of chieftaincy together with its traditional councils as established by customary law and usage. (Library of Congress 1995)
}

However, differently from previous constitutions, this constitution, still in place today, shows the heavy influence of the United States Constitution, as exemplified by the following changes: Ghana would from then on be jointly governed by 1) the executive 
branch, consisting of a democratically elected president who serves a four-year term (with the possibility of being re-elected to one additional term), 2) the legislative branch which is vested in the hands of the National Parliament, and 3) a judicial branch made up of federal and local courts that have independent power from the executive and legislative branches (Commonwealth Governance 2014; United States Department of State, Bureau of Democracy, Human Rights and Labor 2011). In its previous attempts at democracy, Ghana elected presidents via democratic elections; yet, the 1992 constitution introduced Ghana to new democratic practices that it had yet to experience: equal opportunity and equal distribution of powers. This change warrants that no president could establish himself as a dictator and that no other power could overthrow the presiding administration via military coup. With the branches of government working with equal power to each other and the emerging power of political actors, all people have the ability to change Ghana's governing system via democratic, non-violent means. Expanding upon these initial changes, the Constitution also guarantees human rights to all Ghanaian people, something that had not been promised or ensured before (Human Rights Advocacy Centre 2013; Library of Congress 1995).

Following the creation of the 1992 Constitution, the other pieces of Ghana's democratic progress began to fall into place. On November 3, 1992, by way of free and fair democratic elections, Rawlings was elected president and the NDC remained the governing administration. Rawlings and his Vice President K.N. Arkaah were inaugurated on January 7, 1993, beginning the Fourth Republic. In 1996, Rawlings was re-elected to his second term as president: "Under Jerry Rawlings' rule, Ghana became the most politically stable and prosperous nation in West Africa and provided a model of 
development for the rest of sub-Saharan Africa" (GhanaWeb 1994). However, the greatest proof that Ghana was functioning as a successful democracy came in December of 2000 with the election and swearing in of a new president, John A. Kufuor of the New Patriotic Party (NPP) (Smith 2002).

Of all elections leading up to this point, arguably this was the most significant and was the greatest test of Ghana's strength as a democracy. If Rawlings had at any point recanted his stance on democracy and declared himself "president for life" as Nkrumah did, democracy would have collapsed. Similarly, if opposing parties, candidates, military groups, or citizens, initiated violent (and successful) uprisings, democracy would have crumbled. As Ghana's history has proven, violent coups were the device by which all previous democracies ended (BBC News 2013). Because the Fourth Republic was still in its infancy during the 2000 elections, if a coup emerged, this republic would have had a high risk of ending in the same manner as its predecessors. Instead, the 2000 election was an instance of development and democratic strength and "marked the first peaceful democratic transition of power in Ghana since the country's independence in 1957" (Ghana Broadcasting Corporation 2012).

In December of 2004, Kufuor was re-elected for a second term. Perhaps the most successful focuses of Kufuor's governing strategy were his prioritization of the needs of all citizens regardless of their place in society, his lack of tolerance for any government corruption, and his greatest emphasis on establishing unity across Ghana's regions and cultures, all things that had been longstanding causes of conflict (Agyeman-Duah 2003). His ideological choices and emphases showed his commitment to implementing democratic government. He proved to the populace that Ghana had adopted true, all- 
encompassing democracy. Proof of this can be seen in the following quotation from

\section{Gocking's The History of Ghana:}

He [Kufuor] called upon Ghana's business people to lead an economic transformation of the country...indicative of the new country's determination to create unity, it [the administration] offered positions to leaders of opposing parties...ironically, it was one of their ministers who provided them with their first opportunity to demonstrate 'zero tolerance for corruption.' $(2005,257-259)$

Democratic measures did not cease with the end of this administration. Rather, the 2008 election and the swearing-in of President John Evans Atta Mills in 2009 strengthened Ghana's democracy. The fact that Ghana remained a stable democracy during the 2008 election and did not experience violent protest or opposition is a testament to the extent to which Ghanaians (government officials, political actors, and the general public) believe in the benefits and necessity of democracy in this state. This election was the "closest" election in Ghana's short democratic history with Mills prevailing by a margin of less than one percent (Nossiter 2012). Like Kufuor, Mills focused his presidency on improving the livelihood of the citizenry, improving the economy, and advancing Ghana's place in the global community: "in recent years, oil discoveries and a blossoming middle class have drawn waves of foreign capital... such investment helped make Ghana Africa's fastest-growing economy last year, expanding 13.5\% from a year earlier" (Hinshaw 2012).

Unfortunately, Mills' presidential contribution to the nation was cut short by his untimely death on July 24, 2012. John Dramani Mahama, Mills' vice-president and successor, was sworn into office that same day. Having only been in office for months as of yet, Mahama's presidential actions and accomplishments have been justifiably limited; however, it is already apparent that Mahama is committed to following the democratic plans of Mills and upholding democracy more generally. Examples of this 
can be seen in his focus on "Jobs, Stability, Development, and...WORKING FOR YOU" as proven by his expansion of the Better Ghana agenda which is discussed in depth below (The Presidency: Republic of Ghana 2014). Via the democratic administrations of the late twentieth and early twenty-first centuries, Ghana has drastically improved its commitment to democracy and the focus of "government by the people, for the people." Arguably, as the levels of democracy have increased and continue to increase, so have and will the levels of wellbeing, as exemplified by the corresponding ways in which democracy positively impacts food security levels as analyzed below.

\section{Learning from the Past to Shape the Present and Future}

While Ghana's democracy is only twenty-two years old — tracing back to 1992already, the benefits of this transition are clear. Arguably, one of the most prominent benefits is the drastic increase Ghana has experienced in its levels of food security since the 1990s. What explains this? In analyzing how the theories and literature discussed in chapter two apply to Ghana, it is apparent that the argument about the mechanisms of democracy being conducive to higher levels of food security is a reality for Ghana. Ghana's federal government has not always prioritized the health and wellness of its citizens and, as a result, food security levels were not always as high as they are now. This is most obvious when contrasting the different governing strategies and policies of the 1980 s and early 1990 s authoritarian regime to the subsequent democracy of the 1990 s to present. This change in the government's focus post-democratization shows that democracy's commitments to serving the electorate have drastically improved the state's 
food security status. This study does not analyze the years prior to the 1980 s because of a lack of available food security data. While Dietary Energy Supply (DES) data exists for the late 1960s and 1970s, it is one of very few Ghanaian food security sources that date further back than the 1980s. For instance, the FAO's Food Price Level Index and the IFPRI's Global Hunger Index (GHI) do not provide data for years previous to the 1980s. Because of this significant limitation, any findings and analysis comparing Ghana's food security levels prior to the 1980s to post-democratization levels would be largely unfounded. Therefore, this study analyzes the years since 1980 and utilizes data that shows the food security developments over this time period.

\section{0s Economic Improvements Provided Few Benefits for Average Citizens}

Indisputably, economic improvements during the 1980s are often attributed by many scholars, such as Chad Leechor and Ishan Kapur et al., as being the radical turning point in Ghana's growth and development because Rawlings and the PNDC pulled Ghana out of the debt it had been emerged in for decades. However, existing literature tends to overlook the many ways in which the 1980s economic policies advanced Ghana's economy at the expense of the general public. Rather than using these policies to simultaneously improve the wellbeing of Ghana's citizens by tackling poverty and malnutrition levels, Rawlings largely ignored these concerns during his years of authoritarian rule. The extent to which Rawlings purposely ignored social issues and focused all of his attention on improving the state's economy to improve its ranking in the global community is debatable. For instance, questions emerge as to whether or not he took this policy path because he did not care about the many social issues facing 
Ghana and only cared about the state's economic status, or if he took this path because he did care about the general public and thought that improving the economy was the initial step necessary to achieving improvements throughout all of society. The answer to this is largely held in the eye of the beholder. For instance, Kevin Shillington and John Adedeji argue that Rawlings introduced economic reform efforts to better address the needs, values, and wellbeing of citizens (1992; 2001). Opposingly, Kwamina Panford, scholar and critic of Shillington's Ghana and the Rawlings Factor, insinuates that the Rawlings administration purposely prioritized economic growth over Ghanaians civil and political rights. He argues that citizen wellbeing was not an inherent effect of economic growth (Panford 1994).

Regardless of his intentions, Rawlings accomplished his goal of improving Ghana's overall economy but he did not make equal improvements to the economic standing of Ghana's citizens. Without doubt, the 1980s marked a time of drought and hardship; however, Rawlings' lack of focus on the needs of citizens greatly exacerbated this hardship. Evidence supporting this finding and showing the extent to which authoritarianism hindered health and food security improvements lies in analyzing the policies and strategies that Rawlings implemented, as discussed extensively below.

Transforming the Economy. After taking executive power in December of 1981, Rawlings and the PNDC were forced to immediately address the issue of Ghana's deteriorating economy, which at the time was arguably in the worst condition of its history. With debt vastly exceeding the Gross Domestic Product (GDP), "the economy recorded an annual average growth of -2.2 percent between 1975 and 1982, with average 
annual inflation of 64.9 percent and balance of payments deficit of $\$ 6.8$ million over the same period" (Baah-Boateng 2004, 4). Like so many rulers before him, authoritarian and democratic, Rawlings proclaimed that Ghana had no choice but to focus its attention and resources on stabilizing what little was left of the economy. Taking on the burden of completely rebuilding the economy, one of Rawlings' first policies was to establish a strategic plan that would transform Ghana from being a state heavily dependent on imports to one that was booming because of abundant exports: The Economic Recovery Program (ERP) of 1983.

The IMF and Structural Adjustment Programs. The ERP grew out of the 1970s and 1980s IMF and World Bank Structural Adjustment Programs (SAPs), rooted in neoliberalism. While this thesis' case study is about the progression of Ghana specifically, it must be acknowledged that Ghana was not the only country to take part in a SAP. The 1980s marked an upswing in neo-liberalism, a political and economic ideology in support of economic globalization, open markets, and free trade:

\footnotetext{
At its core is a belief in the free market and minimum barriers to the flow of goods, services and capital. It is an extension of the traditional liberal philosophy, which argues for a separation of politics and economics and that markets should be "free" from interference of government. (WHO 2014)
}

At this time, countries all across the world, from first world to third world, were undergoing neo-liberal adjustment programs in the hopes of addressing international economic struggle. As acknowledged in "The IMF and the Silent Revolution," third world countries were particularly vulnerable to severe economic hardship and the “international realities" of the economy. In response, many of these governments' economic and governing philosophies transformed drastically: "From a starting point at 
which the state was viewed as holding a primary responsibility for controlling economic development, the "third world" gradually diminished and even rejected that role in favor of privatization and reliance on market incentives" (Boughton 2000).

While SAP goals intended to reduce economic struggle and debt in largely underdeveloped countries, their long-term effects were not conducive to overall development and often left citizens heavily impoverished because of the elimination of much needed government assistance and support. However, SAPs in primarily authoritarian countries, such as Ghana at this time, as discussed below, did little to combat corruption and poverty: "In political terms, it has been demonstrated that SAPs were predicated on authoritarian governments. The WB [World Bank] and the IMF comfortably negotiated SAPs with many such governments for years and the good governance conditionalities instituted in the late 1980s did not amount to support for democracy" (Tsikata N/A). John Adedji articulates that the adoption of economic restructuring programs in the 1980s facilitated a greater divide between the small elite and the overwhelming impoverished majority. Structural adjustment can have a very different impact on the different socio-economic classes of society, especially when implemented in authoritarian regimes in which citizens' demands for assistance and equality may be more easily suppressed (Adedji 2001; Bangura 1992; Mustapha 1992). Furthermore, Meltem Şener elaborates on this in arguing that structural adjustment programs are usually implemented “...in undemocratic environments and also foster repression and undemocratic practices once they are applied...reforms within the context of structural adjustment programs that were applied in many African countries would be very hard to implement in a democratic environment" $(2004,6)$. 
As the sections below show, the ERP was no exception to this finding. However, as Samuel Gayi argues efforts could and should have been initiated to lessen the social costs of SAPs, in Ghana's case the ERP. Including pro-poor and poverty alleviating policies within the ERP could have helped combat this hardship. Nevertheless, with little accountability to the populace, Ghana's authoritarian regime did not address poverty concerns in implementing the ERP (Gayi 1995).

Economic Recovery Program (ERP). The ERP was a three-part program established out of Rawlings' belief that, if society worked together to mass produce exports, efforts to improve the economy would be of little cost to the government and the state would drastically improve its domestic economy. He believed that, as a result, Ghana would emerge as an inspiration among African states and the global community. The first phase of the ERP focused on reducing the state's burden of the failing economy and implementing subsequent economic reform methods (Ahiakpor 1991). Largely, the federal government relied on the people to contribute all they could to improve the economy. Primarily, this program reduced government expenditures and worked to drastically increase private production and tax collection. Rawlings also drastically reduced the value of the cedi, Ghana's currency, so that within months, Ghana's cedi had been devalued by 1,090 percent (Library of Congress 1995). This made Ghana's exports cheaper for purchasing nations, raising Ghana's GDP. In regards to improving Ghana's place within the global economy, the ERP and Rawlings' efforts to rapidly transform the economy were largely successful. As explained by Egor Kraev, Ghana’s annual GDP growth grew from roughly minus one percent in 1980 to roughly five percent by 1989 
(2004).

How the ERP could and should have Improved Food Security. At first glance, the ERP appeared to provide more benefits than costs; however, the main focuses of the ERP show that this program aimed to improve the strength of the economy and the state, not necessarily the lives of the state's citizens (Ibhawoh 1999). Furthermore, improvement to the economy does not automatically translate to improvement in the standard of living, health, and food security. As the concept of human development highlights, "people are the real wealth of a nation...human development is concerned with...advancing the richness of human life, rather than the richness of the economy in which human beings live" (United Nations Development Program 2013). Applying this concept to the study of Ghana, human development in the form of health and food security is entirely dependent on the nation's commitment to food governance and the equal distribution of economic benefits to all of society (Food and Agriculture Organization 2012). Therefore, the key to food security is not held within the economy itself. Rather, it is held within the hands of the government, which holds the power to either equally distribute or not equally distribute the benefits of this economy.

As a result, there are specific preconditions for the economy to positively improve food security levels. According to the FAO, those who are poor and subject to malnutrition can only benefit from economic growth if this growth is directly invested in and accessible to the poor. Most applicable to the history of Ghana's economic transformation, for the economy to progress the nation's food security status, Rawlings and the government as a whole would have had to increase work and income 
opportunities for the poor and malnourished so that these individuals could afford adequate food and health resources. Government should also apply a sufficient portion of its new, increased revenue to establishing nationwide, reliable and stable "protection systems/safety nets" that focus on food and nutrition, tackling hunger, and health and wellbeing more generally.

Furthermore, government should also invest in increasing job opportunities and prospects for individuals that are in the state's greatest revenue-building sector. In Ghana's case, as is the case in many underdeveloped countries, this sector is agriculture. The significance of this is that the vast majority workers within this sector live rurally and are poor and undereducated. This is the most underprivileged and marginalized population. For this population to benefit from economic growth, the government would need to focus more of its revenue on improving the quantity and quality of goods and services accessible to this population. As the FAO explains, together these preconditions are part of the largest prerequisite of how economic growth can increase food security: good governance. Reverting back to chapter two's discussion of the democratic mechanisms that improve food security, good governance constitutes the following: political stability and government effectiveness, and political participation and government accountability and proficiency. Most often, good governance is prioritized within democracies and is necessary for the economy to be a successful tool for reducing hunger and malnutrition (Food and Agriculture Organization 2012).

Social Costs and Consequences. For Ghana during the 1980s authoritarian regime, these preconditions were never present and, because of this, scholars do not see food security 
improvements as a product of the 1980s economic growth. Rather, as expanded upon below, food insecurity grew. While scholarship written in the late 1980s points to the many ways in which the ERP should and could have benefited the general population's standard of living, the reality of how the program was implemented tells a very different story. As Kwame Asiedu-Saforo states in his article entitled "Economic Reform Programmes and Agricultural Development," the ERP originally asserted that it would focus on

encouraging and sustaining growth and development in both food and
cash crop sectors to reverse low productivity levels of labour and
land...these objectives include: improved input delivery, price
incentives, better marketing and storage opportunities, transmission of
proven technologies and other extension activities... and a general
improvement of support services to the sector. $(1989,362)$

In its infancy, Rawlings, the PNDC, and the ERP promised that this economic reform would benefit all, a promise that was not kept. With the government focusing on addressing national economic issues and with no electorate to hold Rawlings accountable for neglecting the needs of the populace, the 1980s recovery efforts actually disadvantaged average citizens (Cornia, Jolly, and Stewart 1988; Haynes 1991; Adedeji 2001). For example, the vast majority of Ghanaians who worked to increase production for exports, what Rawlings proclaimed would be Ghana's saving grace, did not personally benefit from the ERP.

The struggle of farmers best portrays the extent to which citizens worked to advance the ERP and Ghana's economy but saw little if anything in return. In the 1980s, farmers made up over fifty percent of Ghana's workforce and served as the support structure and work mules of the ERP and Rawlings' plan to drastically increase exports (Baah-Boateng 2004). While farmers' contributions to economic reform were unparalleled elsewhere in society, they were the most taken advantage of and 
economically and physically distressed. From 1987 to 1988, 43 percent of "export farmers" were considered to be "very poor" and from 1988 to 1989, this figure increased to 44 percent. Similarly, from 1987 to 1988 , 46 percent of food-for-consumption farmers were very poor, with this number rising to 53 percent from 1988 to 1989 . These percentages exceeded percentages of all other work sectors during these years (Ghana Statistical Service 1995). In demanding higher agricultural yields and exports, Rawlings cut funds to farmers and to the agriculture sector in order to lessen the economic burden on the state. Shifting the responsibility of supporting and preserving the agriculture industry onto the farmers, in 1991 Rawlings replaced the existing Ghana Federation of Agricultural Cooperatives (GFAC), which was federally supported, with the Ghana National Association of Farmers (GNAF), which rescinded the government's obligation to the agriculture sector and its laborers. In establishing the GNAF, Rawlings required that farmers take full responsibility for and wholly fund the GHAF, a "cooperative venture at the district, regional, and national levels" (Library of Congress 1995). Criticism of the ERP was common among farmers as they felt the growing stress of a dwindling agriculture budget in a decade already overwhelmed with unprecedentedly high poverty and hunger rates: "Farmers suffered as the percentage of the total budget devoted to agriculture fell from 10 percent in 1983 to 4.2 percent in 1986 and to 3.5 percent in 1988, excluding foreign aid projects" (Library of Congress 1995). The ERP's policy implementation also led to an unstable agriculture sector with wavering production rates (Codjoe 2007).

While farmers were the most disadvantaged, the rest of the populace experienced similar ramifications as a result of the ERP. For example, as the U.S. House of 
Representatives' Committee on Foreign Affairs describes in "Structural Adjustment in

Africa: Insights from the Experiences of Ghana and Senegal," Ghana's structural adjustment policies

failed to deal with the key constraints to equitable development...[and] to confront such important food production problems as: inadequate supply and extension of productive technologies, weak credit systems and insufficient overall credit, lack of storage and effective price stabilization...the special problems of women... and an absence of local and regional market development. $(1988,9)$

The primary weakness of Rawlings' authoritarian administration was its complete disregard for these social struggles associated with Ghana's compromised economy and the policies that were implemented to improve it (Asiedu-Saforo 1989). Ghana's development then was largely one-sided, with much economic progress but nearly no social progress. At the time, the greatest weakness of the economy was the disregard for human capital and the necessity of investing in citizens of all skill sets for the betterment of citizens' lives and the nation's progress:

...success...depends on a well functioning and flexible labour market in which labour allocation is done through the market mechanism and also creates sufficient incentives for human capital investment...Critics... argue that the economic reform measures have failed to create jobs for the increasing labour force and alleviate poverty because the measures focused mainly on promoting price stability rather than addressing the underlying weakness of the economy... the initial phase of Ghana's reform paid very little attention to the social dimensions of the programs. The immediate implications of the reform measures for employment and poverty were not explicitly incorporated into the policy formulation and implementation. (BaahBoateng 2004, 4)

The government needed to but did not create policies to tackle these social issues, leaving its people susceptible to continuously increasing poverty and malnutrition rates.

Regarding poverty levels, a large factor in whether or not a citizen can afford food, roughly 56 percent of the general population was considered "poor" from 1987 to 1988 and 60 percent were poor between 1988 and 1989 (Ghana Statistical Service 1995). 
Poverty levels across regions show that the majority of Ghana's poor lived in rural areas. For instance, in the rural-savannah, the percentage of poor residents increased from 66 percent between 1987 and 1988 to 74 percent between 1988 and 1989. These were the highest percentages across all other regions with the next highest percentages being in other rural regions (rural-forest and rural-coastal). Accra, the largest urban region, had the lowest percentage of poor residents. Rural residents had the highest poverty rates overall, many of these residents being farmers (Ghana Statistical Service 1995). As noted by Mohammed Awal, “...the challenge of achieving sustained, accelerated growth and poverty reduction still remained. Ghana... will need to grow faster: the kind which will enable broad base investments in human development and poverty alleviation" (2012).

In the 1980s, one of the only government efforts to address hunger rates was its acceptance of food aid. The 1980s marked the decade in which Ghana was most reliant on food aid, to such an extent that food aid vastly exceeded self-sufficiency. For instance, from 1982 to 1983, Ghana imported 46,000 tons of food aid. Between 1983 and 1984, food aid increased to 91,000 tons, more than doubling the amount of food aid it had received less than a year before (Library of Congress 1995). However, contrary to its purpose, food aid did not lessen malnutrition rates and as data presented below shows, by the end of Rawlings' authoritarian rule, hunger rates were alarming. Food aid in alone was not enough to improve Ghana's food insecurity levels. Also, with a government that persistently emphasized the need to increase production for export, self-sufficiency (a necessity of development) was simply not feasible for Ghana because farmers could devote neither time nor resources to growing crops for consumption. During this time period, Ghana mass-produced cassava, maize, plantain, rice, sorghum, millet, and yam. 
Of these crops, Ghana was only self-sufficient in producing plantain. All other crops were produced for export purposes yet simultaneously imported as part of the state's food aid plan (Codjoe 2007; Library of Congress 1995). Accordingly, "food supply per person dropped almost 30\%" (Codjoe 2007).

As a result of the lack of government support and contribution to the public sector and the populace's social struggles, the ERP also triggered significant declines in government programs dedicated to employment, health, and education. For instance, spending on social programs, including health, education, and welfare,
declined drastically to between 4.7 and 5 percent. As a percentage of
GDP, expenditures on health care fell from 1.2 percent in 1970 to 0.26
percent in $1980-83$; during the same period, spending on education
dropped from 3.9 percent to 0.85 percent. (Library of Congress 1995) This left many individuals un/underemployed, impoverished, malnourished, and undereducated. Directly impacting food security and general health, plummeting employment opportunities and rates left Ghanaian doctors and nutritionists with no other option but to flee from Ghana to countries that provided better business opportunities. Showing signs of "brain drain," Ghana's health care professionals swarmed to Saudi Arabia in droves. In the 1980s, the number of Ghanaian physicians working in Saudi Arabia exceeded the number of those still working in Accra, Ghana's capital and most populated city (Sowa 2002). According to data compiled by the African Renaissance Ambassador Corporation (ARA Corp.), in the 1980s, roughly 60 percent of Ghana's doctors emigrated (ARA Corp. n.d.).

Similarly, with practically no government assistance allocated to education and the growing dropout rates that resulted from students leaving school to try to earn a living for themselves and their families, corresponding teacher unemployment numbers spiked. Similar to the fleeing of doctors, there was an outpour of educators to states that had 
stable education systems. As Nii Kwaku Sowa explains, Nigeria accepted and benefited from waves of Ghanaian teachers who moved to Nigeria because its booming oil reserves fostered government, financial support of education and led to thriving schools. In turn, with few teachers remaining in Ghana, students who remained in school received a deficient education that left them unprepared for the ominous job market (2002).

With equally diminishing employment rates across all other work sectors, the majority of Ghanaians were forced to either work multiple jobs or resort to criminal behavior as a survival strategy (Herbst 1993, 31). However, neither strategy increased average income rates enough that citizens could afford health care and nutritious foods. Even among those with stable employment, access to these necessities was severely limited by simultaneous decreases in pay and increases in the price of goods and services. Even for those who were employed, "serious distortions in the pricing system with inflation mounting to 3-digits as a result of administrative controls over prices and exchange rates caused a drastic decline in real wage such that in 1983, the wage index was only 33\% of what it was in 1977 or 67\% of its level in 1960" (Baah-Boateng 2004, 12). In all, Ghana's authoritarian years were fraught with growing un/under employment rates, a decrease in average wage, and the devaluation of the cedi, which led to increased consumer prices and the growing inability of citizens to afford consumer goods. In 1988, consumer prices were on average four times higher than in 1985 (Library of Congress 1995). Furthermore, the FAO's Domestic Food Price Level Index shows that Ghana's food price level steadily increased from 2.99 in 1991 to 3.16 in 1995. However, in 1996, with three years of democracy underway, this decreased to 2.92 and continued to fall significantly over time (Food and Agriculture Organization 2013a). Index scores of later 
years are elaborated on in the sections below.

Existing data concerning Ghana's hunger and malnutrition rates in the 1980s and early 1990s shows that, when combined, the abovementioned consequences of Rawlings' authoritarian rule and the ERP created a significant ramification for the majority of society: severe food insecurity. This data shows the mass and prolonged presence of food insecurity throughout varying work sectors, geographic regions, and the entire country. First, as specified in chapter three above, the GHI for the year 1990 was taken from averaging data from the years 1988 to 1992, all of which are pre-democratization years besides 1992, the year of Ghana's democratization and first democratic election. Because the effects of converting from authoritarianism to democracy are not immediate, the 1990 GHI score is a true representation of Ghana's hunger levels in the years leading up to democracy. In 1990, the GHI score was 21.4 compared to 16.3 (serious hunger), only six years later. In 1990, Ghana's 21.4 hunger level was considered alarming, the IFPRI's second-most severe hunger classification.

Data of the percent of malnutrition prevalence over time shows that in 1988 roughly 30 percent of Ghana's population was underweight. Similarly, the percentage of undernourished citizens was 34 percent in 1991 (Wiggins and Leturque. 2011). Both of these years and their percentages predate democracy. Substantial decreases in these percentages would not occur until 1996, only four years after democratization. Improvements to percentages of both "underweight" and "malnutrition" are discussed in detail in the sections below. In addition to these primary findings, other indicators of Ghana's high food insecurity levels are Ghana's per capita Dietary Energy Supply (DES) requirement deficiency and low per capita daily caloric intake. As explained in chapter 
three, the per capita DES requirement is 2,118 calories. At the start of Rawlings' authoritarian rule (1982), the per capita caloric intake was 1,600. While this figure started to increase shortly after, it was short-lived and in 1990 sat at 1,800, only 200 calories above its 1982 standing. However, from 1994 to 1996, only a few years after democratization, Ghana would reach and begin to vastly exceed the DES requirement for the first time in decades (Emmanuel Aggrey-Fynn et al. 2006). As explained below, this was one of many food security and health benefits to emerge out of democratization. Post-democratization figures showing the changes in Domestic Food Price Level Index, GHI, the percentage of malnutrition and underweight, and DES are provided in the case study findings below. 


\title{
CHAPTER V
}

\author{
FINDINGS AND ANALYSIS: THE 1990s AND BEYOND - GHANA'S \\ UNPRECEDENTED IMPROVEMENTS RESULTING FROM DEMOCRACY
}

With the food security concerns of previous decades still looming, the 1992

elections and democratization marked a time of anticipation about Ghana's potential for development. As Mohammed Awal best explains,

\begin{abstract}
...Ghana's transition to democracy was for many, a reaction at some level, to the emerging challenges of the ERP/SAP (Abrahamsen, 2000; Hutchful, 2002; Ninsin, 2007). A democratic framework, it is thought, will create not only a new platform for the emergence of a popular, legitimate, and responsible constituency for continued economic reform (Whitfield, 2009a); but it will also, it is thought, establish and deepen a new democratic governance framework for achieving sustainable development (World Bank, 1989). (Awal 2012, 97)
\end{abstract}

With democracy at the forefront, Ghana ushered in an era heavily focused on addressing the needs and struggles of society: most notably in this case, food insecurity. Whether implementing efforts to improve food security specifically or implementing efforts and policies that unintentionally impacted food security, Ghana's democracy has fostered an unequivocally more food secure environment than the nation's previous nondemocracies.

\section{Differences in the Ideologies of Political Parties and Presidents}

Variances in the ways food security issues have been addressed have been largely subject to the ruling party's agenda. In reading this chapter, it should be kept in mind then 
that during each presidency the ideologies of the governing political party and the president himself have largely shaped what health and food security initiatives have been implemented. Differences in the NDC's 2012 Manifesto and the NPP's 2012 Manifesto depict this. Within Ghana, the NDC is the more liberal party and the NPP is the more conservative party of these two leading, opposing political parties. The NDC has remained heavily committed to addressing the following issue areas: improving education, health rates, and poverty rates, agricultural modernization, expanding infrastructure, and ensuring a transparent and accountable governance. The NPP's agenda is rooted in economic transformation, providing basic amenities and supporting job creation, safety, promoting enterprise, and keeping Ghana on the global map. Since democratizing, Ghana has primarily been governed by presidents of NDC origin. Rawlings was the first NDC president, in office from 1993 to 2001. The 2001 election and inauguration of John Kufuor ushered in an eight-year NPP presidency. In 2009, John Atta Mills (NDC) took office, but he died on July 24, 2012 during his third year as President. John Dramani Mahama, the Vice President of Ghana at the time, was inaugurated that same day and is the incumbent President of Ghana, representing the third NDC presidency since 1992. While each president has had his own agenda, as discussed below, the NDC and the NPP have quite similar political ideologies and goals and have largely implemented similar agendas. As explained in "Change for a Better Ghana," "the NDC and NPP are not sharply differentiated along ideological lines. There is a gap between the ideological images constructed by the parties and the actual policies pursued by those parties when in government...the policies pronounced and pursued by the NPP and NDC governments since the 1990s have not been that different" (Whitfield 2009, 
630).

In the years of NPP presidency, Kufuor and the NPP party introduced efforts and policies to improve the economy, agricultural industry, and hunger levels at the national level, local level, and for the wellbeing of individuals' economic status (Foster 2011). In Kufuor's publication “Ghana's Transformation,” he explains his ideological approach during his presidency:

\begin{abstract}
My administration aimed to ensure a more efficient and productive agricultural base that would become the engine of the economy by providing food security, ushering in industrialization, creating jobs, and increasing export revenues. The critical need was-and is-for an agricultural transformation. (Kufuor 2011)
\end{abstract}

Out of this, from 2001 to 2008, the GOG's most significant policy implementations and programs were the Ghana Poverty Reduction Strategy (GPRS) of 2003 and GPRS II (2006), legislation to increase health care professionals' salaries and benefits (2004), and the Food and Agriculture Sector Development Policy (FASDEP) of 2002 and FASDEP II (2007). Each are discussed in depth below.

While each president from NDC origin (Rawlings, Mills, and Mahama) has had his own political ideologies and plans to progress Ghana's development, collectively these presidents' food security principles have been very similar and have expanded upon each others' previous emphases. Together, they have focused attention on citizens' political and voting rights, general health, infrastructure advancements, agriculture industry advancements, the government's relationship with CSOs, and improving food security levels. However, each president has prioritized and addressed certain issue areas more so than others.

Starting with Rawlings' presidency from 1993 to 2001, Rawlings was most concerned with good governance, citizens' health and wellbeing, and agricultural 
development. In “The Legacy of J.J. Rawlings in Ghanaian Politics, 1979-2000,” John Adedeji presents Rawlings' priorities. He states that Rawlings' greatest efforts were "focused on the exploited and poor in Ghana, and his revolutionary 'power to the people" ideology (Adedeji 2001). He also focused on “rebuilding Ghana's crumbling infrastructures including roads, hospitals, and electricity..." (Adedeji 2001). Throughout his two-term presidency, Rawlings and his administration created Ghana Health Services (1996), the Water Resource Center (1996), the Community Water and Sanitation Agency (1998), the Serious Fraud Office (1998), and passed the Citizenship Act (2000).

President Mills, although only in office for less than a complete term, has been largely credited with having a political ideology and plan of action heavily devoted to good governance, human rights, economic development, and improving the health and wellbeing of Ghanaians and citizens of all other African countries (World Profile Group 2013). After his passing, United States President Barack Obama praised Mills for his dedication to human rights efforts for all Ghanaian citizens (BBC News 2012). Furthermore, according to the World Profile Group's publication of "Ghana: Accelerating Africa's Revival," Atta Mills is credited with reducing Ghana's inflation to single digits,
maintaining macro-economic stability, and avoiding hikes in food
prices, applying good governance in the public sector, and conducting a
transparent and educated development of the natural resources sector.
His vision...included stimulating agriculture and industry with oil
revenues, accelerating infrastructure developments, and creating jobs
through improved social services such as health, education, and utility
provision, especially energy and water. (World Profile Group 2013,2)

Out of Mills' vision and goals for Ghana, he and his administration implemented the Breadbasket Initiative (2010), the Ghana Agricultural Insurance Programme (2011), and a 2012 GOG budget heavily focused on increasing infrastructure spending for roads, highways, and transportation issues. 
President Mahama's ideology has been on point with Mills' previous plans. In his 2014 State of the Nation Address, Mahama proclaimed his commitment to expanding and improving good governance, the agriculture industry, food security, self-sufficiency, and building working relationships with CSOs (Parliament of Ghana 2014). While many of Mahama's ideologies, efforts, and plans for Ghana's future are largely in line with that of previous NDC presidents, he has placed a greater emphasis than his predecessors on strengthening the GOG's relationship with CSOs. One of the greatest examples of this administration's improved relationship with CSOs has been the GOG's support of and involvement with agriculture and food security CSOs such as the Ghana Coalition of Civil Society for Scaling Up Nutrition (2013).

To best highlight all of the food security initiatives and advancements that have occurred in the name of democracy, the remainder of this chapter is broken down into two main sections to first portray how the main mechanisms of democracy, as discussed in the literature review, have developed in Ghana. These sections are Political Stability and Government Effectiveness and Political Participation and Government Accountability and Proficiency. Most importantly, within both of these sections, an analysis is given as to how these developments have positively impacted food security specifically. Finally, to show the extent that food security ratings have increased during Ghana's two decades of democracy, the study revisits the indicators analyzed above, the Domestic Food Price Level Index, GHI, malnutrition and underweight percentages, and DES. 


\section{Political Stability and Government Effectiveness}

In looking back at Kwame Nkrumah's pre-independence promise that, if Ghana could achieve self-government, the country would become a paradise within ten years, it seems that Ghana's official democratization in 1992 was long past due in the hearts and minds of Ghanaians. However, the ways that democracy has been successful in bettering the lives of the populace show that while Ghana may not be a "paradise," Nkrumah was not incorrect in believing that self-government (democracy) would have a positive impact on the nation. Undoubtedly, democracy in Ghana today is still fragile; however, political stability is progressing and is unparalleled by any other time in Ghana's history. This has allowed the general public to shed light on and hold government accountable in ways it never could or had before (Merz 2011). The following subcategories show the many ways in which this finding has proven to be true amongst Ghana's political and governing systems since 1992 .

\section{The Political Party System and the Political Environment}

Regarding Huntington's standards of political stability, Ghana has since democratizing been very successful in institutionalizing. While Huntington argued that democratizing before institutionalizing political parties can be dangerous and can create political instability in many Third World countries, Ghana's experience seems to be a case that contradicts this argument. Lindsay Whitfield argues that within Ghana, institutionalization emerged out of the Fourth Republic, simultaneously with democratization. She states that, "in the Fourth Republic, power is not consolidated in individuals but rather through the idea of the party and the party machinery...parties were 
not really institutionalized before... [during] authoritarianism and bouts of military rule, parties only emerged for short periods of time before being disbanded again" $(2009,640)$. Ghana's institutionalization went hand in hand with its democratization, leading to regularity, stable roots, legitimacy, and an organized political party system (Osei 2012). Perhaps what makes Ghana's political system successful is its two-party system consisting of parties that are rooted in political and social ideals and not the political itinerary of one political elite, and its strong political party support and involvement of citizens (Osei 2012). As Whitfield best articulates,

...Ghana is different from several African countries where parties split or form around leaders, who bring their popular support base with them. It is also different in that elections are not dominated by ethnic politicization, because the two main parties in Ghana have a strong political support base in most regions and party identification is based on cross-cutting social cleavages of which ethnicity forms only one part. $(2009,621)$

As a result, Ghana's political party system is characterized as being a "stable party" system (Lindberg 2007).

Since democratizing, Ghana’s political environment has transformed drastically and rapidly. Political leaders and citizens have progressively begun to accept and abide by the democratic standard of requiring a nonviolent and stable political environment in which all people are able to fearlessly participate. As expected, in shifting from a longstanding history of authoritarian rule in which authoritarian regimes' opinions and decisions were end-all be-all, citizens were not quick to criticize or make demands of government. Therefore, until the mid- to late-1990s, citizens were skeptical about what part they would now play in the political arena and governance. As a result, confidence in democracy and Ghana's classification as a democracy was not initially wholly felt. Proving that citizens' trust increased significantly over time, Afrobarometer, “an 
African-led series of national public attitude surveys on democracy and governance in Africa," provides survey data regarding citizens' opinions about Ghana's developing democracy (Afrobarometer 2012a). According to "Popular Attitudes Toward Democracy in Ghana: A Summary of Afrobarometer Indicators, 1999-2008,” since 1999, "satisfaction with democracy has risen more than 25 percent since 1999" (Afrobarometer $2009,1)$. Furthermore, the percentage of citizens surveyed that labels Ghana as either a full-fledged democracy or a democracy with minor problems has risen from 69 percent in 1999 to 83 percent in 2008 (Afrobarometer 2009). As an outside, impartial organization, Freedom House supports these findings in assessing that Ghana has since democratizing grown from being "partially free" to "free" (Freedom House 2013). "Table 1. Freedom in Ghana" presents this data, showing freedom levels for every other year since 1990 (Freedom House 2014).

Table 1. Freedom in Ghana

\begin{tabular}{|c|c|c|c|}
\hline & Country Status & $\begin{array}{c}\text { Civil Liberties } \\
\text { Rating / } 7\end{array}$ & $\begin{array}{c}\text { Political Rights } \\
\text { Rating / } 7\end{array}$ \\
\hline 1990 & $\mathrm{NF}$ & 5 & 6 \\
\hline 1992 & PF & 5 & 5 \\
\hline 1994 & PF & 4 & 5 \\
\hline 1996 & PF & 4 & 3 \\
\hline 1998 & PF & 3 & 3 \\
\hline 2000 & PF & 3 & 2 \\
\hline 2002 & F & 3 & 2 \\
\hline 2004 & F & 2 & 2 \\
\hline 2006 & $\mathrm{~F}$ & 2 & 1 \\
\hline 2008 & F & 2 & 1 \\
\hline 2010 & $\mathrm{~F}$ & 2 & 1 \\
\hline 2012 & F & 2 & 1 \\
\hline
\end{tabular}

*Note: NF - Not Free; PF - Partly Free; F - Free

Until 2003, combined average ratings for Political Rights and Civil Liberties:

1.0-2.5 = Free; 3.0-5.5 = Partly Free; 5.5-7.0 = Not Free.

2003 and beyond, combined average ratings for Political Rights and Civil Liberties:

3.0-5.0 = Partly Free; 5.5-7.0 = Not Free. (Freedom House 2014).

The lower the score, the freer

What these statistics show and their pertinence to the political environment of 
democracy in Ghana are based on the non-violent, open quality of the political system and the comfort, safety, equality, and freedoms that citizens believe in and rely on within this system. According to surveys conducted in 1999, 2005, and 2008 in accordance with the above article, when asked how political leaders should be selected, between 86 and 90 percent of respondents proclaimed that leaders should be selected via "regular, open, and honest elections" (Afrobarometer 2009, 5). Subsequently, when asked how free and fair the last election was, the percentage of respondents stating that elections were entirely free and fair or were free and fair with minor problems increased from 62 percent in 1999, to 77 percent in 2005, and to 83 percent in 2008 (Afrobarometer 2009, 10). In all, the majority of the electorate believes that democratic elections are the most successful and fair means of choosing political leaders. While some elections may not run as smoothly as others, for instance, the 2008 national election discussed below, the electoral process is deemed by citizens and has proven to be healthier for Ghana than previous methods of authoritarian and military rule. This achievement has been one of Ghana's greatest successes in improving its political stability and dedication to governing by and for the people. According to the Institute for Democratic Governance (IDEG), "Since the restoration of civilian rule in 1993, Ghana's most notable achievement has been the progressive improvement of electoral management and the increasing acceptance of election results as fair by participants and observers alike" $(2007,1)$. For Ghana, universal acceptance of elections as free and fair has been crucial to their overall development in two key aspects: 1) acceptance of elections shows that citizens believe that they can make a difference within the political system and make demands of government regarding their needs, and 2) acceptance of elections helps prevent citizens 
from reverting to the use of political violence, which in turn offers an environment in which all citizens are safe and able to vote for political leaders and policies that benefit their health and well-being.

Ghana's nonviolent political environment has also fostered higher citizen involvement and political participation rates (discussed in Political Participation and Government Accountability and Proficiency to follow). What makes modern Ghana drastically different from its authoritarian years and even from other African countries attempting to democratize is the country's ability to refrain from reverting back to violent measures in order to make political change. Differently from citizens during the nation's authoritarian years, Ghanaians today do not need to utilize violent tactics to get government attention. Furthermore, they recognize that in utilizing violent mechanisms, democracy suffers because if society does not collectively abide by democracy's nonviolent requirements, democracy itself has no standing or power within society. This consequently would destroy democracy and potentially return Ghana to authoritarian rule, an outcome that has plagued many other African countries. Viewing this as a serious threat to the nation's future, Ghanaians and political leaders alike have since democratizing accepted and worked diligently to prevent any and all violent, political uprisings (Ace Project 2009).

In "Government Accountability and Responsiveness: Evidence from Afrobarometer Round 5 Survey in Ghana," 93 percent of Ghanaians surveyed said that they would never use political violence (Afrobarometer 2012b). Similarly, as George Ayittey discusses in "Opinion: What Ghana Can Teach the Rest of Africa about Democracy," political leaders have taken a stance against non-violence and have largely 
refrained from making accusatory statements when an election does not end in their favor (Ayittey 2012). This has set precedent among the electorate to encourage non-violent elections and to use nonviolent political participation as a tool to improve Ghana's state as a developing country committed to improving citizen wellbeing. The greatest proof of Ghana's success in this instance is its ranking as the second "most peaceful country in Africa" (Government of Ghana 2007).

Furthermore, while democracy has grown in Ghana, so have levels of political stability and absence of violence. For instance, findings of the World Bank's Worldwide Governance Indicators show that between 1996 to 2012 Ghana's political stability levels and absence of violence have progressively improved. Findings are presented on a scale of -2.5 (weak political stability and absence of violence) to 2.5 (strong political stability and absence of violence). In 1996, only four years after democratization, Ghana's score sat at -0.32 ; however, by 2012, this score was 0.10 (The World Bank 2013). "Table 2. Political Stability and Absence of Violence” displays Ghana's progression over time. Because Ghana is a new democracy that is still adjusting to the use of nonviolent

\begin{tabular}{lcc}
$\begin{array}{l}\text { Table 2. Political Stability and Absence } \\
\text { of Violence }\end{array}$ \\
\hline & Score & Election Year? \\
\hline 1996 & -0.32 & Yes \\
1998 & -0.24 & \\
2000 & -0.44 & Yes \\
2002 & -0.24 & \\
2004 & 0.01 & Yes \\
2006 & 0.02 & \\
2008 & -0.01 & Yes \\
2010 & 0.02 & \\
2012 & 0.10 & Yes \\
\hline
\end{tabular}

political participation, the levels of political stability and absence of violence have been lower during election years. However, the overall trend shows that Ghana has already 
experienced great improvement and continues to undergo a slow, yet significant development in its levels of political stability as it grows as a democracy.

The best example of the nation's progress with political violence and its impact on preserving democracy was the 2008 national elections, which ended with "a less than $0.5 \%$ margin of victory in a highly politicized environment" (United Nations Development Program 2012). Proving to be Ghana's closest election and biggest threat to democracy to date, the electoral environment slowly started to create disorder and chaos as society began to replicate previous habits of alleging that the election was fixed. Some citizens began threatening political violence. However, as Jarreth Merz explains, the citizenry as a whole united and abandoned their previous routine and desire to create a violent uproar and redirected their attention and efforts instead to proclaiming and proving that they wanted a peaceful election and transfer of power. With this solidarity and society's commitment to the democratic political process, Ghanaians returned to the polls three times to recast their ballots before a clear winner was named (Merz 2011). Out of this event, the observer sees that, when tested, the strength of Ghana's democracy and the people's desire to retain democracy proved to be much stronger than their propensity to resort to political violence. Merz reiterates that out of this struggle, Ghanaians have largely come to accept and have proven to other African countries that violence is no longer a feasible tactic for making political change if democracy is to be achieved and maintained. Simply, the lesson learned is that within democracy, "you don't have to rebel. You have the freedom to choose, and with that choice comes a responsibility" (CNN 2011). The Ibrahim Index of African Governance's (IIAG) "safety and rule of law" indicators show the interrelated nature of safety (lack of violence) and the rule of 
law within democracy. The IIAG measures safety and the rule of law based on the following combined subcategories: rule of law, accountability, personal safety, and national security. Findings demonstrate that when combined, safety and the rule of law have been consistently high during the last decade (Mo Ibrahim Foundation 2014).

\section{Government Effectiveness: Preventing Corruption and Abiding by the Rule of Law}

As presented in the literature review, Wise and Sainsbury argue that, differently from that of non-democracies, within democracies "more potential actions are generated for consideration, there is better monitoring and control of government and government bureaucracies, decisions are more likely to reflect the wishes of the majority, and hence government decisions are more likely to be health promoting" (Wise and Sainsbury 2007, 181). While this quotation is presented as a generalization about how democracy's focus on government effectiveness, as defined and described in the literature review above, may positively impact citizens' health rates, Ghana's progress in government effectiveness shows that this is not only a generalized theory but also a reality in this specific case. The GOG has incorporated preventative measures to tackle and suppress corruption and has created legislation and sectors of government specifically responsible for ensuring that government officials and agents at all levels abide by the rule of law. In addition to taking measures to ensure that all citizens are equally held accountable to Ghanaian laws, the GOG has also devoted the last thirty years to working to equally distribute government attention and social services. When coupled, these advancements have drastically contributed to Ghana's success in using government effectiveness to improve food security levels. 
Still skeptical about how committed government is to fighting corruption, roughly 50 percent of Afrobarometer survey respondents believed that "some" elected officialswhether or not they are in the office of the Presidency, members of Parliament, or government officials - were corrupt (Afrobarometer 2012b, 30). Even with this common conception of corruption within the GOG, it must be stressed that even though corruption has not and likely cannot be completely eliminated, since democratizing, the GOG has instituted many successful efforts to minimize it. With the establishment of the 1992 Constitution, the GOG instituted the Commission on Human Rights and Administrative Justice (CHRAJ), which serves as not only a human rights institution but also as an agency that serves to prevent corruption so that human rights can be fully reached. To this end, the commission investigates any and all reports of corruption. This allows everyday citizens to report experiences with, and to hold accountable, corrupt government officials. No individual is exempt from investigations of corruption. Furthermore, the CHRAJ will first tell individuals that are found guilty of corrupt acts that they have three months to make the necessary changes. After this point, the commission will take legal action via the court system (Access 2013). The most profound indicator of the CHRAJ's success and effectiveness is exemplified in its 2010 reports of the corruption complaints and administrative justice complaints that it handled for that given year. As reports show, the commission investigated 38 cases in which governing officials were accused of corrupt acts. Additionally, the commission investigated 978 allegations of administrative injustice. The most common allegations were "unlawful dismissal" of which there were 131 cases and "unlawful termination of appointment" of which there were 125 cases (Commission on Human Rights and Administrative Justice 
2010). Herein we see that the CHRAJ is still honoring its promise and responsibility to investigate all claims of corruption that are brought before the committee.

Similarly, in 1998 Ghana established the Serious Fraud Office (SFO) and in 2006 passed the Whistleblower Act to encourage citizens to report more instances of corruption (Parliament of the Republic of Ghana 2006). In addition to passing the Whistleblower Act, the SFO has been effective in fighting fraud and corruption within Ghana because of its success in investigating significant corruption and fraud cases that if not investigated would have been detrimental to society and the federal government. As Sam K. Asibuo mentions, such cases include, but are not limited to, the following: Capital Telecom, Council of Indigenous Business Association, the State Enterprises, A Life Supermarket, Impregillo Group of Companies, and Sabat Motors Limited. The effectiveness of the SFO lies in the powers it has when conducting investigations. As explained by Alan Doig, David Watt, and Robert Williams, SFO officers have "police powers, the right of access to and seizure of documents, freezing of accounts, the right of prosecution (with approval of Attorney-General), the power to pay rewards, and the expectation of co-operation of, or powers of, other bodies as required in pursuit of its investigations" (2005). While there have been cases in the SFO's history that the government did not take seriously or did not respond to in the way in which the SFO hoped for, the SFO has shined light upon and drawn public attention to many issues of corruption that would have otherwise remained in the shadows (see International Association of Anti-Corruption Authorities 2012, Ghana Web 1999, and Asibuo 2001). Undoubtedly, corruption is still an issue of concern as it is within any state; however, in recent decades, Ghana has made unparalleled strides to ensure that 
corruption does not return to its previous frequency. This is best exemplified by two separate cases of corruption within the national government and subsequent prosecution. In 2001, an NPP appointed minister of sports was charged, prosecuted, and found guilty of fraud (IDEG 2007b). In 2012, Alfred Agbesi Woyome, an avid supporter of the NDC political party, was charged with attempting to bribe governing officials. Three others were charged with "aiding and abetting a crime." (Reuters 2012). While this may be perceived as a step backwards for the NDC party, the conviction of corrupt political figures is a step forward for the government and people of Ghana.

Even more impressively, Ghana's pledge to follow the rule of law, as stipulated in the 1992 Constitution, has been one of its greatest democratic successes. With the acceptance of democracy has come a distinct separation of powers. Most notably, the judicial branch has grown in power within the triad of federal branches and via the Constitution has been given the specific authority of "judicial independence." The overwhelming power of the executive branch, a constant struggle of pre-democratization, has also been given much needed attention and revision. One of the greatest changes to the executive branch since the implementation of the 1992 Constitution is that it is now held strictly accountable for its actions and misconducts:

\footnotetext{
Executive powers are subject to checks by Parliament, the judiciary, and to a limited extent the Council of State, an advisory body, as well as by constitutional oversight institutions such as CHRAJ. Disobedience of a decision of the Supreme Court on the constitutionality of any act is a crime, and a ground for removing the president or vice-president from office. (IDEG 2007b, 7)
}

Existing data shows that the GOG now holds honoring the rule of law with utmost importance. According to the "Rule of Law Index, 2012-2013" prepared by members of the World Justice Project, Ghana ranks first in the region and twenty-ninth in the world in its protection of citizens' fundamental rights. Ghana is also accredited for having an 
effective system of checks and balances. Internationally, Ghana is ranked twenty-third and is regionally ranked second only to Botswana (Agrast, Mark David et al. 2013).

Using Government to Better the Lives of the Populace. By devoting itself to holding all individuals accountable to the law, Ghana is committed to impartiality and fairness within its growing democracy. In this case, honoring impartiality and fairness not only applies to holding all citizens responsible for their crimes but also gives government the obligation to work just as diligently to improve all citizens' standards of living. As a result, the GOG has made the following efforts: focusing on reducing the nation's poverty level and addressing the populace's health care needs. First, as part of the nation's growing focus on development and equality-based policy implementation, the GOG created the Ghana Poverty Reduction Strategy (GPRS I) in 2003 and the GPRS II, an extension of the GPRS, in 2006. The main priority of both the GPRS I and II was to enhance livelihood and reduce poverty throughout all of Ghana via a government emphasis on social services distribution and good governance. Most applicable to health, GPRS I and II were largely successful in increasing the government budget allotted to increasing all citizens' access to education, health care and organizations focused on improving health and wellbeing, safe water, and environmental health (Government of Ghana 2007). Because of GPRS I and II and other poverty-reduction strategies, the percentage of citizens living in poverty has progressively decreased over the last, roughly, 15 years: average rate of $1.5 \%$ per year, from high of $51.7 \%$ in $1991 / 92$ to $39.5 \%$ 
in $1998 / 99$ and then further to $28.5 \%$ in $2005 / 6$ (GLSS 5). The accelerated economic growth and poverty reduction put the country en route to achieving the key poverty Millennium Development Goal (MDG) well ahead of schedule. (Government of Ghana 2007, 24)

Another example of the energy that the GOG has put forth to improve citizen livelihood is the government's recent focus on reducing "brain drain" among health care professionals. In 2004, the GOG initiated many incentives to help keep doctors, nurses, pharmacists, and other health specialists from emigrating. First, the GOG stepped in to ensure that all health care workers received better salaries, benefits, and general treatment within their fields. As James Antwi and David Phillips conclude in their study of the impact of wage reform in the public sector, increasing wages within the medical field has already opened the door to more and better health care providers within Ghana (2012). Secondly, the government introduced "paid study leave" and programs such as the College of Physicians and Surgeons to ensure that medical personnel educated in Ghana are also given post-graduate training within Ghana (Awumbila et al. 2008).

Even with these government initiatives, "brain drain" has lessened but is still a cause of concern within Ghana. However, in 2004, "health worker brain drain" was at one of the lowest points in the nation's recent history (Awumbila et al. 2008). Furthermore, citizens today have already experienced more opportunities for better and more accessible health care. Also, with the increase of available health workers, the GOG has been able to increase the number and quality of health clinics in Ghana's historically most deprived communities. The GOG has also prioritized maternal health care. To address the reality that pregnant women are among Ghana's most vulnerable, the GOG instituted the National Delivery Exemption Policy which offers free delivery care for all pregnant women (Witter et al. 2009). 


\section{Political Stability, Government Effectiveness and Food Security}

The progress and growth of Ghana's democracy, as detailed above, lay the foundation upon which many food security advancements have been made. In stepping away from its authoritarian tendency to prioritize the needs of the wealthy few over the needs of the masses, the GOG as a democracy has applied its values of honoring the 1992 Constitution, the rule of law, equality, and representing the populace to improving its food security status. Most notably and applicable to the majority of the nation's general population, the GOG has worked endlessly to improve hunger levels of the country's most food insecure and disadvantaged: largely the working class and Ghana's youth. In democratizing the GOG ushered in a citizen-centered approach to governing. Rather than using citizens (especially export farmers and other members of the working force) for the benefit of government, the GOG started using government to benefit the food security needs of citizens, a complete transformation from its pre-democracy days. As former President John Kufuor discussed in an interview with Elly Kaganzi of the FAO, "health, nutrition, social justice, infrastructure and better livelihoods all need to be addressed in order to achieve food security in any country. It requires government commitment coupled with support from the private sector, civil society and the populace...in ensuring eradication of food insecurity and poverty" (Kaganzi 2013). The GOG has publically acknowledged and displayed that it is committed to making these necessary efforts.

Cultivating Improved Production Among Farmers. The way in which the GOG has aided and supported the nation's farmers is one of the greatest displays of the GOG's citizencentered commitments and the impact that said commitments have had on Ghana's food security levels. In the years leading up to democratization, the most food-insecure individuals were undoubtedly farmers, who for decades powered the country's increase in 
exports and economic growth but were themselves going hungry. During authoritarian rule then, farmers served as a pawn of the GOG who prioritized Ghana's international image and economic growth over the needs and struggles of the people. Working to mend the government's fragile relationship with farmers, the GOG has made necessary changes to its expectations of and aid to the farming industry. Working cooperatively with farmers and NGOs, the GOG has initiated many successful production and distribution-based programs. With this support, farmers—-who now account for 56 percent of the labor force - have in turn been able to greatly expand upon the production of crops grown for internal sale and consumption, a key influence in the country's declining hunger levels (United States Government 2013; Ghana Business News 2013a).

The GOG's most successful agricultural production programs have been the Ghana Agricultural Insurance Programme (GAIP) and farmer education programs such as the Breadbasket Initiative and "The Role of Agriculture in Achieving Middle-Income Status" workshop. GAIP was established in 2011 as an initiative of the National Insurance Commission (NIC), a government-based commission effective under the Insurance Act, 2006 (Act 724), with the support of the German International Cooperation (GIZ) (Ministry of Food and Agriculture: Republic of Ghana 2011; National Insurance Commission 2009). Directly influencing the creation of GAIP, in 2010, economists and scholars Dean Karlan et al. conducted a pilot study and experiment in rural Ghana in which local farmers were surveyed about their perception of economic risk in the farming profession (Karlen et al. 2010; Karlen et al. N/A). Their findings show that in many instances, farmers neglected to apply for bank loans out of fear that extended, unfavorable weather would reduce their yields, income, and ability to make loan payments. Similarly, as discussed by Innovations for Poverty Action (IPA), farmers were 
often hesitant to invest in new technologies and techniques for fear that they may fail:

\begin{abstract}
Underinvestment in agricultural inputs such as fertilizer, hybrid seeds, or labor is thought to drive low crop yields in Africa and other parts of the developing world. Several factors may help explain why farmers fail to invest in such potentially profitable inputs. It is possible that they are wary of the riskiness of adopting new agricultural methods or tools - if they invest and their crops still fail, they will have even less money than if they had not invested at all. (2011)
\end{abstract}

In these cases, risk, not an absence of capital, was often the main factor preventing farmers from adopting modern farming techniques (Innovations for Poverty Action 2011).

As a result of these findings, Ghana instituted GAIP as its first crop insurance program. GAIP consists of nineteen insurance companies that provide varying types of risk management crop insurance for everything from small-scale farming to commercial farming (Ghana Agricultural Insurance Programme 2013). As the NIC Board of Directors Chairman Frederick Quaye Nortey explains, GAIP was founded in order to

\footnotetext{
...improve access to agricultural and rural finance, smooth farmers' income and improve food security in both the medium and long term...Through GAIP we...protect our farmers against risks associated with the negative effects of climate change... reduce vulnerability and thus reduce poverty. (Ministry of Food and Agriculture: Republic of Ghana 2011)
}

The general process is as follows: farmers participating in GAIP pay one-tenth of their crop costs to GAIP at the start of each farming season. If twelve successive days pass without rainfall, farmers are given an automatic payout to compensate for this disruption of yields. Specifically, GAIP analyzes data collected by government built and sponsored automatic weather stations (AWSs) which monitor temperature, rainfall, humidity, wind, and other weather changes that could inhibit yields (Oppong-Ansah 2013). Since its origin two years ago, GAIP has made payments to roughly 140 insured farmers (Ghana News Agency 2012). The effectiveness of GAIP is best corroborated by 
farmers' personal experiences. For instance, when asked about his experience with GAIP, Alhaji Alhassan Gunda Zakaria, a large-scale farmer, explained that GAIP has not only helped him but has also been beneficial for the 3,000 smallholder farmers that he directs and supervises on a regular basis (Oppong-Ansah 2013). Similarly, smallholder farmer Suleman Mustapha Simbia stated the following: "I no longer think of losing my yield due to the low or high rainfall. My confidence and love for farming has grown. And this year, I have increased the number of acreages I cultivate from 1.2 to 2.4 hectares" (OppongAnsah 2013). Together, these personal experiences show that the effects of GAIP are evident in both top down and bottom up scenarios. While GAIP is a recent initiative and it is too soon to see how it has positively impacted the very expansive issue of food security, it has already proven to be an effective program at the ground level and shows great potential for changing the future of food security in Ghana. Arguably, with less production pressure on farmers' shoulders, the farming industry as a whole is already able to plant more and new varieties of their standard crops, and to try new approaches and techniques to increase yields. If continued and expanded upon, this could have a very significant and positive impact on food security overall.

Via agricultural extension and advisory services, educating farmers on how best to improve their practice and quality and quantity of their yields has been a significant and crucial stride for the GOG and the country itself. The Breadbasket Initiative of 2010, a program implemented by the GOG's Ministry of Food and Agriculture (MOFA) and supported by the Alliance for a Green Revolution in Africa (AGRA), is an example of this development. The initiative is "aimed at doubling yields, increasing the food security and incomes of around 250,000 smallholder farmers, and creating 15,000 jobs in 
agriculture-related sectors including agro-dealership, marketing, transport, and processing" (Karuga 2012). Historically, especially pertaining to smallholder farmers, staple foods such as maize were scatter-planted in a way that severely hindered the growth and yields of that plant. Until the MOFA and the AGRA started focusing on educating and training farmers to think and act strategically when planting, yields were quite poor. Currently, as part of the Breadbasket Initiative, farmers are educated about the importance of planting in straight lines and with appropriate spacing to maximize yield potential. The initiative has also introduced farmers to the benefits of manure, fertilizer, and compost. As part of their education, farmers are shown how to correctly use these tools to prevent over-fertilization and other negative consequences of improper use (Oppong-Ansah 2011). In a similar fashion, farmers are being taught simple yet effective methods of fighting and counteracting agricultural viruses, diseases, and insects (Gyamfi 2006). With local, small-scale farmers as the prominent target, the initiative is an of-thepeople platform that is greatly helping farmers adopt "best practice" approaches to their existing technique. Similar to GAIP, the Breadbasket Initiative is in its infancy and for this reason, it is difficult to measure how this program has influenced food security. However, the initiative is indicative of progress made to better small-scale farming meant for internal consumption. Over time this will likely perpetuate citizens' access to nutritious foods, creating a healthier citizenry and therefore higher levels of food security overall.

Additional educational opportunities have been presented to the agriculture community via workshops that are held for farmer representatives, legislators, and agricultural experts across the globe with the purpose of working together to improve Ghana's agricultural industry, farmers' livelihoods, and improved food security for the 
populace. An example is "The Role of Agriculture in Achieving Middle-Income Status," a workshop held in Accra, Ghana, in 2007, to inform attendants of the next steps that the country needs to take in order to reach its food security goals. Working collectively, GOG officials, farming representatives, and international specialists, are educating farmers on their crucial role in improving food security. Also, officials are becoming more aware of how they can help farmers and the agricultural industry improve production rates and the quality and availability of that production to Ghana's citizens (FANRPAN 2007; IFPRI 2007).

Other government-supported programs that have positively impacted crop production in Ghana are the Root and Tuber Improvement Programme (RTIP) of 1999 to 2004 and the ensuing Root and Tuber Improvement and Marketing Programme (RTIMP) of 2007 and 2014. The RTIP and RTIMP have together successfully distributed new, more effective, varieties of staple crops to rural and often poor farmers as a means to increase those farmers' yields, increase the farmers' incomes as a result of those yields, and in turn increase the amount of staple foods made available to citizens. In evaluating how successful the RTIP has been, the International Fund for Agricultural Development (IFAD) has stated that

[the] RTIP has been well-managed and successfully implemented with good results in most areas. Its greatest strength was in creating a wellfunctioning nationwide system for multiplication and distribution of improved planting materials. In the process it strengthened numerous institutions, increased farmer access to information, improved production practices and contributed to better household food security. (2003)

The RTIMP has since achieved similar successes and progressed beyond the RTIP (Ministry of Food and Agriculture: Republic of Ghana 2013a).

Just as crucial to production as the quality of the crops themselves, Ghana's irrigation systems had long needed revamping. Founded by the Ministry of Agriculture in 
1977 and now managed and funded by the MOFA of the GOG, the Irrigation Development Authority (IDA) is responsible for investigating potential irrigation plans, managing these plans, and maintaining existing irrigation schemes. To date, this authority has initiated 22 of its own irrigation projects, totaling 6,505 hectares throughout the country. An additional 22 schemes are constructed under the Small Scale Irrigation Development Project (SSIDP) and six schemes are under the Small Farms Irrigation Project (SFIP). In all, the construction of these systems has been most advantageous for rural small-scale farmers; however, currently the IDA is working to more efficiently maintain the irrigation systems that it has developed, as some systems already require more upkeep than the IDA has been able to handle. This then is a remaining challenge of irrigation development in Ghana (Ministry of Food and Agriculture: Republic of Ghana 2013b).

Infrastructure Advancements: Roadways, Water Supply, and Sewage Disposal. While increasing the amount and quality of yields designated for internal use is crucial to generating food security, production is only one the of the many steps in delivering nutritious and safe foods to citizens. Following production, crops must be accessible. Furthermore, crops are inedible without safe water with which to clean and cook food. It is also crucial that citizens have safe water to drink and that human waste does not come into contact with water and in turn be digested. Government developments in these regards have very recently become a priority of the GOG and a crucial step in reducing hunger levels and food- and water-borne illnesses.

Effort to better infrastructure in the way of roadways is a relatively new effort of the GOG, as historically roadway development had been stagnant. Even as recently as 
2011, the World Economic Forum's Global Competitiveness Report argued that inadequate roadways was one of the most problematic issues to overcome in conducting business in Ghana (Oxford Business Group 2012). Equally, infrastructure has been a longstanding concern for farmers needing to take their products to market. Consequently, this has had repercussions for citizens' accessibility. Furthermore, while roadway infrastructure is a new focus of the GOG and it may be too early to measure the degree to which changes have impacted food security, the GOG must be credited for its most recent focus on improving infrastructure as a means to improve human life: “The key theme of the 2012 budget... is infrastructure spending, with a particular focus on transport and energy. It encompasses agricultural, water, health and education facilities as well” (Oxford Business Group 2012). More specifically, the motto of the 2012 budget, "Infrastructural Development for Accelerated Growth and Job Creation," reflects the GOG's intentions to strengthen livelihood, reduce hunger and poverty, and improve general health (Ministry of Finance and Economic Planning: Republic of Ghana 2011). While Ghana's road systems far exceed the roadways of other low-income nations, improving and expanding upon existing roadways and constructing new roadways are priorities of the GOG in its efforts to raise Ghana to middle-income status (The International Bank for Reconstruction and Development / The World Bank 2010). For instance, in 2012 the GOG allocated the highest budgets (of all its ministries) to the Ministry of Roads and Highways and the Ministry of Transport. The Ministry of Roads and Highways received a budget of GHS908 million, equivalent to $\$ 538.35$ million U.S. dollars (USD) and the Ministry of Transport received a budget of GHS99 million, comparable to $\$ 58.69$ million USD. In addition to increasing the budgets of these 
ministries, the GOG has instituted a program referred to as the "Gang of Six," a project to complete six major highways that span throughout the nation (Ministry of Finance and Economic Planning: Republic of Ghana 2011). As reported by the Ministry of Roads and Highways in 2013, the Gang of Six's 2012 budget and 2013 budget, of GHS 3.96 million, will fall short of what would be needed to complete all six highways. However, it is projected that three highways will be completed this year, arguably a step in the right direction for an infrastructure sector that fell by the wayside for years (Ghana Web 2013).

Since democratizing, the GOG has progressed considerably in providing citizens with access to proper sewage facilities and safe water sources, both necessities in reducing food- and water-borne diseases. According to the FAO's Food Security Indicators and as shown in "Table 3. Access to Improved Drinking Water," the

Table 3. Access to Improved Drinking Water

\begin{tabular}{lc}
\hline & Percentage of Population \\
\hline 1990 & 53 \\
1995 & 62 \\
2000 & 71 \\
2005 & 79 \\
2010 & 86 \\
\hline
\end{tabular}

percentage of Ghana's population that has access to an "improved drinking water source" has grown in recent decades. Specifically, between 1993 and 2010, this percentage grew from only 59 percent to 86 percent (Food and Agriculture Organization 2013a). As explained by the International Bank for Reconstruction and Development, "Ghana is one of only five African countries that have already achieved the MDG target for water supply" (The International Bank for Reconstruction and Development / The World Bank 2010, 16). Democratization marked the turning point in addressing Ghana's water safety concerns. In 1996, under Rawlings' democratic administration, the Water Resources 
Commission (WRC) was founded via Act 522 of Parliament. The WRC serves to "regulate and manage Ghana's Water Resources and co-ordinate government policies in relation to them...ownership and control of all water resources are vested in the President on behalf of the people...the WRC [is]...the overall body responsible for water resources management in Ghana" (Water Resources Commission of Ghana 2011a).

The establishment of the WRC spawned the creation and passing of other essential water safety initiatives such as the Public Utilities and Regulatory Commission (PURC) (Act No. 538), which was created in 1997 to monitor the quality of citizens' water supplies and protect citizens from being given water that is not safe for consumption. The PURC was originally focused on addressing these concerns in urban Ghana (Public Utilities Regulatory Commission 2012). One of the greatest failures of water safety in Ghana's authoritarian years was the disregard for rural residents' needs. Again, rural residents represent the vast majority of Ghana's impoverished and food insecure population throughout its history. This neglect fed fuel to the proverbial fire. For instance, "until the early 1990 s...only 2.2 million (28\%) of the rural population had access to improved water whilst urban coverage was over 60\%" (Community Water and Sanitation Agency 2013). In 1998, Ghana made strides to address this by creating the Community Water and Sanitation Agency (CWSA) (Act No. 564), dedicated to serving rural residents and their right to safe water. Shortly after the CWSA was introduced, this responsibility was in large part handed down to local District Assemblies as part of the GOG's decentralization efforts to ensure that citizens can more easily express their needs to their local representatives and in turn see a quicker, more direct, and efficient response. In 2001, the GOG executed its first government-mandated water use regulations via the 
Parliament's approval of the Water Use Regulations Legislative Instrument (L.I.) 1692 (2001). Regulations now stipulate that the WRC is responsible for distributing and monitoring proper water use permits and water rights. As of 2009, the WRC approved and monitored 154 registered water users. In 2010, the WRC increased this number to 171, 63 percent of which provide "domestic and/or municipal water supply" (Water Resources Commission of Ghana 2011b). Together, these initiatives have increased the percentage of Ghana's population that has access to an improved drinking water source as discussed above.

As the GOG has expanded its focus on providing citizens with access to safe and consumable water, it has simultaneously taken equal strides to improve the nation's sanitation system. Throughout the 1970s and 1980s, Ghana's sewage systems were largely insufficient because of disintegrating pipe lines and pumping systems. Because the government's attention was focused on the Economic Recovery Programme, sewage concerns were given minimal attention (Ghana Water Company Limited 2012). However, by the mid-1990s, the GOG recognized the importance of investing in proper sewage systems and the negative health effects that a poor sewage system had on citizens up until that point. However, as part of the CWSA's decentralization process, in 1993, District Assemblies were also put in charge of transforming the rural sewage systems. One year later, Ghana's Environmental Protection Agency (EPA) was founded to monitor and safeguard the environment and, in this case, to ensure that sewage disposal is conducted appropriately and does not intermix with the nation's consumable water sources (Environmental Protection Agency: Ghana 2013; Ghana Water Company Limited 2012). In 1999 , the GOG created its first fully state-owned limited liability company, the Ghana 
Water Company Limited, which is fully responsible for all urban water supply in Ghana (Ghana Water Company Limited 2012).

While these developments have directly aided in reducing food- and water-borne illness throughout the nation, they have also positively impacted food security efforts in unexpected and less direct ways. For example, improvements to sanitation have fostered an abundance of foodstuff businesses and kiosks in locations that used to be contaminated by human waste (The World Bank 2002). The FAO's Food Security Indicators supports these findings of Ghana's slow but effective improvements in the nation's sanitation methods and systems. Between 1990 and 2010, the percentage of Ghana's population with access to sanitation facilities doubled from seven percent to 14 percent, proving that, although gradual, the GOG's efforts are making a visible impact (2013a).

\section{Political Participation and Government Accountability and Proficiency}

In addition to creating a nonviolent, citizen-centric and social services based focus, the GOG has made progress in encouraging and supporting citizens' political participation and working hand-in-hand with civil society organizations to make progress for the betterment of its citizenry and the state's democracy. While historically, during authoritarian rule, the GOG viewed political participation and non-government initiated governance as a burden and hindrance to the government, it now recognizes that citizen involvement and civil society are crucial to maintaining free and fair political involvement of its citizenry and enabling citizens to contribute to the government's decision-making process. 


\section{Voting Rights and Political Participation}

In addition to committing itself to a fair, open, and nonviolent political system, since democratizing Ghana has focused on protecting all citizens' rights to political participation and voting. According to Afrobarometer, in 2008, 78 percent of citizens surveyed said that they felt "completely free" to express their opinions. Similarly, when asked in 1999, 2003, and 2005 if the variable "freedom to say what you think" was better or worse than in previous years, the vast majority of citizens responded with "better/ much better" (Afrobarometer 2009, 11). In an effort to improve political inclusion and equal voting rights among the electorate, modifications to the 1992 Constitution were made in 2000, implementing a new delineation of "citizenship." In years previous to democratization, Ghana struggled to decipher who and what embodies citizenship. Put simply, should non-native residents be permitted to acquire citizenship? Perhaps the greatest obstacle to providing non-native residents with the opportunity to acquire citizenship lay in the general public's resistance and fear that expanding citizenship to non-native born residents would lessen the natives' share of government aid and services (Kobo 2010). To native citizens, providing citizenship opportunities to "outsiders" was perceived as a zero-sum game. However, democratization fostered an environment in which expanding citizenship was no longer deemed as a threat to the masses. Democracy changed this alleged threat because it promised and proved to citizens that democracy's commitment to equality, such as political participation and voting equality and the equal distribution of government attention and social services, would prevent new, non-native citizens from preferentialism and vice versa.

The degree to which native citizens and political leaders overcame this divide 
within society is exemplified in the Citizenship Act, 2000, which was proposed and implemented in order to make citizenship a possibility for persons of all ages, classes, and origin who previously struggled to achieve citizenship (Parliament of the Republic of Ghana 2001). Of course, as with any law, the Citizenship Act came with some criticisms. Most notably, and the key concern expressed by the United Nations Committee on the Elimination of Discrimination against Women (CEDAW), the act allows male citizens' wives to acquire dual citizenship with little restrictions while female citizens' husbands must be "permanently resident" in Ghana in order to become citizens. While this disparity is attributed to the state's need to protect women from marrying men who enter into marriage for the sole purpose of obtaining citizenship, the CEDAW asserts that "it merely serves to reinforce, albeit erroneously, the image of women as being incapable of looking after themselves and always being in need of protection" (CEDAW 2005, 37).

Notwithstanding this discrepancy, the Citizenship Act, 2000, has as a whole been fundamentally successful in efforts to “...provide a [more] fair and non-discriminatory way of establishing citizenship rights. Moreover, since reforms were enacted in 2000, both men and women can pass on Ghanaian citizenship to their foreign spouses and to their children" (IDEG 2007a, 9). These are some, although far from all, of the ways that the democratic government of Ghana has expanded citizenship since 1992 in order to increase political participation and equal voting rights. Proving to be vital to the political system, non-native citizens provide democracy with not only a more diverse electorate, but as Ousman Kobo explains, they are also a political asset because they have created a larger “'vote bank' that must be harnessed to ensure victory during highly contested elections" (Kobo 2010, 68-69). This portion of the population has not only benefitted 
from democracy, but in turn has had a reciprocal influence on democracy via its considerable presence in the electoral process in which it votes in accordance with the needs of the less privileged members of society.

With the exception of the unequal impact that the Citizenship Act has on female citizens' spouses when compared to that of male citizens' spouses, democracy has provided women with an outlet to become more politically active than they were previously allowed to before democratization. This is evident in three key developments: women's right to vote, the formation and growing strength of women's organizations, and the increasing amount of women holding political office. With this growing political activity, women have stressed and pressured the government of Ghana to increase the attention that it gives to women's issues and to implementing laws and procedures that address the needs of Ghana's women.

The women of Ghana have long been as being central to the health and wellbeing of Ghanaian families and households (Fallon 2003; CEDAW 2005). As noted by a survey participant of scholar Kathleen M. Fallon's case study regarding democracy's impact on women's rights, in many Ghanaian homes, women are the head of the household. In addition to this, “...61\% of urban and $53 \%$ of rural female-headed households fall in the poorest $20 \%$ of the population" (CEDAW 2005, 37). With this in mind, it is alarming that women were not allowed to vote and shape the way that government impacts the health and welfare of families until Ghana democratized. Undoubtedly, democracy and its prioritization of giving all people the right to vote has allowed women to emerge from their homes and the theoretical woodwork of society. This is a complete transformation from Ghana's previous years of military rule in which voting and elections did not exist 
(Fallon 2003). Moreover, women have come to use the right and power of their vote to change their health and economic status and that of their families. As one woman activist says:

Elections are very important because for a long time we were under military rule. Elections give us the opportunity to select who we [women] want.... Even if we don't work in the formal sector, we still work hard. Many women are the head of the household. So, if women know the right thing to do, it will help a lot.... We...want to educate women on their right to vote and the importance of voting...(Fallon 2003, 535)

In addition to the right to vote, democracy has given the women of Ghana the opportunity to freely and fearlessly organize. As discussed in “Women's Rights

Organizations and Funding Regimes in Ghana," authoritarian regimes and military rule left women with very few ways to politically organize; however, in the 1990s, postdemocratization, women's organizations flourished:

In this period, there were a growing number of women's organizations involved in various areas of activism...Each worked separately, either delivering services or advocating policy changes on behalf of particular categories of women or women as a whole. As the 1990s wore on, these organizations consolidated and grew in number and strength. Some organizations shifted their activities from service delivery to policy advocacy or combined both activities because of a growing recognition of the importance of policy advocacy for delivering lasting change in women's lives...(Apusigah, Tsikata, and Mukhopadyay 2011, 13)

To date, prominent non-governmental organizations (NGOs) working to improve women's involvement in the political sphere and their lives in Ghana more generally include but are not limited to the Women's Initiative for Self-Empowerment (WISE), the Ghana Association of Women Entrepreneurs (GAWE), the Network for Women's Rights in Ghana (NETRIGHT), and Abantu for Development, the Regional Office for Western Africa (ABANTU-ROWA).

The degree to which women have used their collective political rights and power 
to change their health and wellbeing within Ghana is best embodied in the Women's Manifesto of Ghana. Established by ABANTU-ROWA in 2004, the Women's Manifesto was drafted because the women of ABANTU-ROWA recognized that gender inequality was largely at the root of other significant societal issues such as poverty and hunger (Global Fund for Women 2012). Within this manifesto, women demanded further advances to their equal rights, better and fairer treatment by the government, and better treatment within society. Largely in response to this Manifesto and the actions and demands of other women's organizations, the number of female elected representatives in district assemblies drastically increased in 2006, along with female officials holding office as "Parliamentary Speaker, Police Inspector General and Attorney General" (Global Fund for Women 2012). Also as a result, Ghanaian government has accomplished the following: the establishment of the Domestic Violence Bill, growth and advancements within the Domestic Violence and Victims Support Unit (DOVVSU) of the Police Service, and the creation of the Free Maternal Health Care program (Zaney 2012). Ghanaian women's organizations still utilize their manifesto as a political tool to remind the government of the remaining and emerging women's issues that still need to be addressed.

Similarly, Ghana is now renowned for having a disability rights protection emphasis within the constitution that far exceeds its previous position (IDEG 2007a). As Franklin Oduro explains, "it is estimated that $10 \%$ of the Ghanaian population are disabled, the majority $(55.5 \%)$ being women... Rectifying this deficit was imperative"'(2009, 628). Most pertinent to voting rights and political participation, the 2004 introduction of tactile ballot papers provided blind citizens with an accommodating 
voting method, increasing blind voter turnout. Citizens with mental disabilities have also been given the legal right to vote within public psychiatric institutions (Ssengooba 2013). Most importantly, in 2006, the federal government passed the Persons with Disability Act (Act 715) which serves to eliminate ableism of political, civil, and social origin. Because of these efforts, the disabled have become more accepted and immersed within the political system (Oduro 2009).

As initially touched on above, the 2008 presidential election marked a time of transformation for Ghana's political system. Not only was it an instance in which all citizens had the right to take part in free and fair elections, but most importantly, it was the first time in which citizens showed up in droves to vote, not only once, but three times. For this reason, it is the perfect example of how advancements in equal political rights have drastically improved Ghana's political environment, the voting system, and democracy. Throughout this election, Ghanaians witnessed tallies that were too close to call a president elect. Because of this Ghanaians willingly returned to the polls again and again. This election shows how even in controversial, difficult elections, the citizens have remained committed to exercising their democratic right to participate in elections.

\section{Freedom of Speech and the Media}

Just like its successful voting and elections system, Ghana's media outlets are in the best state in the country's history and among the best in Africa. As George Ayittey explains, the success of democracy in Ghana is largely attributed to the freedom of the press and the ability of citizens to utilize the press as a tool to portray their needs to government. Before democratization members of the media were heavily restricted in 
what information and opinions they could share with the general public. Punishment for distributing a news release that the government disapproved of was often severe. The Rawlings administrations' pre-democracy enforcement of the Criminal Libel Law of the Criminal Code 1960 Act left Ghana with a press that was unable to write or speak of the personal struggles and needs of the Ghanaian people out of fear of being legally punished (Boafo-Arthur 2007). Punishment could be anything from a fine of forty cedis to three years imprisonment (Anku-Tsede 2013, 26). However, the implementation of the nation's new democratic constitution in 1992 and the abolition of the Criminal Libel Law in 2001 opened the doors for a more open, honest, and demanding press (IDEG 2007a, 5).

Without doubt, democratization has fostered political participation and citizens' yearning to employ their political rights to better the standard of living; however, general citizens have not readily applied this to the more specific issue of food security. The following section entitled "The Inherent Influence of Civil Society" explores the many ways that civil society organizations (CSOs) have become politically involved and have made demands on government to address food insecurity and have themselves positively influenced food security; however, citizens at large have not jumped on this bandwagon to the same extent and media outlets have been slow in covering this issue. Arguably, this may be the case because, after democratizing, the government made many visible efforts to address food security and nutrition and, therefore, citizens did not feel inclined to make demands.

Because of this lack of participation, CSOs have started reaching out to citizens and have directly called upon the media to help them spread the word about the 
importance of proper nutrition and food security for all. This undoubtedly is a work in progress. However, the greatest example of the strides that are being made in this regard is the very recent introduction of food security and nutrition workshops held specifically for members of the media as a way to educate them about food security and the need for their involvement in order to reach the nation's goals. For instance, the latest workshop, given on September 5 of this year, focused on explaining and showing how members of the media could significantly, positively impact food security because publications, radio messages, and television broadcasts are perhaps the quickest and most inclusive forms of contact throughout Ghana. For this reason, when utilized, these media outlets can dramatically influence citizens' knowledge about nutrition and food security and reiterate that citizen involvement is crucial in fighting food insecurity and understanding what citizens' food security and nutrition needs are. The media then can be, and is slowly beginning to be, a helpful outlet in communicating this to citizens (Ghana News Agency 2013).

\section{The Influence of Civil Society}

Within Ghana, government support of emerging and strengthening civil society organizations (CSOs) has been slow to develop. Historically, the government and political authorities have perceived CSOs as being unnecessary and burdensome (Darkwa, Akosua, Nicholas Amponsah, and Evans Gyampoh 2006). However, since implementing the 1992 Constitution, government as a whole has worked to lessen this view of CSOs and to engage CSOs in the decision-making process: "These efforts have been further bolstered by proactive civil society engagement and systematic joint efforts on the part of government and development partners (DPs) on national policy issues" 
(Akologo 2011, 56). Most importantly, CSOs are more involved, have a greater voice, and are stronger than ever before, leading to increased activism and advancements in "social justice, human rights...public accountability...poverty alleviation, good governance...[and] social accountability” (Apusiga 2009, 5). CSOs founded after democratization and which are devoted to bettering these democratic focuses include the following: the Centre for Policy Analysis (CEPA) founded in 1993, Third World Network (TWN) established in 1994, the Ghana Center for Democratic Development (CDD) initiated in 1998, the Institute for Democratic Governance (IDEG) created in 2000, and Innovations for Poverty Action (IPA) instituted in 2003.

In addition to working with government, civil society has done its own part to make much needed changes within society. Because of this, Ghana continues to make strides in how accountable government is to its people. These strides are unparalleled in its history and largely within Africa, a primarily undemocratic continent. As highlighted in the literature review, democratic government allows civil society to not only exist but to also interact with it to make change. True democracies do not fear or feel threatened by civil society but instead purposely allow civil society to take its own actions. By interacting with and listening to civil society organizations and therefore the voices of the electorate, Ghana has created and expanded upon its levels of proficiency. Again, "proficiency" refers to the government's commitment to implementing new and improving on existing government ministries, departments, and organizations committed to improving citizens' wellbeing. Ghana's growth and progress in this nature is discussed in greater depth below. 


\section{Proficiency and Development}

Coupled with its successful CSOs and the government's growing appreciation of these CSOs, Ghana has made prominent advancements in its government agencies, ministries, and departments to achieve this same goal. Concerning improving the general health of Ghana's citizens, perhaps one of the most germane ministries has been the Ministry of Health $(\mathrm{MOH})$. While the $\mathrm{MOH}$ was historically responsible for distributing health services to the populace, with the passing of ACT 525 in 1996 - a requirement of the 1992 Constitution - this responsibility was handed down to the newly established Ghana Health Service (GHS) (Ghana Health Service 2012). In doing so, the government continued to expand upon efforts to distribute health services via the GHS but at the same time gave the $\mathrm{MOH}$ more opportunity to focus its time and energy on the policy aspects of health services. Now, the $\mathrm{MOH}$ is responsible for "policy formulation, monitoring and evaluation, resource mobilization and regulation of the health services delivery" and is committed to its primary goal as follows: "to improve the health status of all people living in Ghana through effective and efficient policy formulation, resource mobilization, monitoring and regulation of delivery of health care by different health agencies" (Ministry of Health 2012). While the MOH is not focused solely on food security, its influence on health policymaking and monitoring has served as a model of success and jumping off point for many ministries, agencies, and departments that are heavily concentrated on food security concerns. These ministries, agencies, and departments are discussed below following the discussion on civil society's impact on food security. 


\section{Political Participation, Government Accountability and Proficiency, and Food Security}

While the previous sections shed light on the ways democracy has produced a more participatory electorate and civil society, the following section delves further into how civil society groups and government ministries and departments focus specifically on food security concerns and how they work together to bring Ghana's food security goals to fruition.

The Powerful Presence of Food Security-Based Civil Society Groups. In addition to many health related civil society groups in Ghana, the GOG's emphasis on food security has sparked the formation of many food security and nutrition civil society groups. Perhaps the most renowned is the Ghana Alliance against Hunger and Malnutrition (HAG), which was founded in 2005. It is currently made up of over 60 supporting CSOs and, arguably, its most successful objective to date has been its dedication to fusing Ghana's legislature and food security policies with civil society and its food security goals: "HAG seeks to address hunger and malnutrition in Ghana through effective networking, advocacy, campaign, monitoring, research, partnership and peer-to-peer capacity building" (United Nations Development Programme N.d.). Examples of its success can be seen in the organization's physical feats and the alliances it forged with the GOG and other CSOs around the world. Currently, it is an alliance of the FAO's Alliance Against Hunger and Malnutrition (AAHM) (Alliance Against Hunger and Malnutrition n.d.).

To date, HAG deserves credit for co-founding many community development programs, including the Ghana School Feeding Programme and the Village Food 


\section{Banking Concept Development in Rural Ghana. The Ghana School Feeding Programme}

was established in 2005 as a collective effort made by HAG, other affiliate CSOs, and the GOG as a supplemental program rooted in suggestions made by the African Union-New Partnership for Africa's Development (AU-NEPAD). AU-NEPAD is a continentallybased governance structure composed of African leaders who prioritize the importance of having a

strategic framework for pan-African socio-economic development... [as] both a vision and a policy framework for Africa in the twenty-first century. Within this broad goal, one of the AU-NEPAD's main concerns is food security and poverty within all African states. One key emphasis of this nature is to encourage African states to adopt societal practices that utilize local and 'home-grown' products. (NEPAD 2013)

As a result of AU-NEPAD, Ghana became one of nine African countries to institute a preliminary, trial school feeding program. In turn, Ghana's School Feeding Programme was created, grounded in the GPRS II (Afoakwa n.d). At its core, the program serves to improve children's daily caloric and nutritional intake by providing students of Ghana's most food-insecure regions with government-funded, daily hot lunches at their respective schools. In some cases, the program's meals are the only nutritious and substantial meal that these students receive in a given day. As a result of this program, there is not only an increase in these students' consumption but an equally important improvement and increase in school attendance (Commission on Human

Rights and Administrative Justice 2010). For example, in a study conducted by the World Food Programme, results show that

The objective of using the school feeding programme in the three schools to increase enrolment and improve retention and attendance is being achieved. Also, the three schools have not experienced any school drop-outs in the last two years. Furthermore, punctuality in the schools was said to have been improved...from discussions with the communities, it was confirmed that all children of school age in the three communities are in school. $(2007,18)$ 
This is a great leap forward for those schools that on average have high drop-out and truancy rates. Additionally, utilizing local farmers' products has also improved the wellbeing and income of the nation's farmers. The GOG requires that within this program products be purchased from the corresponding local farmers within the schools' districts (Afoakwa n.d.). This ensures that not only do students get fresh and nutritious local ingredients but also that local farmers receive a steady stream of income as a result of being a part of the program. Not only did HAG play a fundamental role in advocating for the creation of this program but it has also played a direct role in how the program is run. Up until 2009, the executive director of HAG also served as the head of the Ghana School Feeding Programme, working hand-in-hand with the GOG to ensure the successful implementation of the program (United Nations Development Programme n.d.)

Similarly, HAG worked with the Global Food Banking Network (GFN) to produce the Village Food Banking Concept Development in Rural Ghana. In order to help farmers advance their skills, practices and incomes, this program has taken one step past the GOG's programs as discussed above (GAIP, RTIP and RTIMP, workshops, etc.) and has given Farmer Based Organizations (FBOs) access to new technologies such as cell phones and the internet and awards grants to assist in paying the financial burdens of farming. In return, these recipients are asked to give their excess yields to their local community food banks (The Global Food Banking Network 2007/2008). HAG has largely taken the nation's Eastern region under its wing in regards to the general operating procedure of this program (United Nations Development Programme n.d.). In addition to the food security programs that HAG has helped spearhead in 
Ghana, it is also one of the nation's most interactive CSOs because it assembles many of Ghana's other food security, nutrition, and health CSOs in order to advocate society's needs and opinions to the GOG. One of its greatest achievements is the Ghana Parliamentarians Caucus Against Hunger and Malnutrition, a bipartisan caucus within the nation's parliament. The primary purpose of the caucus is to make all legislators aware of emerging and existing food security concerns and to utilize the caucus as a way for CSOs and parliament to jointly address these concern. The participation of parliamentarians shows that Ghana's CSOs have the ability to influence policy-making in Ghana and have already achieved a mutual understanding with the GOG that food security and nutrition are at the forefront of the country's development goals (Alliance Against Hunger and Malnutrition n.d.).

The caucus and HAG have also worked collaboratively to join Scaling up Nutrition, an international organization that strengthens the relationship between CSOs and national governments for the purpose of securing a country-led approach to "scaling up" the importance of nutrition in society (Scaling up Nutrition 2013). As a direct outcome of joining the Scaling up Nutrition community, Ghana, i.e. a group of the nation's CSOs with the support of the GOG, founded the Ghana Coalition Of Civil Society Organisations for Scaling up Nutrition (GHACCSSUN) in 2013 (Ghana Coalition of Civil Society for Scaling Up Nutrition 2013). Although in its infancy, GHACCSSUN has already provided Ghana's CSOs with an advantage that the nation was lacking for decades: a coalition in which CSOs brainstorm ways that adequate nutrition and the right to food can be expanded upon and procured for all citizens. Already, the coalition and its CSO members have been given support by two 
separate but equally valuable allies: the United Nations World Food Programme (WFP) and the Ghana Parliamentarians Against Hunger and Malnutrition Caucus, one of its cofounders. To help give GHACCSSUN a preliminary leg to stand on, the WFP has donated \$374,500 (USD). The WFP's funding is set to cover the years 2012 to 2015 (United Nations Development Programme 2013b). At the operational level, the caucus has pledged to expand its role as a co-founder by being a sounding board and listening ear for the issues that arise within GHACCSSUN and to be responsive and accountable to GHACCSSUN during the policy-making process. In his speech presented at the inauguration of the GHACCSSUN, Honorable Kwabena Appiah Pinkrah, the Cochairman of the Ghana Parliamentarians against Hunger and Malnutrition Caucus, declared that he and the caucus' other participating parliamentarians are eager to utilize GHACCSSUN to facilitate greater communication and coordination between the nation's CSOs and the nation's parliamentarians to introduce new food security and nutrition policies (Ghana Business News 2013b). He also explained that

the Caucus would lobby for increased budget allocation for nutrition programmes in general, while serving as the ally of civil society platforms for the intensification of national advocacy to raise the visibility of nutrition in Ghana and work towards the attainment of a well-nourished and productive Ghanaian society. To achieve these targets and commitments, he said, the Caucus would contribute to the process for the integration of nutrition and agriculture at the policy level by supporting dialogue and consultation processes on the linkages between nutrition and agriculture at the highest level of governance. (Government of Ghana 2013)

Lastly, Honorable Kwabena Appiah Pinkrah confirmed that, in joining the Scaling up Nutrition Movement, the nation now has a new "nutrition policy" and approach to tackling remaining nutrition struggles (Ghana Business News 2013b; Government of Ghana 2013). 


\section{Merging Accountability with Proficiency: Innovative Strategies, Research and}

Development. Not only is there evidence to support that CSOs have the power and knowhow to democratically influence food security and nutrition policy within democratic Ghana in ways that were previously absent, but also, CSOs have helped the government improve proficiency by participating in the implementation of many GOG food security strategies and plans such as the Food and Agriculture Sector Development Policy (FASDEP) of 2002 and the Food and Agriculture Sector Development Policy II (FASDEP II) of 2007. Together, these are two of the nation's most successful agricultural strategies for addressing food security thus far. FASDEP was created to improve the services, skills, and technologies within Ghana's agriculture sector to modernize the sector as a whole and therefore improve the nation's economy and standing in the international community. Since the implementation of the original FASDEP, FASDEP II was crafted to restructure FASDEP to achieve unaccomplished goals (Ministry of Food and Agriculture: Republic of Ghana 2013c; The Comprehensive Africa Agriculture Development Programme n.d.). FASDEP II exists to more thoroughly serve the people of Ghana in a direct manner by achieving "“...modernised agriculture culminating in a structurally transformed economy...evident in food security, employment opportunities and reduced poverty"' by 2015 (Ministry of Food and Agriculture: Republic of Ghana 2007). To accomplish previously unsuccessful goals, which largely failed because of "underfunding [and] standalone and uncoordinated projects", MOFA strongly encourages assistance and input from non-state actors (Sharma 2011). Agents of the private sector, NGOs, and CSOs provide insight into what the food and agriculture sector is like at the ground level and what changes are necessary in bringing the goals of FASDEP II to 
fruition (Ministry of Food and Agriculture: Republic of Ghana 2007).

The initiatives addressed in the above section of "Government Accountability and Proficiency and Food Security" show many of the programs that the GOG has created in line with FASDEP II and in the name of improving the distribution of food security social services to all citizens; however, other initiatives have been introduced under FASDEP II in order to advance the food and agriculture sector specifically. Six "programmes" are outlined within the FASDEP II strategy, two of these being as follows: food security and emergency preparedness and science and technology applied in food and agriculture development. While the food security and emergency preparedness program addresses many focuses that were discussed extensively above (i.e., crop production and distribution, water management, support for improved nutrition, etc.), the science and technology program surpasses this and concentrates on advancing food and agriculture research and technology in order to advance the quality of the aforementioned social services (The Comprehensive Africa Agriculture Development Programme 2009). While FASDEP II is still a policy in progress, the MOFA has already executed and fulfilled some of these research and technology plans of action.

While Ghana was plagued with insufficient agricultural research and development (R\&D) in the 1990s and early 2000, FASDEP II ushered in an agricultural R\&D evolution that was historically unparalleled and is still largely unmatched by other African states today. First, since initiating FASDEP II, the GOG has drastically increased its budgetary allotment for agricultural R\&D. According to the Agricultural Science and Technology Indicators (ASTI) facilitated by IFPRI, in 2008, “Ghana spent 352 billion cedis or 95 million PPP dollars on agricultural R\&D (both in 2005 constant prices) 
compared with 151 billion cedis or 41 million dollars in 2002" (Flaherty, Owusu, and Asare 2010, 1). Via FASDEP, FASDEP II, government-sponsored agricultural R\&D agencies such as the Crops Research Institute, and higher education agencies such as the University of Ghana's Institute of Agricultural Research, and the public sector, Ghana has witnessed a much-needed escalation in funds allotted to agricultural R\&D. The IFPRI's Agricultural Science and Technology Indicators show the agricultural R\&D funding patterns of the government sector, higher education sector, and public sector. Most notably, between 2002 and 2008 alone, funding from the three collective sectors soared to levels higher than ever before. This incremental growth occurred more rapidly than the collective growth preceding this time span (2013). Between 2001 and 2008, Ghana had the second highest increase in agricultural R\&D spending in Africa with a $\$ 56$ million USD increase (Beintema and Stads 2011). Out of this budget growth, the number of agricultural researchers and scientists and the quality of resources available to these researchers and scientists have risen. According to ASTI, although the growth in agricultural researchers and scientists did not occur as quickly as that of the budget allotments, there has been a steady increase since 2000 (Flaherty, Owusu, and Asare 2010). Furthermore, researchers now have more resources than ever before. An ASTI study conducted by Nienke Beintema and Gert-Jan Stads found that Ghana is one of only two countries in Sub-Saharan Africa with higher "resources per scientist" in 2000 than in 1981 (Beintema and Stads 2006).

Out of R\&D modifications, scientists can more thoroughly address some of the nation's agricultural shortcomings. For instance, a study led by Teunis van Rheenen et al. reviews many agricultural $R \& D$ advancements since Ghana's democratization. In 
surveying scientists of agricultural research organizations, it was found that 70 percent of respondents developed new agricultural technologies in response to requests made by the MOFA and farmers. Additionally, 28 percent developed new technologies in response to an increase in funding and resources (van Rheenen et al. 2012).

These technologies include, but are not limited to, the following issue areas: an integrated approach to pest management of groundnut, snail farming, and the improved cassava variety Afisiafi. First, improvement to groundnut yields is crucial because 90 percent of households in northern Ghana, the nation's most food insecure and poverty stricken region, cultivate groundnut. However, because of overwhelming devastation brought on by diseases and pest, this product, which was once very profitable and popular, was largely abandoned by farmers in the 1970s and 1980s. Consequently, 13 scientists ushered in three phases of research and trials, starting in 1997 and spanning until 2012, to find a solution. Today, groundnut cultivating has increased again in direct response to these scientists' development of an effective and environmentally friendly pest control that regulates soil invertebrates (van Rheenen et al. 2012).

In addition to advancing technologies for pest control and therefore increasing production, scientists have also devised tools to begin producing foods that were historically imported, an example being snails. Snails are high in protein, iron, and amino acids, which has made them very popular among Ghanaians for decades (Cobbinah, Vink, and Onwuka 2008). However, until the late 1980s and early 1990s, snails were heavily imported from neighboring Côte d'Ivoire. While the idea to introduce Ghanaians to snail farming emerged in the late 1980 s, the realization and greatest strides in this regard occurred very recently because of the plethora of advanced research, workshops, 
and publications. Farmers have been taught about the affordability of snail farming and about the nationwide high snail consumption rates. Today, the annual consumption rates of snails are roughly 15,000 tonnes, the equivalent to roughly 15,000 metric tons (van Rheenen et al. 2012). With local availability, this rate is likely to increase and, in turn, local farmers can reap the benefits of domestic sales.

Lastly, scientists have made many strides to strengthen the quantity and quality of Ghana's staple foods, as seen in the improved cassava variety Afisiafi. As of 2005, roughly 80 percent of Ghanaians have relied on cassava as the primary starch in their daily diet. Furthermore, as van Rheenen et al. explain, “cassava remains an important source of Ghana's food security since it is cheap, easy to transport, and can withstand storage for long periods..." (2012). However, similar to groundnut, pests and diseases can hinder production levels and the quality of yields. To address this, scientists generated the Afisiafi cassava in 1993 and made improvements on this variety in 2005 and again in 2010. The benefits of this variety are numerous: "It yields two and a half times the traditional varieties and is also disease and pest-resistant. It is also more suitable for making gari, a granular flour of varying texture made from cassava tuber, and agbelima, a fermented cassava meal..." (van Rheenen et al. 2012). Ultimately, van Rheenen et al.'s survey shows that since democratizing, especially since the early 2000 s, scientists have used the agricultural R\&D budgetary increase to transform the agricultural sector and to fulfill farmers' demands and the food security needs of the nation at large. 


\section{Data Indicators of Significant Food Security Improvements}

As was compiled and presented for Ghana's pre-democracy years in chapter four (see page 67), the following section refers back to data pertaining to the Domestic Food Price Level Index, GHI, malnutrition and underweight percentages, and DES to provide statistical support of qualitative findings. Collectively, these findings give statistical support of the above-discussed finding that, over time, democracy has had a powerful, positive impact on food security levels in Ghana.

Beginning with the FAO's Domestic Food Price Level Index, Ghana's Food Price Level Index in 1996, only four years after democratizing, was 2.92, compared to 3.05 in 1992. Over the next decade the index fell rather steadily and rapidly. By 2012, the index dropped to 1.77 , which marked the lowest point within at least a 21-year time frame (Food and Agriculture Organization 2013a). To show the nation's progress, "Table 4. Domestic Food Price Level" below presents Ghana's FAO food price levels, showing the decline in food price level of every fourth year from 1992 to 2012 (Food and Agriculture Organization 2013a).

Table 4. Domestic Food Price Level

\begin{tabular}{lc}
\hline & Price Level \\
\hline 1992 & 3.05 \\
1996 & 2.92 \\
2000 & 2.43 \\
2004 & 2.34 \\
2008 & 2.13 \\
2012 & 1.77 \\
\hline
\end{tabular}

Data from the IFPRI's Global Hunger Index (GHI) shows that just as Ghana's Domestic Food Price Level Index has decreased in post-democratization decades, so has the nation's GHI score. To review, the GHI score is an accumulation of the state's "percent of undernourished," the "prevalence of underweight in children younger than 
five years," and the "under-five mortality rate (\%)" over a five-year period (For further review about how the GHI is calculated, refer back to page 39 above). Since democratizing, GHI scores have been tallied for the years of 1996 (with data from 19941998), 2001 (with data from 1999-2003), and 2012 (with data from 2005-2010). Very differently from the 21.4 GHI score (which the IFPRI considered to be "alarming") in 1990, by 2012, the score fell to a staggering 8.9, a "moderate" hunger score, and the lowest score in at least 22 years. Similar to the Domestic Food Price Level Index, the GHI index scores from 1990 to 2012 were each significantly lower than preceding scores.

"Table 5. Global Hunger Index Scores" depicts this trend with scores taken from the IFPRI's 2012 Global Hunger Index (International Food Policy Research Institute 2012).

Deconstructing Ghana's GHI scores shows that the three components that determine a GHI score have all exhibited significant improvement over time; furthermore, the "percent of undernourished" and the "under-five mortality rate (\%)" have all progressively decreased from year to year without regressing. The only lapse

Table 5. Global Hunger Index Scores

\begin{tabular}{ccc}
\hline & Score & Hunger Classification \\
\hline 1990 & 21.4 & Alarming \\
1996 & 16.3 & Serious \\
2001 & 12.8 & Serious \\
2012 & 8.9 & Moderate \\
\hline
\end{tabular}

among the "prevalence of underweight in children younger than five years" occurred between 1994 and 1998 during which time the score jumped from 24 to 25.1 during the years of 1988 and 1992. Collectively, this data demonstrates that hunger levels have significantly decreased as a result of and in accordance with drastic improvements to these other serious factors (IFPRI 2012).

Data of the percentage of malnutrition prevalence over time shows that in 
1988 a little over 30 percent of Ghanaians were underweight. However, by 2008 it plunged to 17.3 percent, dropping a total of 12.7 percent since 1988 (Wiggins and Leturque 2011). Below, "Table 6. Percentage of Population Underweight" shows the decreasing proportion of the population that are underweight.

Table 6. Percentage of Population Underweight

\begin{tabular}{cc}
\hline Year & Percent Population Underweight \\
\hline 1988 & 30.3 \\
1998 & 24.9 \\
2003 & 21.8 \\
2008 & 17.3 \\
\hline
\end{tabular}

Correspondingly, as mentioned above, the magnitude of the population that was undernourished was 34 percent in 1991. In 2005 undernourishment was only prevalent in eight percent of Ghana's population. This constitutes a change of 26 percent since 1991, leaving only a minority of the population subject to undernourishment (Wiggins and Leturque 2011). "Table 7. Prevalence of Undernourishment" conveys the descending rates of undernourishment since democratization.

Table 7. Prevalence of Undernourishment

\begin{tabular}{cc}
\hline & Percent Population Undernourished \\
\hline 1991 & 34 \\
1996 & 16 \\
2001 & 12 \\
2005 & 8 \\
\hline
\end{tabular}

Analyzing where Ghana falls regarding the per capita Dietary Energy Supply (DES) requirement, which stipulates that the per capita daily caloric intake should not fall short of 2,118 calories, shows that Ghana has achieved higher DES levels than it did in authoritarian decades. From 1987 to 1989, Ghana's citizens averaged a daily caloric intake of only 2,000 calories. This was 118 calories short of the DES requirement. However, between 2001 and 2003, this figure rose to approximately 2,600 calories. As 
shown in table eight below, this is an improvement of 600 calories and has left Ghana 482 calories above the DES requirement (Agble 2009).

Table 8. Daily Energy Supply

\begin{tabular}{lll}
\hline & $\begin{array}{l}\text { Per Capita Daily } \\
\text { Caloric Intake }\end{array}$ & DES Requirement \\
\hline $1987-1989$ & 2,000 & Deficient 118 cal. \\
$1994-1996$ & 2,400 & Surpassed by 282 cal. \\
$2001-2003$ & 2,600 & Surpassed by 482 cal. \\
\hline
\end{tabular}

\section{Continuing Food Security Commitments and International Recognition}

In addition to the above-mentioned strides, Ghana has pledged its allegiance and membership to the G8 Summit "New Alliance for Food Security and Nutrition." Born out of the 2012 Camp David Summit of the G8, the alliance aims to "lift 50 million people out of poverty over the next 10 years by using a collective approach of pro-poor policies committed to by African governments, substantial private sector investment in order to increase agriculture productivity and farmer incomes, and donor governments aligning behind country-led plans" (ONE n.d.). Ghana is one of only six African countries to join the alliance (ONE n.d.; The White House: Office of the Press Secretary 2013). As a member, the GOG promises to focus its budget, resources, and overall attention on improving the following: agriculture regulations, fertilizer and seed distribution and use, and increasing investment(s) in agriculture by reducing the costs and risks of doing so. In being an active member of the alliance and through all of the government's accomplishments discussed above, the GOG proves to the international community and its citizens that fighting hunger does not come with a quick fix but rather that it takes years of trial and error, struggle, and devotion to make a noticeable change to such a nationally debilitating issue.

For Ghana, years of democratic developments and policies have come to fruition 
as the GOG has been internationally recognized for its progress, most notably by the FAO. On June 16, 2013, Ghana was one of only two countries in Africa and eighteen in the world to receive one of the FAO's most highly esteemed awards, the Award for Notable and Outstanding Progress in Fighting Hunger. Hailed for reducing hunger levels from 40.5 percent between 1990 and 1992 to less than five percent between 2010 and 2012, Ghana is being lauded for achieving the first Millennium Development Goal two years before its 2015 target (Ministry of Food and Agriculture: Republic of Ghana 2013; Food and Agriculture Organization 2013b). Because of this success and the nation's publically proclaimed promise to further food security in the name of democracy and via the democratic mechanisms discussed above, democratization provided the conditions in which a grassroots food security movement grew and state-level pro-food security policies proliferated. In this case study, this was the powerful tool that transformed the nation's food security status in only 20 years time. 


\section{CHAPTER VI}

\section{SUMMARY, CONCLUSIONS, AND RECOMMENDATIONS}

\section{Summary of the Research Problem, Methods, and Findings}

In the late twentieth century, Amartya Sen argued that famine did not and could not exist in any country that is a democracy with a relatively free press. His findings were considered groundbreaking within the discipline of political science and among democracy scholarship specifically. However, now in the twenty-first century, little research has been conducted to test the applicability of Sen's findings to today's society. Specifically, the following question is still unanswered in existing literature: Do democratic mechanisms have an impact on combatting lesser forms of hunger, and if so, how? This study served to address this research problem and to expand the limitations of existing literature. Finding it overzealous to attest that democracy always improves food security within any given state, especially considering the high levels of hunger within democratic India, this study set out to demonstrate that democracy has positively impacted food security in the specific case of Ghana.

Ghana was chosen for this case study for many reasons. First, the nation's food security improvements over the last two decades are a remarkable exception in an otherwise predominantly hunger-ridden continent. When coupled with the 1992 democratization and democratic growth that progressed simultaneously with these food security improvements, questions emerge as to if these improvements occurred simultaneously for a reason or if they occurred coincidentally. Is democracy the 
independent variable in this instance? Furthermore, because Ghana has made some of the greatest strides in recent decades regarding food security and democracy within Africa, studying Ghana served to potentially showcase to other African countries how democracy has bettered Ghana's food security. While there is no proof that democratizing or advancing an existing democracy will advance other nations' food security levels, it may facilitate thought and discussion within other African countries about the benefits of democracy.

To test this hypothesis, this researcher chose a small-N research design, a longitudinal case study, instead of a large- $\mathrm{N}$ study because her purpose was to analyze why, and especially how, the main mechanisms of democracy-political stability and government effectiveness, and political participation and government accountability and proficiency — have directly, positively impacted Ghana's food security levels over time. Conducting a large- $\mathrm{N}$ study would have been valuable if this study intended to conduct a cross-national study to see what countries have seen improved food security levels as a result of democracy. However, conducting quantitative, large-scale research often leads to findings that are indicative of an outsider's perspective and is not as engaging. Also, these studies can often lack empirical details and richness. They cannot easily explain or illustrate the link between the independent variable and dependent variable. A case study approach is more suitable to show the microprocesses that link variables. For these reasons, this study facilitated qualitative research, "a predominantly inductive, and discovery-oriented, approach ...embodying a view of social reality as a constantly changing property of individuals' perceptions... and aiming to get an 'insider's' perspective... of the phenomena under study" (Heath and Tynan 2010). The study analyzed the following primary sources: surveys, Freedom House scores, news releases, 
GOG documents, policies and legislation, CSO programs, the Domestic Food Price Level Index, GHI, malnutrition and underweight percentages, and DES.

\section{Conclusions and Implications}

This study concludes that democratic processes have fostered an environment that has increased food security levels within Ghana. Notably, the greatest food security strides have emerged under the government effectiveness and government accountability and proficiency umbrellas. While media outlets are slowly being educated about food security and are in turn beginning to use their powers of mass communication to educate citizens about the importance of their political involvement in reducing hunger, the citizenry has been slow to make individual food and nutrition-based demands of government. However, citizens have collectively, via CSOs, made many food security demands and efforts to not only hold government accountable, but also to increase food security through the CSOs themselves. Together, the GOG and CSOs have made ample efforts and have achieved equally as many successes in this regard, as exemplified by the Ghana Parliamentarians Caucus Against Hunger and Malnutrition and GHACCSSUN. On its own, the GOG has distributed numerous food security related social services. Regarding agriculture and food production, the GOG has initiated crop insurance programs such as GAIP, farmer education programs including the Breadbasket Initiative and "The Role of Agriculture in Achieving Middle-Income Status" workshop, crop advancement programs such as RTIP and RTIMP, irrigation development via the IDA, and infrastructure advancements including roadway development, safe water supply, and improved sewage disposal. Lastly, Ghana has advanced its agricultural research and development (R\&D) through escalated research funds and advancements within the agriculture and food sector, as exemplified by groundnut pest management 
developments, the introduction and growth of snail farming, and the improved cassava variety Afisiafi.

The implications that arise from these findings are that, through democracy, Ghana has ushered in a new era of food security and made significant strides in the last two decades to become one of the most food secure nations in Sub-Saharan Africa. It serves as a model success story of how the mechanisms of democracy, when successfully implemented, can draw national attention and efforts to the importance of prioritizing citizens' needs, respecting human rights, and in turn focusing on the right to food. Citizens have been given the opportunity to demand improved food security levels, government is held accountable to the people and must focus on their needs, and government and CSOs have joined together to facilitate top-down and grassroots efforts in solving the issue of hunger.

Potential for future studies emerge out of these findings. While this study has focused on showing how the mechanisms of democracy have been conducive to furthering food security levels in Ghana specifically, the illustrated democratic variables can be tested in other cases and may contribute to theory building within the discipline. Doing so would add to the significance of this study and potentially improve Sen's findings, and draw attention to the larger implications of democracy's potential influence on food security throughout the world. This study then serves as a starting point for further democracy and food security theory building.

\section{Recommendations for Future Research}

Out of this study's findings come suggestions for future research. Primarily, within this study, the greatest limitation and hindrance was the geographical distance 
between the author and Ghana. Because of this, the sources utilized were surveys, data, and policies that were already conducted and presented via other scholars and organizations. Conducting action research would have benefitted this study in that the author could have physically communicated with citizens, governing officials, and CSO representatives to better understand how and why food security improved because of democracy. Therefore, although this case study provides a greater "insider" perspective than a large-N research design would, it is suggested that in further researching Ghana's food security levels that the researcher incorporate action research.

Also, in conducting future research, scholars should examine the nation's lingering food security issues. Through this case study, it became evident that while food security has increased drastically throughout Ghana as a whole since democratizing, food insecurity and hunger are still hitting some heavily disadvantaged groups within society. Mainly, women and residents of northern Ghana are the most food insecure. It would be advantageous then to research why this is the case and how food security developments can be more evenly distributed in the years to come. 


\section{REFERENCES}

Abbassi, Asim Nawaz. 2013. "Accountable Democracy is Democracy that Delivers."

Your Common Wealth. Web. http://www.yourcommonwealth.org/2013/07/19/ accountable-democracy-is-democracy-that-delivers/ (Accessed October 16, 2013).

Access. 2013. "Commission on Human Rights and Administrative Justice of Ghana." National Human Rights Institution. Accessed May 20, 2013.

Ace Project. 2009. "Experts Gather in Ghana to Develop Improved Standards for African Elections." http://aceproject.org/today/feature-articles/experts-gather-in-ghana-todevelop-improved (Accessed May 10, 2013).

Adedeji, J.L. 2001. "The Legacy of J.J. Rawlings in Ghanaian Politics." African Studies Quarterly 5(2): Web. http://web.africa.ufl.edu/asq/v5/v5i2a1.htm (Accessed October 17, 2013).

Adekson, J. 'Bayo. 1976. "Army in a Multi-Ethnic Society: The Case of Nkrumah's Ghana, 1957-1966.” Armed Forces and Society 2 (January): 251-272.

Afoakwa, Emmanuel Ohene. N.d. "Home Grown School Feeding Programme - The Ghanaian Model as Icon for Africa." Global Child Nutrition Foundation. Web. http://www.gcnf.org/library/Ghana-School-Feeding-Programme-Overview-andProgress.pdf (Accessed July 10, 2013).

African Renaissance Ambassador Corporation. N.d. "Brain Drain in Africa: Facts and Figures.” http://www.aracorporation.org/files/factsandfigures.pdf (Accessed January 1, 2014).

Afrobarometer. 2009. "Popular Attitudes toward Democracy in Ghana: A Summary of Afrobarometer Indicators, 1999-2008.” Accessed May 5, 2013.

Afrobarometer. 2012a. "Home." http://www.afrobarometer.org/index.php (Accessed May $15,2013)$.

Afrobarometer. 2012b. "Government Accountability and Responsiveness." http://www.afrobarometer.org/files/documents/media_briefing/gha_r5_presentatio n2.pdf (Accessed May 15, 2013). 
Agble, Rosanna et al. 2009. "Nutrition Country Profile: Republic of Ghana." FAO, Nutrition and Consumer Protection Division. Accessed April 2, 2012 ftp://ftp.fao.org/ag/agn/nutrition/ncp/gha.pdf

Agrast, Mark David et al. 2013. WJP Rule of Law Index 2012-2013. Washington D.C.: The World Justice Project.

Agyeman-Duah, Ivor. 2003. Between Faith and History: A Biography of J.A. Kufuor. New Jersey: Africa World Press, Inc.

Ahiakpor, James C.W. 1991. "Rawlings, Economic Policy Reform, and the Poor: Consistency or Betrayal?" The Journal of Modern African Studies 29 (4): 583600 .

Aidoo, Thomas Maxwell. "The Context and Provenance of Democratization in Ghana, 1990-1992.” Historia Actual Online 9 (Winter): 7-16.

Akologo, Samuel Zan. 2011. "Ghana - Democratic Ownership and Development Results: Are the Politics, Policies, Power, and Institutions Properly Aligned?" In Democratic Ownership and Development Effectiveness: Civil Society Perspectives on Progress Since Paris, ed. Brian Tomlinson. The Philippines: IBON Books, 56-61.

Alliance Against Hunger and Malnutrition. N.d. "Ghana Alliance Against Hunger and Food Insecurity." http://www.theaahm.org/alliances-profiles/national-alliancedetail/en/c/12/?no_cache=1 (Accessed January 14, 2014).

Anderson, Leslie E. 2010. Social Capital in Developing Democracies: Nicaragua and Argentina Compared. New York: Cambridge University Press.

Anderson, Sue Ann. 1990. "Core Indicators of Nutritional State for Difficult-to-Sample Populations.” The Journal of Nutrition 120 (November): 1559-1600.

Anku-Tsede, Olivia. 2013. "The Media and Offence of Criminal Libel in Ghana: Sankofa." Journal of Law, Policy and Globalization 9: 26-34.

Antwi, James and David C. Phillips. 2013. "Wages and Health Worker Retention: Evidence from Public Sector Wage Reforms in Ghana." Journal of Development Economics 102 (2013): 101-115.

Apusiga, Agnes A. 2009. "Civil Society Legitimation and Public Policy in Ghana." Institute for Democratic Governance, Policy Research Series 5 (2009). 
Apusigah, Agnes A., Dzodzi Tsikata, and Maitrayee M. Mukhopadyay. 2011. Women's Rights Organizations and Funding Regimes in Ghana. Ghana: Pathways of Women's Empowerment RPC (West African Hub) and the Centre for Gender Equality and Advocacy (CENGENSA).

Asia-Pacific Center for Security Studies. 1998. "Food Security and Political Stability in the Asia-Pacific Region." Seminar on September 11, Honolulu.

Asibuo, Sam K. 2001. "The Role of an Anti-Corruption Agency in the Struggle Against Corruption: the Case of the Serious Office in Ghana." African Administrative Studies 56: 1-14.

Asiedu-Saforo, Kwame. 1989. "Economic Reform Programmes and Agricultural Development: Macro Policy Sequencing in Ghana, 1983-88." Food Policy 14 (November): 359-270.

Austin, Dennis. 1976. Ghana Observed: Essays on the Politics of a West African Republic. New York: Africana Publishing Company.

Awal, Mohammed. 2012. "Ghana: Democracy, Economic Reform, and Development, 1993-2008.” Journal of Sustainable Development in Africa 14 (1): 97-118.

Awumbila, Mariama et al. 2008. Migration Country Paper (Ghana). Ghana: Centre for Migration Studies, University of Ghana.

Ayittey, George. "Opinion: What Ghana can Teach the Rest of Africa about Democracy." CNN Opinion. December 6. http://www.cnn.com/2012/12/06/ opinion/ghana-elections-george-ayittey (Accessed May 2, 2013).

Baah-Boateng, William. 2004. "Employment Policies for Sustainable Development: The Experience of Ghana." Presented at a national workshop on an employment framework for Ghana's poverty reduction strategy, Ghana.

Bangura, Yusuf. 1992. "Authoritarian Rule and Democracy in Africa: A Theoretical Discourse." In Authoritarianism, Democracy and Adjustment: The Politics of Economic Reform in Africa, eds. P. Gibbon, Y. Bangura, and A. Ofstad. Uppsala: Nordiska Afrikainstitutet, pp.39-82.

BBC News. 2008. “1957: Ghana Celebrates Independence.” On this Day. March 6. http://news.bbc.co.uk/onthisday/hi/dates/stories/march/6/newsid_2515000/251545 9.stm (Accessed January 21, 2014).

BBC News. 2012. "Ghana's President John Atta Mills Dies." BBC News: Africa. July 24. http://www.bbc.com/news/world-africa-18972107 (Accessed March 18, 2014). 
BBC News. 2013. “Ghana Profile.” BBC News: Africa. June 20. http://www.bbc.co.uk /news/world-africa-13434226 (December 18, 2013).

Beetham, David. 1997. "Linking Democracy and Human Rights." Peace Review 9 (3): 351-356.

Beetham, David. 1999. Democracy and Human Rights. Cambridge, UK: Polity Press.

Beintema, Nienke, and Gert-Jan Stads. 2006. "Agricultural R\&D in Sub-Saharan Africa: An Era of Stagnation.” International Food Policy Research Institute: Agricultural Science and Technology Indicators (ASTI). http://www.ifpri.org/publication/ agricultural-rd-sub-saharan-africa-0?print (Accessed May 4, 2013).

Beintema, Nienke, and Gert-Jan Stads. 2011. "African Agricultural R\&D in the New Millennium.” International Food Policy Research Institute: Agricultural Science and Technology Indicators (ASTI). http://www.ifpri.org/publication/africanagricultural-rd-new-millennium (Accessed May 4, 2013).

Besley, Timothy, and Masayuki Kudamatsu. 2006. "Health and Democracy." The American Economic Review 96 (2): 313-318.

Birmingham, David. 1998. Kwame Nkrumah: The Father of African Nationalism. Ohio: Ohio University Press.

Birner, Regina. 2009. "Improving Governance to Eradicate Poverty and Hunger" in The Poorest and Hungry: Assessments, Analyses, and Actions: 529-539.

Boafo-Arthur, Kwame, ed. 2007. Ghana: One Decade of the Liberal State. New York: Zed Books Ltd.

Boughton, James M. 2000. "The IMF and the Silent Revolution: Global Finance and Development in the 1980s." September 11. http://www.imf.org/external/pubs/ft /silent/ (Accessed March 25, 2014).

Bratton, Michael. 1989. "Beyond the State: Civil Society and Associational Life in Africa." World Politics 41 (April): 407-430.

CNN. 2011. "Merz: Democracy can Thrive in Africa." Latest News. October 16. http://www.cnn.com/2012/12/06/opinion/ghana-elections-george-ayittey (Accessed May 2, 2013).

Cobbinah, J.R., Adri Vink, and Ben Onwuka. 2008. Snail Farming: Production, Processing, and Marketing. Wageningen, The Netherlands: Agromisa Foundation. 
Codjoe, Samuel Nii Ardey. 2007. "Supply and Utilisation of Food Crops in Ghana, 19602000." African Journal of Food, Agriculture, Nutrition, and Development 7 (2).

Commission on Human Rights and Administrative Justice (CHRAJ). 2010. "Seventeenth Annual Report 2010." http://chrajghana.com/wp-content/uploads/2012/08/Annual _Report_2010.pdf (Accessed January 4, 2014).

Commonwealth Governance. 2014. "Ghana.” Nexus Strategic Partnerships Limited. http://www.commonwealthgovernance.org/countries/africa/ghana/constitution/ (Accessed January 22, 2014).

Community Water and Sanitation Agency. 2013. “About Us.” Web. Accessed July 20, 2013. http://www.cwsagh.org/cwsa_select.cfm?corpnews_catid=3

The Comprehensive Africa Agriculture Development Programme (CAADP). N.d. "Ghana: FASDEP-ASP-Programmes 1 \& 2." Web. http://www.caadp.net/pdf/ Investment\%20Plan\%20Documents\%20-\%20Ghana.pdf (Accessed July 10, 2013).

The Comprehensive Africa Agriculture Development Programme (CAADP). 2009. "ECOWAS Agricultural Policy (ECOWAP) / Comprehensive African Agriculture Development Programme (CAADP) Compact: To Support the Successful Implementation of the Ghana Food and Agriculture Sector Development Policy (FASDEP II)." CAADP. October 28. http://www.nepad-caadp.net/pdf/Ghana.pdf (Accessed July 13, 2013).

Cornia, Giovanni Andrea, Richard Jolly, and Frances Stewart. 1988. Adjustment with a Human Face. 2 vols. UK: Clarendon Press.

Dahl, Robert A. 1989. Democracy and its Critics. New Haven, Connecticut: Yale University.

"Defining Civil Society." 2010. The World Bank. Web. http://web.worldbank.org/ WBSITE/EXTERNAL/TOPICS/CSO/0,,contentMDK:20101499 menuPK:24475 2 pagePK:220503 piPK:220476 theSitePK:228717,00.html (Accessed February, 2 2012).

Democracy Web. 2012. "Accountability and Transparency: Essential Principles." Comparative Studies in Freedom. http://www.democracyweb.org/accountability /principles.php Accessed October 12, 2012.

Department for International Development. 2004. "Pro-Poor Growth Briefing Note 1." Policy Division (February): 1-4. 
De Soysa, Indra et al. 1999. "To Cultivate Peace: Agriculture in a world of Conflict." PRIO Report 1/99. Oslo: International Peace Research Institute.

de Waal, Alex. 1990. "A Re-assessment of Entitlement Theory in the Light of the Recent Famines in Africa." Development and Change 21 (July): 469-490.

de Waal, Alex. 1996. "Famine and Human Rights." In Development in States of War, ed. Deborah Eade. UK: Oxfam, 33-38.

Diamond, Larry. 1994. "Rethinking Civil Society: Toward Democratic Consolidation." Journal of Democracy 5 (July): 4-17.

Diamond, Larry. 2004. "What is Democracy?" Presented at the Lecture at Hilla University for Humanistic Studies.

Diamond, Larry. 2005. "The State of Democratization and the Beginning of the 21 st Century." The Whitehead Journal of Diplomacy and International Relations 6 (Winter/Spring): 13-18.

Dobel, Patrick. 1978. "The Corruption of a State." The American Political Science Review 72 (September): 958-973.

Donnelly, Jack. 1999. "Human Rights, Democracy, and Development." Human Rights Quarterly 21 (3): 608-632.

Ebadi, Shirin. 2013. "The Framework of Democracy is Human Rights Law." 50.50 Inclusive Democracy. May 27. http://www.opendemocracy.net/5050/shirinebadi/framework-of-democracy-is-human-rights-law (Accessed January 21, 2014).

Edkins, Jenny. 2001. Whose Hunger? Concepts of Famine, Practices of Aid. Minneapolis: University of Minnesota Press.

Environmental Protection Agency: Ghana. 2013. “About Us.” Web. http://www.epa.gov .gh/index.php?option=com_content\&view=article\&id=46\&Itemid=109 (Accessed July 10, 2013).

FANRPAN. 2007. "Ghana: The Role of Agriculture in Achieving Middle-Income Status.” FANRPAN. November 16. http://www.fanrpan.org/documents/d00466/ (Accessed July 25, 2013).

Flaherty, Kathleen, George Owusu, and Roland Asare. 2011. "African Agricultural R\&D in the New Millennium." International Food Policy Research Institute:

Agricultural Science and Technology Indicators (ASTI). http://www.ifpri.org/ publication/african-agricultural-rd-new-millennium (Accessed May 4, 2013). 
Food and Agriculture Organization (FAO). N.d. "Food Supply Data." FAO. Accessed 5 March 2013. http://www.fao.org/ag/agn/nutrition/Indicatorsfiles/FoodSupply.pdf

Food and Agriculture Organization (FAO). 1999. "The State of Food Insecurity in the World 1999": 24.

Food and Agriculture Organization (FAO). 2004. "Voluntary Guidelines to Support the Progressive Realization of the Right to Adequate Food in the Context of National Food Security, Part II.” IGWG. $127^{\text {th }}$ Session of the FAO Council, 22-27 November.

Food and Agriculture Organization (FAO). 2008. "Methods to Monitor the Human Right to Adequate Food, Volume II." The Right to Food.

Food and Agriculture Organization (FAO). 2012. "The State of Food Insecurity in the World: Economic Growth is Necessary but not Sufficient to Accelerate Reduction of Hunger and Malnutrition." www.fao.org/docrep/016/i3027e/i3027e.pdf (Accessed April 1, 2013).

Food and Agriculture Organization (FAO). 2013a. FAO-Food Security Indicators Download Data. http://www.fao.org/economic/ess/ess-fs/essfadata/en/\#.UznXOCjg0nU (Accessed 1 May 2013).

Food and Agriculture Organization (FAO). 2013b. "38 Countries Meet Anti-Hunger Targets for 2015." June 12. http://www.fao.org/news/story/en/item/177728/ (Accessed July 13, 2013).

Foster, Max. 2011. "Former Ghana President: Fight Poverty with Wealth Creation, not Charity." CNN. March 22. http://edition.cnn.com/2011/BUSINESS/03/22/john. kufuor.ghana/ (Accessed March 17, 2014).

Fox, Jonathan. 2000. "Civil Society and Political Accountability: Propositions for Discussion." Presented at Institutions, Accountability and Democratic Governance in Latin America, The Helen Kellogg Institute for International Studies, University of Notre Dame.

Franco, Álvaro, Carlos Álvarez-Dardet, and Maria Teresa Ruiz. 2004. "Effect of Democracy on Health: Ecological Study." BMJ: British Medical Journal 329 (December): 1421-1423.

Freedom House. 2010. "Methodology." Freedom in the World 2010. http://www.freedom house.org/report/freedom-world2010/methodology?page=351\&ana_page $=363$ \&year=2010 (Accessed February 19, 2012). 
Freedom House. 2012. "Methodology." Freedom in the World 2012. http://www.freedom house.org/report/freedom-world-2012/methodology (Accessed February 19, 2012).

Freedom House. 2013. "Freedom in the World 2013: Democratic Breakthroughs in the Balance - Selected Data From Freedom House's Annual Survey of Political Rights and Civil Liberties." Freedom House. http://www.freedomhouse.org/sites /default/files/FIW\%202013\%20Booklet\%20-\%20for\%20Web_0.pdf (Accessed February 19, 2013).

Freedom House. 2014. "Freedom in the World: Country Ratings and Status, FIW 19732014 (EXCEL)" Freedom House. http://www.freedomhouse.org/reporttypes/freedom-world\#.UyMjVijg0nU (Accessed March, 14 2014).

Fukuyama, Francis. 2011. "Samuel Huntington's Legacy: Why his Work on World Order-Political and Otherwise_-are Still Relevant Today.” Foreign Policy. January 5. http://www.foreignpolicy.com/articles/2011/01/05/samuel_huntingtons _legacy (Accessed March 30, 2014).

Gayi, Samuel K. 1995. “Adjusting to the Social Costs of Adjustment in Ghana: Problems and Prospects." The European Journal of Development Research 7 (1): 77-100.

Ghana Agricultural Insurance Programme. 2013. "GAIP Agricultural Insurance: Empowering Ghana's Agricultural Sector.” http://www.gaip-info.com/wp/ (Accessed June 1, 2013).

Ghana Broadcasting Corporation. 2010. "Obama: Ghana's Economy and Democracy is a Success Story.” http://www.gbcghana.com/index.php?id=1.811563 (February 2, 2013).

Ghana Broadcasting Corporation. 2012. "The Fourth Republic of Ghana." http://www. gbcghana.com/?launch=fourth_republic (December 17, 2013).

Ghana Business News. 2013a. "Food Security Dependent on Smallholder Farmers - Yara Ghana." Ghana Business News. June 19. http://www.ghanabusinessnews.com/ 2013/06/29/food-security-dependent-on-smallholder-farmers-yara-ghana/ (Accessed June 21, 2013).

Ghana Business News. 2013b. "Ghanaian Parliamentarian Calls for Public Support to End Hunger.” Web. http://www.ghanabusinessnews.com/2013/06/06/ghanaianparliamentarian-calls-for-public-support-to-end-hunger/ (Accessed August 10, 2013).

Ghana Coalition of Civil Society for Scaling Up Nutrition (GHACCSSUN). 2013. "Welcome to GHACCSSUN." Web. http://ghanasuncso.org/ (Accessed August $10,2013)$. 
Ghana Health Services. 2012. "About Us." http://www.ghanahealthservice.org/aboutus. php?inf=Background (Accessed May 20, 2013).

Ghana News Agency. 2012. "Ghana Agricultural Insurance Pays First Claims to Farmers." Ghana News Agency. October 10. http://ghananewsagency.org/social/ ghana-agricultural-insurance-pays-first-claims-to-farmers-50404 (Accessed July 10, 2013).

Ghana News Agency. 2013. "Journalists Schooled on Nutrition.” Ghana News Agency. September 6. http://www.ghananewsagency.org/health/journalists-schooled-onnutrition-64445 (Accessed September 13, 2013).

Ghana Statistical Service. 1995. The Pattern of Poverty in Ghana, 1988-1992. Accra: January.

Ghana Water Company Limited. 2012. "About Us.” Web. http://www.gwcl.com.gh/ pgs/history.php (Accessed June 15, 2013).

Ghana Web. 1994. "Political History." Ghana Web. http://www.ghanaweb.com/Ghana HomePage/republic/polit_hist.php (Accessed March 3, 2013).

Ghana Web. 1999. "The Ghanaian Chronicle.” April 8. Web. http://www.ghanaweb.com/ GhanaHomePage/NewsArchive/artikel.php?ID=6178

Ghana Web. 2013. "Millions Needed to Complete 'Gang of Six' Roads." Ghana Web. April 22. http://www.ghanaweb.com/GhanaHomePage/NewsArchive/artikel. php?ID=271767 (Accessed July15, 2013).

Glasgow, Garrett. 2013. "Political Science 15 - Lecture 16: Small-N Methods.” Web. http://www.polsci.ucsb.edu/faculty/glasgow/ps15/ps15lect16.pdf (Accessed September 5, 2013).

Global Fund for Women. 2012. "Women's Leadership: Abantu For Development." Global Fund for Women. Web. Accessed June, 24 2012. http://www.globalfund forwomen.org/impact/success-stories/62/1778-womens-leadership-abantu-fordevelopment

The Global Food Banking Network, 2007/2008. "Food." Web. http://www.foodbanking .org/site/DocServer/Winter_2008_v4.pdf?docID=147 (Accessed July 10, 2013).

GlobalSecurity.org. 2011. "Ghana - Rawlings Coup.” November 7. http://www.global security.org/military/world/war/ghana-coup.htm (December 16, 2013).

Gocking, Roger S. 2005. The History of Ghana. Connecticut: Greenwood Publishing Group. 
Goldschmidt, Jenny. 1980. "Ghana Between the Second and the Third Republic Era: Recent Constitutional Developments and their Relation to Traditional Laws and Institutions." African Law Studies 18: 43-61.

Goldsmith, Arthur. 1986. "Democracy, Political Stability, and Economic Growth in Developing Countries." Comparative Political Studies 18: 517-31.

Goldsworthy, David. 1973. "Ghana's Second Republic: A Post-Mortem.” Oxford University Press 72 (January): 8-25.

Goodell, Grace, and John P. Powelsen 1982. "The Democratic Prerequisites of Development." In Freedom in the World, ed. R. Gastil. New York: Freedom House, 167-76.

Government of Ghana. 2007. "Strengthening Efforts for the Eradication of Poverty and Hunger." The Annual Ministerial Review.

Government of Ghana. 2013. "Ghana Coalition of Civil Society Organisations for Scaling up Nutrition (GHACCSSUN) Launched In Accra." August 2. http://www.ghana.gov.gh/index.php/2012-02-08-08-32-47/general-news/2304ghana-coalition-of-civil-society-organisations-for-scaling-up-nutrition-ghaccssunlaunched-in-accra (Accessed August 10, 2013).

Gyamfi, Sylvester. 2006. "Food Security in Ghana: The Development and Diffusion of Appropriate Technologies." Presented to the Ghana Statistical Service, November.

Hadenius, Axel, and Fredrik Uggla. 1996. "Making Civil Society Work, Promoting Democratic Development: What can States and Donors do?" World Development 24 (10): 1621-1639.

Hafner-Burton, Emilie M., and Kiyoteru Tsutsui. "Justice Lost! The Failure of International Human Rights Law to Matter Where Needed Most." Journal of Peace Research 44 (4): 407-425.

Hassanein, Neva. "Practicing Food Democracy: A Pragmatic Politics of Transformation." Journal of Rural Studies 19 (2003): 77-86.

Haynes, Jeff. 1991. "Human Rights and Democracy in Ghana: The Record of the Rawlings' Regime.” African Affairs 90 (July): 407-425.

Hazra, Anupam. 2009. "Hunger and Under-Nourishment In India." Rajagiri Journal of Social Development 1 (December): 35-50.

Heath, M. Teresa Pereira, and Caroline Tynan. 2010. "Crafting a Research Proposal.” The Marketing Review 10 (2): 147-168. 
Herbst, Jeffrey Ira. 1993. The Politics of Reform in Ghana: 1982-1991. California: University of California Press.

Hinshaw, Drew. "President Credited in Ghana's Growth Dies Unexpectedly." The Wall Street Journal. July 24. http://online.wsj.com/article/SB100008723963904432 95404577547050902356104.html (Accessed March 10, 2013).

Human Rights Advocacy Centre. 2013. "History of Human Rights in Ghana." http://www.hracghana.org/headlines/hr-in-ghana/history-of-human-rights-inghana/ (December 17, 2013).

Huntington, Samuel P. 1968. Political Order in Changing Societies. New Haven: Yale University Press.

Huntington, Samuel P. 1996. "Democracy for the Long Haul.” Journal of Democracy 7 (2): 3-13.

Ibhawoh, Bonny. 1999. "Structural Adjustment, Authoritarianism, and Human Rights in Africa." Comparative Studies of South Asia, Africa, and the Middle East 19 (1): 158-167.

Innovations for Poverty Action (IPA). 2011. "Examining Underinvestment in Agriculture: Returns to Capital and Insurance Among Farmers in Ghana." Our Work. http://www.poverty-action.org/project/0072 (Accessed June 12, 2013).

International Business Publications, USA. 2012. Ghana: Country Study Guide. Washington, D.C.: IBP.

International Institute for Democracy and Electoral Assistance. 2010. "Constitutional History of Ghana." http://www.constitutionnet.org/country/constitutional-historyghana (December 17, 2013).

Institute for Democratic Governance (IDEG). 2007a. "Ghana: Democracy and Political Participation." Open Society Initiative for West Africa. http://www.afrimap.org/ english/images/report/AfriMAP_Ghana_PolPartDD.pdf (Accessed May 8, 2013).

Institute for Democratic Governance (IDEG). 2007b. "Ghana: Justice Sector and the Rule of Law." Open Society Initiative for West Africa. http://www.afrimap.org/english/ images/report/AfriMAP_Ghana\%20JusticeDD.pdf (Accessed May 25, 2013).

International Association of Anti-Corruption Authorities. 2012. "Serious Fraud Office (SFO)." http://www.iaaca.org/AntiCorruptionAuthorities/ByCountriesandRegions /G/Ghanajidou/201202/t20120209_801534.shtml (Accessed January 10, 2014). 
International Bank for Reconstruction and Development / The World Bank. 2010. "Ghana's Infrastructure: A Continental Perspective" Africa Infrastructure Country Diagnostic: Country Report. March: 1-46.

International Food Policy Research Institute (IFPRI). 2007. "Accelerating Growth and Raising Incomes through Agricultural Development." IFPRI. http://www.ifpri.org /pressrelease/accelerating-growth-and-raising-incomes-through-agriculturaldevelopment?print (Accessed July 25, 2013).

International Food Policy Research Institute (IFPRI). 2010. "Ghana: Recent Developments in Agricultural Research." June. http://www.ifpri.org/sites/ default/files/publications/ghana-note.pdf (Accessed July 9, 2013).

International Food Policy Research Institute (IFPRI). 2011. "Former Presidents of Ghana, Brazil Awarded 2011 World Food Prize.” June 22. http://www.ifpri.org/blog/ former-presidents-ghana-brazil-awarded-2011-world-food-prize (Accessed February 27, 2013).

International Food Policy Research Institute (IFPRI). 2012. "2012 Global Hunger Index: The Challenge of Hunger - Ensuring Sustainable Food Security Under Land, Water, and Energy Stresses.” IFPRI. http://www.ifpri.org/sites/default/files/ publications/ghi12.pdf (Accessed March 2, 2013).

International Food Policy Research Institute: Agricultural Science and Technology Indicators (ASTI). 2013. "Data and Graphics." IFPRI. http://www.asti.cgiar. org/data/ (Accessed March 2, 2013).

International Fund for Agricultural Development (IFAD). 2003. "Ghana: Root and Tuber Improvement Programme (RTIP).” Evaluation. http://www.ifad.org/evaluation/ public_html/eksyst/doc/prj/region/pa/ghana/gh_rtip.htm (Accessed July 3, 2013).

Jenkins, J. Craig and Stephan J. Scanlan. 2001. "Food Security in Less Developed Countries, 1970 to 1990." American Sociological Review 66 (October): 718-744.

Kaganzi, Elly. 2013. "Pathways Represented at Food Security Expert Meeting in Ghana." Pathways to Empowerment: Africa Regional Office of the Food and Agriculture Organization (FAO) Expert Meeting, Ghana.

Kapur, Ishan et al. 1991. "Ghana: Adjustment and Growth, 1983-1991.” International Monetary Fund, Occasional Paper 86, Washington D.C.

Karlan, Dean et al. 2010. "Crop Price Indemnification Loans for Farmers: A Pilot Experiment in Rural Ghana." International Food Policy Research Institute.

Karlan, Dean et al. N/A. "Examining Underinvestment in Agriculture: Returns to Capital and Insurance Among Farmers in Ghana." Innovations for Poverty Action. 
Karuga, James. 2012. "Breadbasket Initiative Begins Bearing Fruits in Northern Ghana." New Agriculturist. January. http://www.new-ag.info/en/developments/devItem. php?a=2423 (Accessed July 15, 1 2013).

Kaufmann, Daniel. 1997. "Corruption: The Facts." Foreign Policy. Summer. http://www. foreignpolicy.com/archive/articles/2013/10 (Accessed October 11, 2013).

Keane, John. 2004. Violence and Democracy. Cambridge, UK: Cambridge University Press.

Keen, D. 1994. The Benefits of Famine: A Political Economy of Famine and Relief in Southwestern Sudan, 1983-1989. Princeton, NJ: Princeton University Press.

Khohli, Atul. 1986. "Democracy and Development." In Development Strategies Reconsidered, eds. J. Lewis and V. Kallab. New Brunswick: Transaction, 153-82.

Kobo, Ousman. 2010. “'We are Citizens too': The Politics of Citizenship in Independent Ghana." Journal of Modern African Studies 48 (March): 67-94.

Kraev, Egor. 2004. "Towards Adequate Analysis and Modeling of Structural Adjustment Programs: An Analytical Framework with Application to Ghana." Ph.D. diss. University of Maryland, College Park.

Kuenzi, M., and G. Lambright. 2001. "Party System Institutionalization in 30 African Countries." Party Politics 7 (4): 437-468.

Kufuor, John Agyekum. 2011. "Ghana's Transformation.” IFPRI. http://www.ifpri.org/ sites/default/files/publications/bkt_ess_kufuor_web.pdf (Accessed March 17, 2014).

Kurth, James. 2009. "Samuel Huntington (1927-2008): Ideas Have Consequences." Foreign Policy Research Institute. January. https://www.fpri.org/enotes/200901 .kurth.samuelhuntingtonideashaveconsequences.html (Accessed March 30, 2014).

Kwame Nkrumah Academy. 2013. “About KNA.” http://www.kwamenkrumahacademy .org/about-us/mission/ (Accessed April 2, 2013).

Lake, David A., and Matthew A. Baum. 2001. "The Invisible Hand of Democracy: Political Control and the Provision of Public Services." Comparative Political Studies 34 (August): 587-621.

Langlois, Anthony J. 2003. "Human Rights without Democracy? A Critique of the Separationist Thesis." Human Rights Quarterly 25 (4): 990-1019.

Lappé, Frances Moore. 2008. "A Shortage of Democracy, Not Food.” The Progressive. July. http://www.progressive.org/mag/lappe0708 (Accessed January, 20 2014). 
Leechor, Chad. 1994. "Ghana: Frontrunner in Adjustment." In Adjustment in Africa: Lessons from Country Case Studies, eds. Ishrat Husain and Rashid Faruqee. Washington, D.C.: The World Bank, 153-192.

Leite et al. 2000. "Ghana: Economic Development in a Democratic Environment." International Monetary Fund Occasional Paper 199. http://www.imf.org/external /pubs/nft/op/199/ (December 16, 2013).

Levkoe, Charles Z. 2006. "Learning Democracy through Food Justice Movements." Agriculture and Human Values 23 (Spring): 89-98.

Library of Congress. Federal Research Division. 1995. A Country Study: Ghana. Washington, D.C.: Federal Research Division.

Lin, Ro-Ting et al. 2012. "Political and Social Determinants of Life Expectancy in Less Developed Countries: A Longitudinal Study." BMC Public Health 12 (85): 1-8.

Lindberg, Staffan. 2007. "Institutionalization of Party Systems? Stability and Fluidity among Legislative Parties in Africa's Democracies." Government and Opposition 42 (2): $215-241$.

London, Bruce, and Kirk Williams. 1990. "National Politics, International Dependency, and Basic Needs Provision." Social Forces 69: 565-84.

Lumsden, D. Paul. 1980. “Towards Ghana's Third Republic.” Canadian Journal of African Studies 13 (3): 471-477.

Lupu, Noam, and Rachel Beatty Riedl. "Political Parties and Uncertainty in Developing Democracies." Comparative Political Studies 46 (11): 1339-1365.

Martin, Andrew. 2010. "More Research Design.” http://www.slideshare.net/mandrew martin/research-design-pt-2 (Accessed September 5, 2013).

Mboukou, Alexandre. 1983. "The Pan African Movement, 1900-1945: A Study in Leadership Conflicts Among the Disciples of Pan Africanism." Journal of Black Studies 13 (March): 275-288.

Merz, Jarreth. 2011. "Filming Democracy in Ghana." Presented at the TED Global Conference, Edinburgh, UK.

Messer, Ellen, Marc J. Cohen, and Jashinta D’Costa. 1998. “Food from Peace: Breaking the Links between Conflict and Hunger." Food, Agriculture, and the Environment Discussion Paper 24. Washington, D.C.: International Food Policy Research Institute. 
Ministry of Health. 2012. "About Us." http://www.moh-ghana.org/section.aspx?id=1 (Accessed May 19, 2013).

Ministry of Finance and Economic Planning: Republic of Ghana. House of Parliament. 2011. Budget Speech: Budget Statement and Economic Policy of the Government of Ghana for the 2012 Fiscal Year. 21 November.

Ministry of Food and Agriculture: Republic of Ghana. 2007. "Food and Agriculture Sector Development Policy (FASDEP II)." www.grain.org/attachments/2685/ download (Accessed August 5, 2013).

Ministry of Food and Agriculture: Republic of Ghana. 2011. "Agric Insurance for Maize.” http://mofa.gov.gh/site/?p=2440 (Accessed June 1, 2013).

Ministry of Food and Agriculture: Republic of Ghana. 2013a. "Root \& Tuber Improvement \& Marketing Programme (RTIMP)." http://mofa.gov.gh/site/?page _id=715 (Accessed July 3, 2013).

Ministry of Food and Agriculture: Republic of Ghana. 2013b. "Ghana Irrigation Development Authority." http://mofa.gov.gh/site/?page_id=2976 (Accessed June 13, 2013).

Ministry of Food and Agriculture: Republic of Ghana. 2013c. "FASDEP II." http://mofa.gov.gh/site/?page_id=598 (Accessed August 1, 2013).

Mo Ibrahim Foundation. 2014. "Country Profiles: Ghana." The Ibrahim Index of African Governance. Web. http://www.moibrahimfoundation.org/ghana/ (Accessed March 31, 2014).

Moon, Bruce E., and William J. Dixon. 1985. "Politics, the State, and Basic Human Needs." American Journal of Political Science 29: 661-94.

Mustapha, A.R. 1992. "Structural Adjustment and Multiple Modes of Livelihood in Nigeria." In Authoritarianism, Democracy and Adjustment: The Politics of Economic Reform in Africa, eds. P. Gibbon, Y. Bangura, and A. Ofstad. Uppsala: Nordiska Afrikainstitutet, pp.188-216.

Nathan, Andrew. 1997. “China: Getting Human Rights Right.” The Washington Quarterly 20 (2): 137-140.

National Insurance Commission (NIC). 2009. “About NIC.” http://www.nicgh.org/live/ en/?pg=103\&pp=93 (Accessed June 13, 2013).

NEPAD. 2013. "About Us.” Web. http://www.nepad.org/about (accessed July 10, 2013). Newton, Kenneth. 2001. "Trust, Social Capital, Civil Society, and Democracy." International Political Science Review 22 (2): 201-214. 
Nezhad, Iraj Rezaee, Ahad Khazai, and Saber Afrasyabi. 2011. "Human Rights and Democracy: A Positive Approach.” Australian Journal of Basic and Applied Sciences 5 (12): 346-348.

Norman, Julie M. 2005. "Human Rights and Democracy: Conceptualization and Application in Palestine." Web. Accessed 1 November 2012. http://66.241.209.237/Doc/Reports/2005/Conseptualization_and_Application_ in_Palestine.pdf

Nossiter, Adam. 2012. "John Atta Mills, President of Ghana, Dies at 68." The New York Times. July 24. http://www.nytimes.com/2012/07/25/world/africa/john-atta-millsghanas-president-dies-68.html?_r=0 (Accessed March, 1 2013).

Nussbaum, Martha. 2007. "Human Rights and Human Capabilities." Harvard Human Rights Journal 20: 21-24.

O’Brien, Edward L., Eleanor Greene, and David McQuoid-Mason. 1994 Human Rights for All. New York: Glencoe/McGraw-Hill.

Oduro, Franklin. 2009. "The Quest for Inclusion and Citizenship in Ghana: Challenges and Prospects." Citizenship Studies 13 (December): 621-639.

Office of the United Nations High Commissioner for Human Rights. 1966. International Covenant on Economic, Social and Cultural Rights, 16 December. Resolution 2200A (XXI) no. 5433. Pt. III, Article 11.

Omari, Peter. 1972. Kwame Nkrumah: The Anatomy of an African Dictatorship. New York: Africana Publishing Corporation.

ONE. n.d. "New Alliance for Food Security and Nutrition: Part 1." Web. http://www.one.org/us/policy/policy-brief-on-the-new-alliance/ (Accessed July 12, 2013).

Oppong-Ansah, Albert. 2011. "The mFarm initiative and the Ghana Breadbasket Strategy." Ghana Web (Ghana News Agency). April 24. http://www.ghanaweb .com/GhanaHomePage/NewsArchive/artikel.php?ID=207410 (Accessed July 25, 2013)

Oppong-Ansah, Albert. 2013. "Insuring Ghana's Smallholder Farmers Against the Weather." Global Issues. July 18. http://www.globalissues.org/news/2013 /07/18/17080 (Accessed July 25, 2013).

Osei, Anja. 2012. "Party System Institutionalization in Ghana and Senegal." Journal of Asian and African Studies 48 (5): 577-593. 
Osmani, Siddiqur Rahman. 2005. "Poverty and Human Rights: Building on the Capability Approach." Journal of Human Development 6 (July): 205-219.

Oxford Business Group. 2012. "Budgetary Spending: Government Expenditure Focuses on Improving Infrastructure." http://www.oxfordbusinessgroup.com/news/ budgetary-spending-government-expenditure-focuses-improving-infrastructure (Accessed July 20, 2013).

Paarlberg, Robert L. 2002. "Governance and Food Security in an Age of Globalization." International Food Policy Research Institute Discussion Paper 36 (February).

Panford, Kwamina. 1994. "Ghana and the Rawlings Factor by Kevin Shillington." The International Journal of African Historical Studies 27 (1): 166-168.

Parliament of the Republic of Ghana. 2001. "Citizenship Act, 2000 (Act 591)." Web. Accessed May 14, 2013. http://www.un.org/en/documents/udhr/index.shtml

Parliament of the Republic of Ghana. 2006. "Whistleblower Act, 2006 (Act 720)." Web. Accessed May 20, 2013. http://www.parliament.gh/assets/file/Acts/Whitsleblwer $\% 20$ Act\%20720.pdf

Pinstrup-Anderson, Per, and Derrill D. Watson II. 2011. Food Policy for Developing Countries: The Role of Government in Global, National, and Local Food Systems. Ithaca, New York: Cornell University Press.

Poe, Steven C., and C. Neal Tate. 1994. "Repression of Human Rights to Personal Integrity in the 1980s: A Global Analysis." The American Political Science Review 88 (December): 853-872.

The Presidency: Republic of Ghana. "The NDC Administration of John Dramani Mahama 2013-2016 Working for You by Creating Opportunities for All.” Better Ghana Agenda. http://www.presidency.gov.gh/better_ghana (Accessed January 22, 2014).

Przeworski, A. M., A. J. A. Cheibub, and E. Limongi. 2000. Democracy and Development: Political Institutions and Well-Being in the World, 1950-1990. Cambridge: Cambridge University Press.

Public Utilities Regulatory Commission (Ghana). 2012. "Who We Are." Web. Accessed July 20, 2013. http://www.purc.com.gh/purc/features/fusion-menu

Reuters. 2012. "Four of Ghana's Ruling Elite Charged with Corruption." Reuters. February 7. http://www.reuters.com/article/2012/02/07/ozatp-ghanacorruption-idAFJOE81601L20120207 (Accessed May 20, 2013). 
Ruger, J.P. 2005. "Democracy and Health." QJM: An International Journal of Medicine 98 (4): 299-304.

Sharma, Ramesh. 2011. "Ghana - Mainstreaming Trade Policy.” In Articulating and Mainstreaming Agricultural Trade Policy and Support Measures, eds. Ramesh Sharma and Jamie Morrison. Rome: FAO Trade and Markets Division, 147-165.

Safaei, Jalil. 2006. “Is Democracy Good for Health?” International Journal of Health Services 36 (4): 767-786.

Scaling up Nutrition. 2013. Civil Society Network.” Web. http://scalingupnutrition.org/ the-sun-network/civil-society-network (Accessed August 5, 2013).

Şener, Meltem. 2004. "The Relationship Between Neoliberalism and Authoritarian States: The Case of Turkey." Web.http://scholar.google.com/scholar?hl=en\&lr= $\& q=$ cache:LIAFByRgW5UJ:www.soc.uiuc.edu/about/Transnational $/$ meltem $\% 25$ 20yilmaz\%2520sener.pdf + meltem+y\%C4\%B1lmaz + sener (Accessed March 26, 2014).

Sen, Amartya. 1998. "Economic Rewards of Liberty and Free Press." The Washington Times. October 20, A12.

Sen, Amartya. 1999a. "Democracy as a Universal Value." Journal of Democracy 10 (October): 3-17.

Sen, Amartya. 1999b. "Famines and Other Crises." Development as Freedom. New York: Oxford University Press: 160-88.

Sen, Amartya. 2002. "Why Half the Planet is Hungry." The Observer. Print: June 16.

Sen, Amartya. 2009. The Idea of Justice. Cambridge, Massachusetts: Belknap Press of Harvard University Press.

Shillington, Kevin. 1992. Ghana and the Rawlings Factor. New York: St. Martin's Press.

Smith, Paul. 1998. "Food Security and Political Stability in the Asia-Pacific Region." Presented at the Asia-Pacific Center for Security Studies Seminar, Honolulu.

Smith, Daniel. 2002. "Ghana's 2000 Elections: Consolidating Multi-Party Democracy." Electoral Studies 21 (2002): 519-526.

Smith, Tom W. 2003. "Developing Comparable Questions in Cross-National Surveys." In Cross Cultural Survey Methods, eds. Janet A. Harkness, Fons J.R. Van de Vijver, and Peter Ph. Mohler. New Jersey: John Wiley \& Sons, Inc., 69-92. 
Sorensen, Georg. 1991. Democracy, Dictatorship and Development. London, England: Macmillan.

Sowa, Nii Kwaku. 2002. "An Assessment of Poverty Reducing Policies and Programmes in Ghana." Presented at a MIMAP Workshop on Assessing Poverty Policies, Morocco.

Spicker, Paul. 2008. "Government for the People: The Substantive Elements of Democracy." International Journal of Social Welfare 17: 251-259.

Ssengooba, Medi. 2013. "Ghana Elections: A Victory for Mental Health?” Think Africa Press. January 8.

Strauss, Z., and D. Horsten. 2013. "A Human Rights-Based Approach to Poverty Reduction: The Role of the Right of Access to Medicine as an Element of the Right of Access to Health Care.” Potchefstroom Electronic Law Journal 16 (3): 336-375.

Svensson, Jakob. 2005. "Eight Questions about Corruption." Journal of Economic Perspectives 19 (Summer): 19-42.

Tsikata, Dzodzi. N/A. "Effects of Structural Adjustment on Women and the Poor." Third World Network. http://www.twnside.org.sg/title/adjus-cn.htm (Accessed March $25,2014)$.

United Nations. 2013a. "Democracy and Human Rights." Global Issues. http://www.un. org/en/globalissues/democracy/human_rights.shtml (Accessed 20 October 2013).

United Nations. 2013b. "Democracy and Civil Society." Global Issues. http://www.un .org/en/globalissues/democracy/civil_society.shtml (Accessed 21 October 2013).

United Nations Committee on the Elimination of Discrimination against Women (CEDAW). Convention on the Elimination of All Forms of Discrimination against Women. 2005. Combined Third, Fourth, and Fifth Periodic Reports of States Parties: Ghana. New York City: CEDAW.

United Nations Development Programme (UNDP). 2012. "Peace and Development at Stake in Ghanaian Vote.” December 7. http://www.undp.org/content/undp/en/ home/presscenter/articles/2012/12/07/peace-and-development-at-stake-inghanaian-vote/ (Accessed May 10, 2013).

United Nations Development Programme (UNDP). 2013a. "Human Development Report 2013." www.hdr.undp.org (Accessed December 26, 2013). 
United Nations Development Programme (UNDP). 2013b. "Scaling up Nutrition Movement MPTF." Multi-Partner Trust Fund Office. Web. http://mptf.undp.org/ factsheet/fund/SUN00 (Accessed August 10, 2013).

United Nations Development Programme (UNDP). N.d. "Scaling up Nutritional Civil Society Organization Proposal for Ghana." Multi-Partner Trust Fund Office. Web. (Accessed August 10, 2013).

United Nations General Assembly. 1966. International Covenant on Economic, Social and Cultural Rights, December 16, United Nations, Treaty Series, Vol. 993: p. 3. http://www.unhcr.org/refworld/docid/3ae6b36c0.html (February 20, 2013).

United Nations Office on Drugs and Crime. 2012. "Where Corruption Flourishes, Development and the Rule of Law Fail, Says UNODC Chief." UNODC. September 24. Web. http://www.unodc.org/unodc/en/frontpage/2012/September/ where-corruption-flourishes-development-and-the-rule-of-law-fail-says-unodcchief.html

United State Department of State. 2012. "G8 Cooperation Framework to Support the 'New Alliance for Food Security and Nutrition' in Ghana." May 17. Web. http://www.state.gov/documents/organization/190626.pdf (Accessed July 15, 2013).

United States Department of State, Bureau of Democracy, Human Rights and Labor. 2011. "Ghana: Executive Summary." Country Reports on Human Rights Practices for 2011: 1-29.

United States Government. 2013. "Country Profile: Ghana." Feed the Future: The U.S. Government's Global Hunger and Food Security Initiative. Web. Accessed July 12, 2013. http://www.feedthefuture.gov/country/ghana

"The Universal Declaration of Human Rights." 1948. The United Nations. Web. Accessed 13 October 2012. http://www.un.org/en/documents/udhr/index.shtml

van Rheenen, Teunis et al. 2012. "Agricultural Research in Ghana: A IFPRI-STEPRI Report.” IFPRI. November 18. http://www.ifpri.org/sites/default/files/publications /gsspwp29.pdf (Accessed July 8, 2013).

Verwimp, Philip. 2012. "Food Security, Violent Conflict and Human Development: Causes and Consequences." United Nations Development Programme Working Paper. January: 1-13.

Wallace, Marshall. 2011. "Famine, Legitimacy, an Do No Harm.” Collaborative Learning Projects. November: 1-6. 
Water Resources Commission of Ghana. 2011a. "Water Resources Commission of Ghana.” Web. Accessed June 15, 2013. http://wrc-gh.org/en/

Water Resources Commission of Ghana. 2011b. "Regulations: Water Use.” Web. Accessed June 15, 2013. http://wrc-gh.org/en/regulations/water-use

The White House: Office of the Press Secretary. 2013. "Fact Sheet: The New Alliance for Food Security and Nutrition." June 18. http://www.whitehouse.gov/the-pressoffice/2013/06/18/fact-sheet-new-alliance-food-security-and-nutrition (Accessed July 12, 2013).

Whitfield, Lindsay. 2009. "“Change for a Better Ghana': Party Competition, Institutionalization and Alternation in Ghana's 2008 Elections." African Affairs 108 (433): 621-641.

Wickrama, K. A. S., and Charles L. Mulford. 1996. "Political Democracy, Economic Development, Disarticulation, and Social Well-Be-ing in Developing Countries." The Sociological Quarterly 37: 375-90.

Wiggins, Steve and Henri Leturque. 2011. "Ghana's Sustained Agricultural Growth: Putting Underused Resources to Work." Overseas Development Institute. Web. http://www.odi.org.uk/publications/5059-ghana-agriculture-growth-developmentprogress (Accessed February 2, 2012).

Wise, Marilyn and Peter Sainsbury. 2007. "Democracy: The Forgotten Determinant of Mental Health." Health Promotion Journal of Australia 18 (3): 177-183.

Witter, Sophie et al. 2009. "Providing Free Maternal Health Care: Ten Lessons from an Evaluation of the National Delivery Exemption Policy in Ghana." Global Health Action 2 (2009).

The World Bank. 2002. "Upgrading Low Income Urban Settlements, Country Assessment Report: Ghana.” AFTU 1 and 2. Web. http://web.mit.edu/urban upgrading/upgrading/case-examples/overview-africa/country-assessments/ download/GHANA.pdf (Accessed July 10, 2013).

The World Bank. 2013. "Political Stability and Absence of Violence." The Worldwide Governance Indicators (WGI) Project - Download Full Dataset. Web. http://info.worldbank.org/governance/wgi/index.aspx\#home (Accessed March 31, 2014).

World Food Programme (WFP). 2007. "Home-Grown School Feeding Field Case Study: Ghana." Web. http://documents.wfp.org/stellent/groups/public/documents /newsroom/wfp207421.pdf (Accessed July 10, 2013).

World Health Organization (WHO). 2012. "Food Security." WHO. Web. Accessed April 24, 2012. http://www.who.int/trade/glossary/story028/en/ 
World Health Organization (WHO). 2014. “"Neo-Liberal Ideas.” WHO. Web. Accessed March 26, 2014. http://www.who.int/trade/glossary/story067/en/

World Profile Group. 2013. "Ghana: Accelerating Africa's Revival.” Foreign Affairs 92 (1): 1-14.

Yergin, Daniel, and Joseph Stanislaw, eds. 1998. Commanding Heights. New York: Simon \& Schuster.

Zaney, G.D. 2012. "Ghana: Eight Years of the Women's Manifesto-An Appraisal." Association for Women's Rights in Development. Web. Accessed June, 242012. http://www.awid.org/Library/Ghana-8-Years-of-the-Women-s-Manifesto-AnAppraisal

Zweifel, T., and P. Navia. 2000. "Democracy, Dictatorship, and Infant Mortality." Journal of Democracy 11: 99-114. 